\title{
NGNP Composites R\&D Technical Issues Study
}

Prepared by AREVA for the Next Generation Nuclear Plant Project

Lewis Lommers September 2008

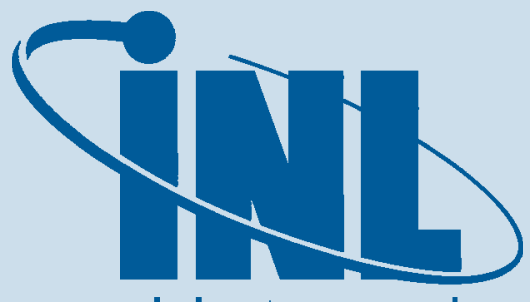

Idaho National Laboratory

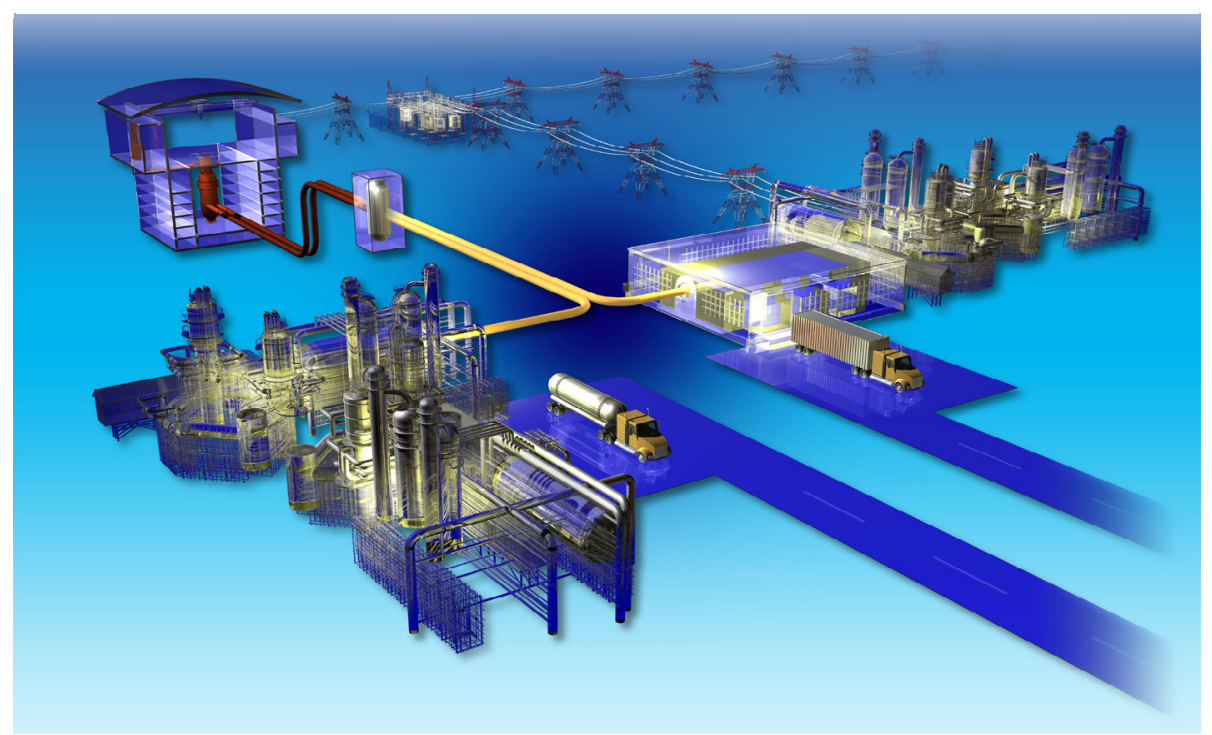

The INL is a U.S. Department of Energy National Laboratory operated by Battelle Energy Alliance. 


\section{DISCLAIMER}

This information was prepared as an account of work sponsored by AREVA for an agency of the U.S. Government. Neither the U.S.

Government nor any agency thereof, nor any of their employees, makes any warranty, expressed or implied, or assumes any legal liability or responsibility for the accuracy, completeness, or usefulness, of any information, apparatus, product, or process disclosed, or represents that its use would not infringe privately owned rights. References herein to any specific commercial product, process, or service by trade name, trade mark, manufacturer, or otherwise, does not necessarily constitute or imply its endorsement, recommendation, or favoring by the U.S. Government or any agency thereof. The views and opinions of authors expressed herein do not necessarily state or reflect those of the U.S. Government or any agency therenf 
Doc. No. TDR-3000807-001

\section{NGNP Composites R\&D Technical Issues Study}

\section{September 15, 2008}

\section{Disclaimer}

This report was prepared as an account of work sponsored by an agency of the United States Government. Neither the United States Government nor any agency thereof, nor any of their employees, nor their contractors and subcontractors, makes any warranty, express or implied, or assumes any legal liability or responsibility for the accuracy, completeness, or usefulness of any information, apparatus, product, or process, or service by trade name, trademark, manufacturer, or otherwise does not necessarily constitute or imply its endorsement, recommendation, or favoring by the United States Government or any agency thereof. The views and opinions of authors expressed herein do not necessarily state or reflect those of the United States Government or any agency thereof.

BEA Contract No. 00075310 


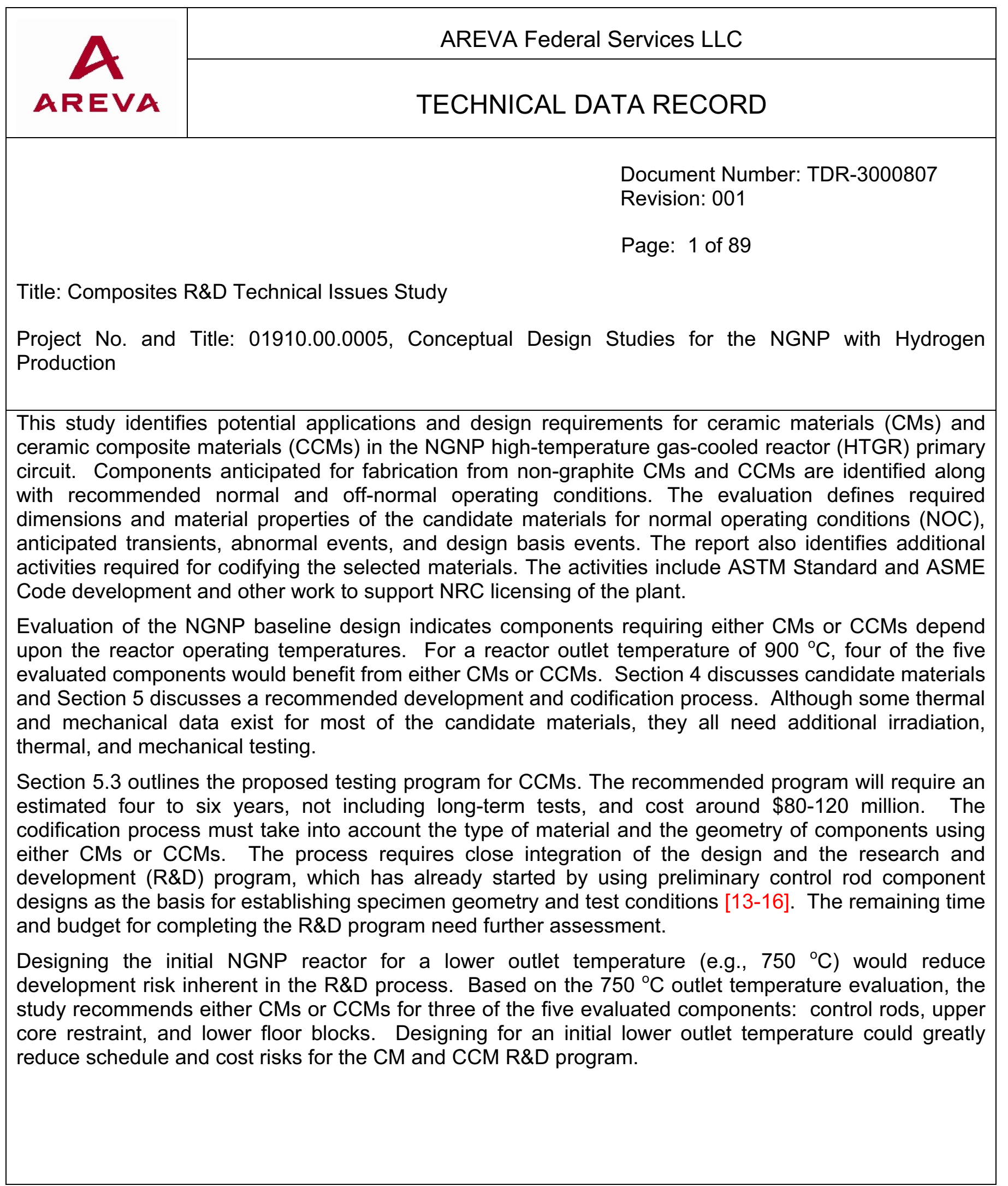

LYH-EN-FRM-003 Rev 01 Issued January 23, 2008

Reference: LYH-EN-PRC-001 Engineering Information Record / Technical Data Records 


\section{Record of Revisions}

\begin{tabular}{|c|c|c|c|}
\hline Revision & Date & Page/Sections Changed & Brief Description \\
\hline 000 & August 2008 & $\mathrm{~N} / \mathrm{A}$ & Initial Release \\
\hline \multirow[t]{13}{*}{001} & September 2008 & All Sections & $\begin{array}{l}\text { Grammatical changes to improve } \\
\text { readability. These changes are only } \\
\text { administrative in nature and have no } \\
\text { substantive effect on the technical } \\
\text { information in the document. }\end{array}$ \\
\hline & & Section 3.2 & $\begin{array}{l}\text { Figure } 3.2-3 \text { changed to } 3.2-4 \\
\text { Figure } 3.2-4 \text { changed to } 3.2-5 \\
\text { Figure } 3.2-5 \text { changed to } 3.2-3\end{array}$ \\
\hline & & Section 3.2 & $\begin{array}{l}\text { Temperatures at } 0 \text { hours updated in } \\
\text { Figures } 3.2-7 \text { and } 3.2-8\end{array}$ \\
\hline & & Section 3.2.2 & $\begin{array}{l}\text { Lower end of the normal } \\
\text { temperature range for inner control } \\
\text { rods from } 500^{\circ} \mathrm{C} \text { to } 530^{\circ} \mathrm{C}\end{array}$ \\
\hline & & Section 3.3 & $\begin{array}{l}\text { In Figure } 3.3-1,0 \text { hour temperature } \\
\text { updated to } 1100^{\circ} \mathrm{C}\end{array}$ \\
\hline & & Section 3.4.1 & $\begin{array}{l}\text { PCC temperature at } 0 \text { hour } \\
\text { corrected }\end{array}$ \\
\hline & & Section 3.4.2 & $\begin{array}{l}\text { Normal temperature range updated } \\
\text { to start at } 530^{\circ} \mathrm{C} \text {, not } 500^{\circ} \mathrm{C}\end{array}$ \\
\hline & & Section 3.5.2 & $\begin{array}{l}\text { Low end of the inner surface } \\
\text { temperature range for the UPS } \\
\text { adjusted to } 530^{\circ} \mathrm{C}\end{array}$ \\
\hline & & Section 3.6 & Temperature at 0 hours updated \\
\hline & & Section 4.6 & $\begin{array}{l}\text { Figure } 4.6-1 \text { added and evaluation } \\
\text { for C/C composites updated and } \\
\text { expanded }\end{array}$ \\
\hline & & Section 4.6 & $\begin{array}{l}\text { Figure } 4.6-2 \text { added and evaluation } \\
\text { for } \mathrm{SiC} / \mathrm{SiC} \text { composites updated and } \\
\text { expanded }\end{array}$ \\
\hline & & Sections $4-5$ and 7 & $\begin{array}{l}\text { Information added to update and } \\
\text { expand the status and expectations } \\
\text { for } \mathrm{SiC} / \mathrm{SiC} \text { composite materials }\end{array}$ \\
\hline & & References & $\begin{array}{l}\text { Reference } 15 \text { added, reference } \\
\text { numbers updated for Ref. } 16-19 \text {, } \\
\text { References } 19-21 \text { added }\end{array}$ \\
\hline
\end{tabular}




\section{Table of Contents}

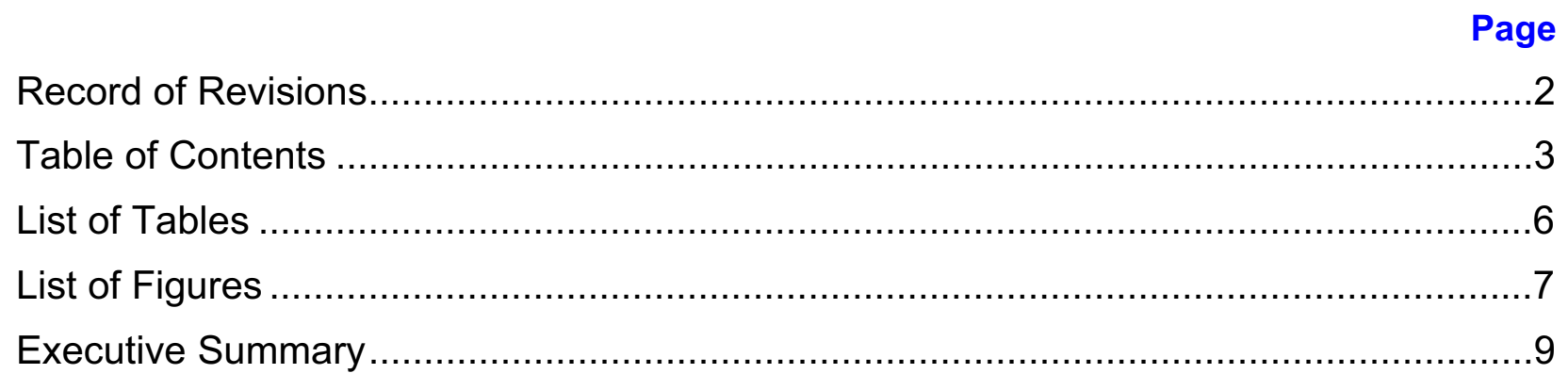

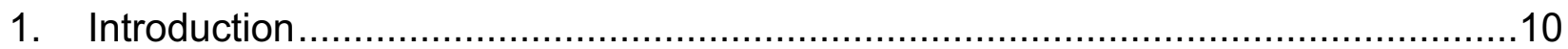

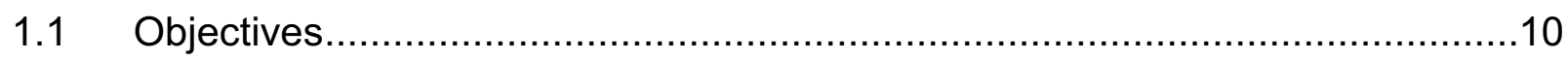

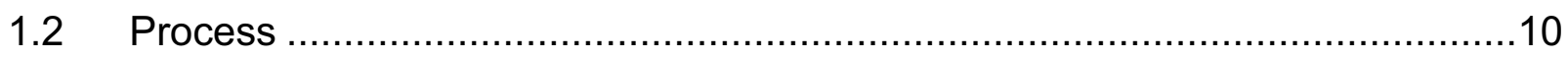

1.2.1 Selection of Potential CM and CCM Locations.......................................10

1.2.2 Estimation of Operating Conditions .....................................................11

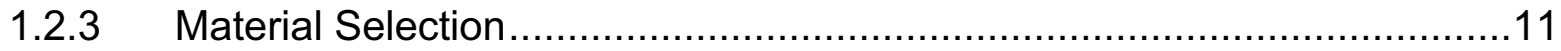

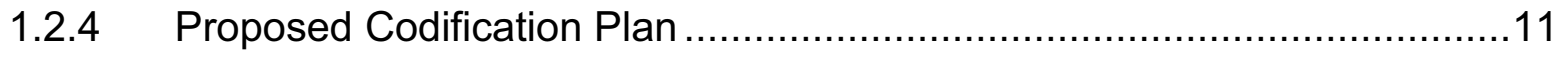

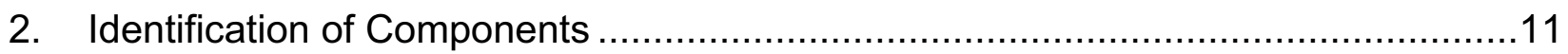

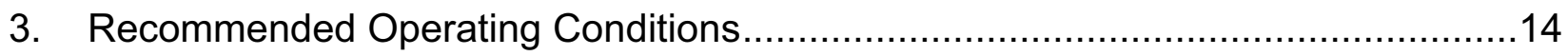

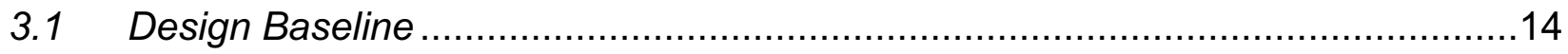

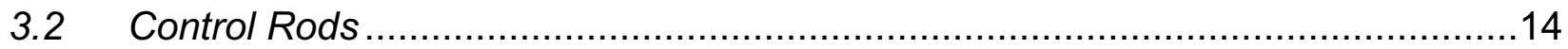

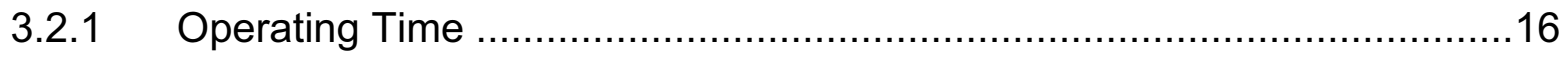

3.2.2 Temperatures (normal and expected off-normal) ................................16

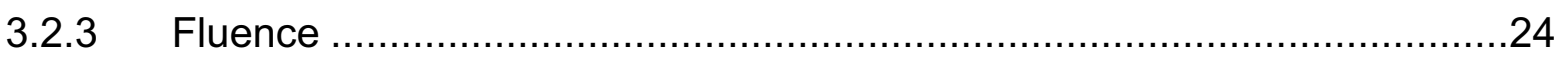

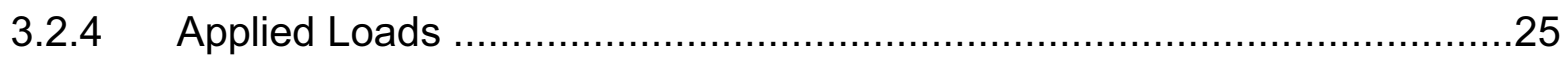

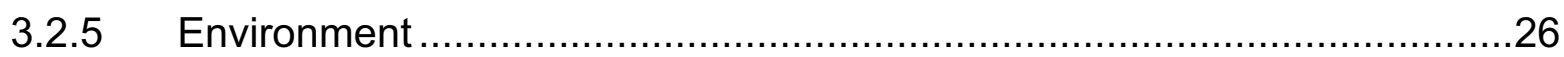

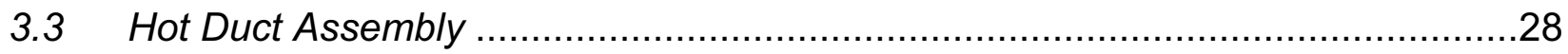

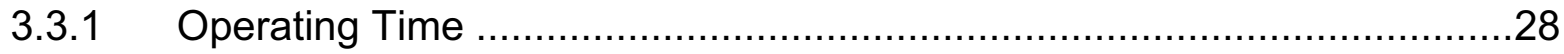

3.3.2 Temperatures (normal and expected off-normal) …...........................28

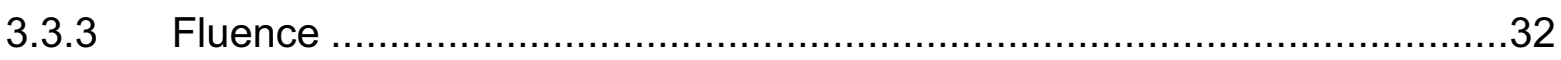

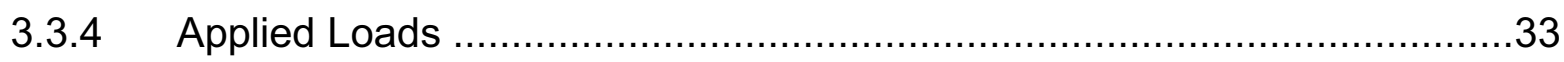

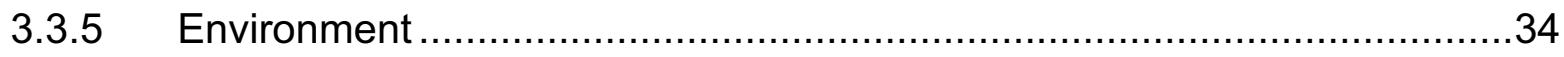


NGNP Composites R\&D Technical Issues Study

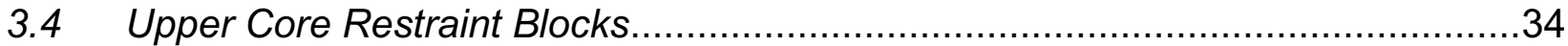

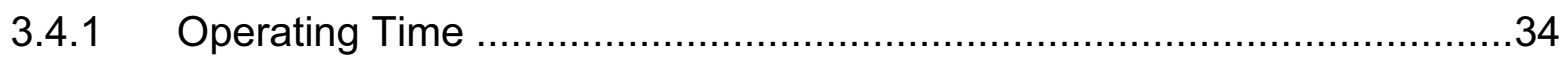

3.4.2 Temperatures (normal and expected off-normal) ..................................35

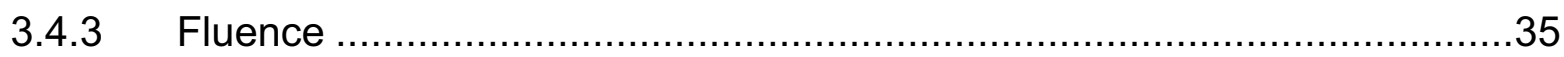

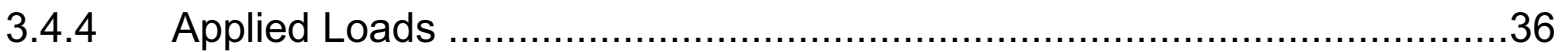

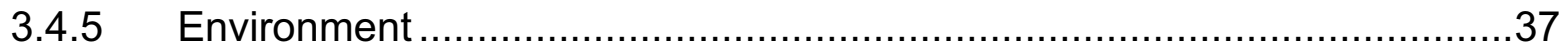

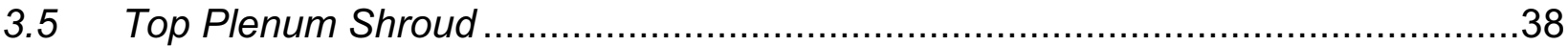

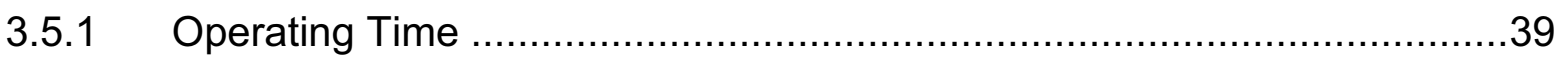

3.5.2 Temperatures (normal and expected off-normal) ..................................39

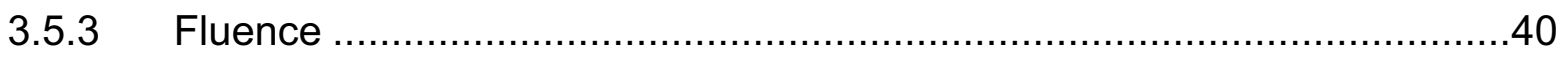

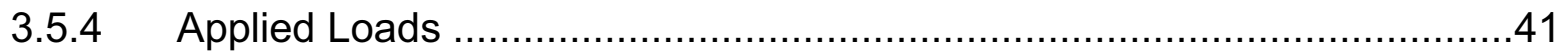

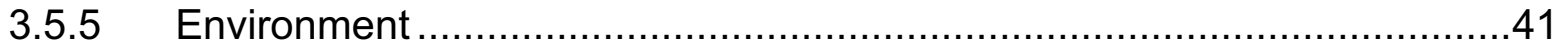

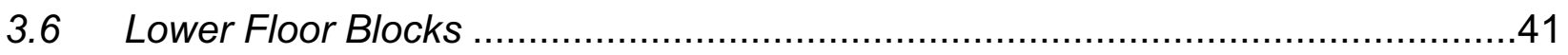

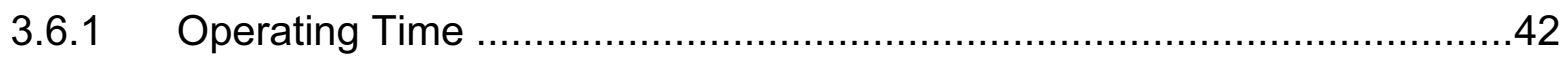

3.6.2 Temperatures (normal and expected off-normal) .................................42

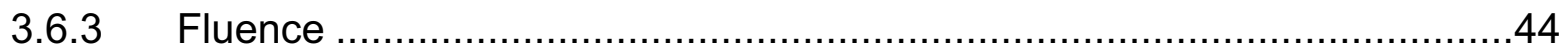

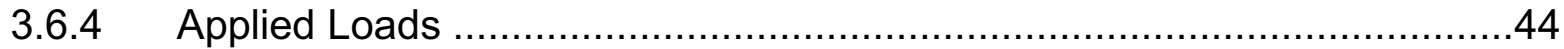

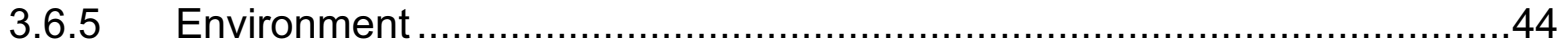

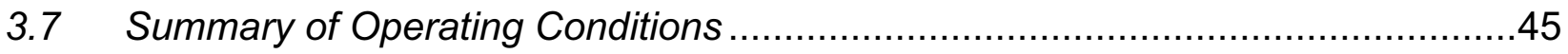

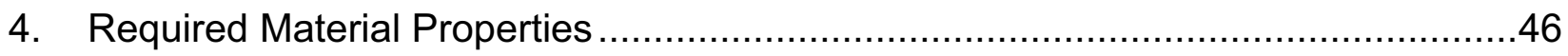

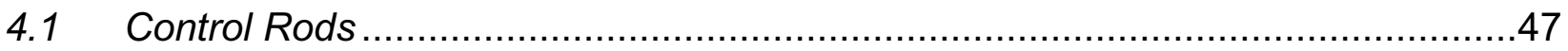

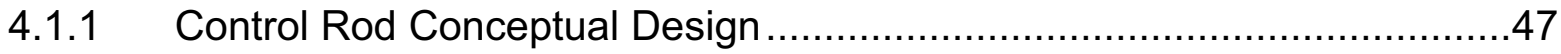

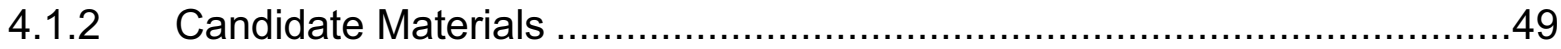

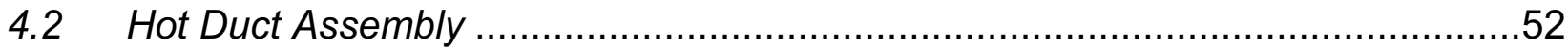

4.2.1 Hot Duct Assembly Conceptual Designs ............................................52

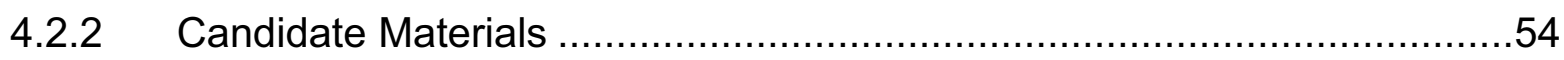

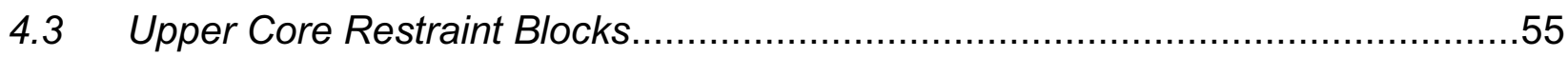

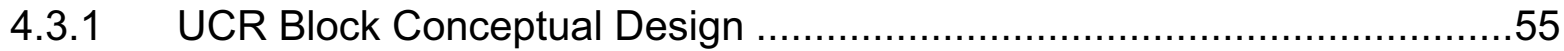

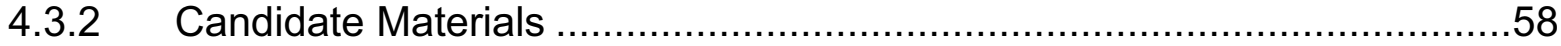


NGNP Composites R\&D Technical Issues Study

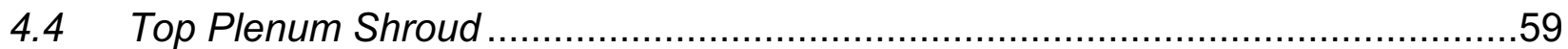

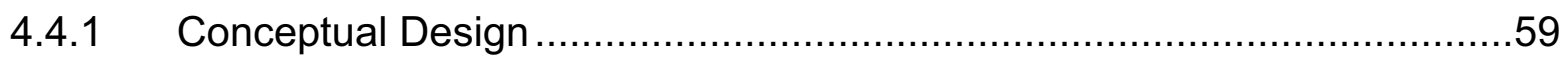

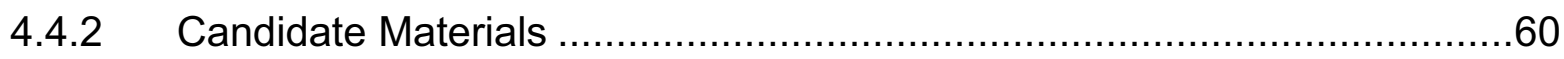

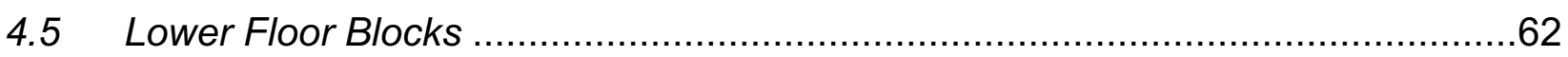

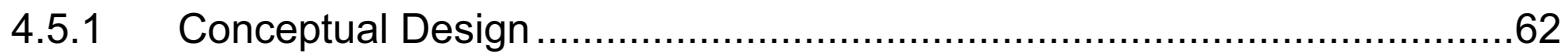

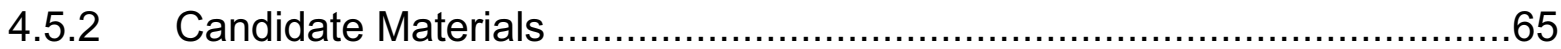

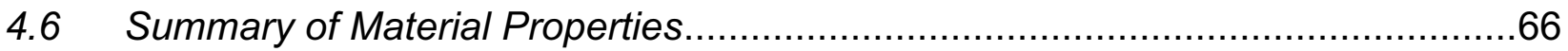

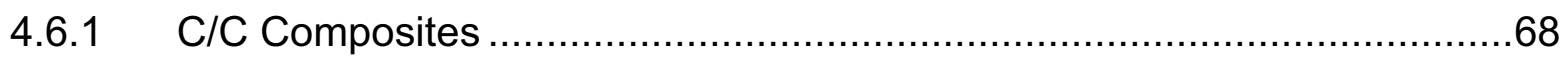

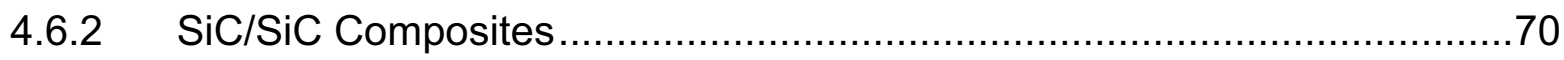

4.6.3 Alumina and Other Refractory Fiber Insulation Materials ........................71

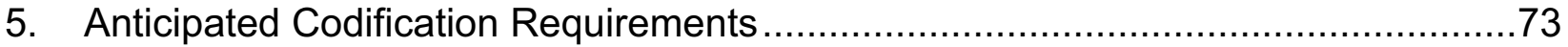

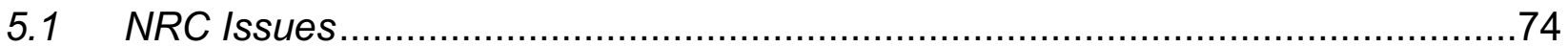

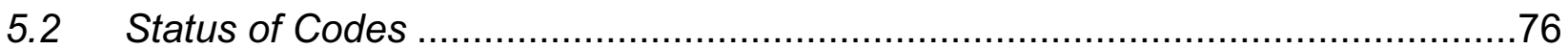

5.2.1 ASME Section III Carbon-Carbon Composite Code ................................76

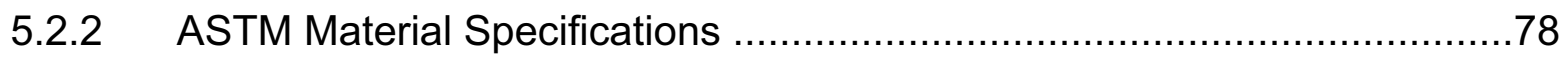

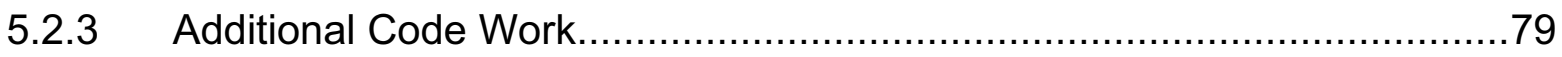

5.2.4 Additional NRC Licensing Support Work ................................................83

5.3 Timeline and Estimated Cost for Codification of Materials .................................83

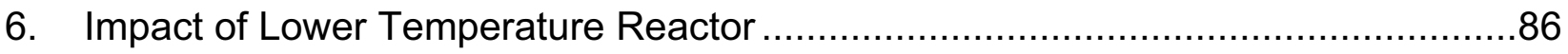

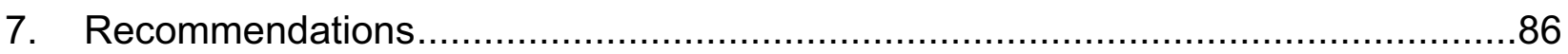

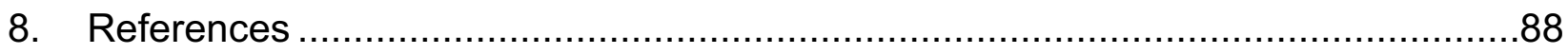




\section{List of Tables}

Page

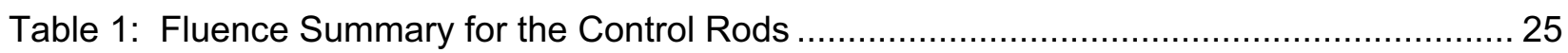

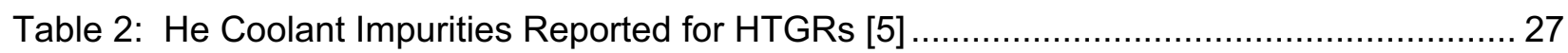

Table 3: Fluence Summary for the Primary Hot Duct Assembly ........................................... 32

Table 4: Fluence Summary for the Upper Core Restraint ....................................................... 36

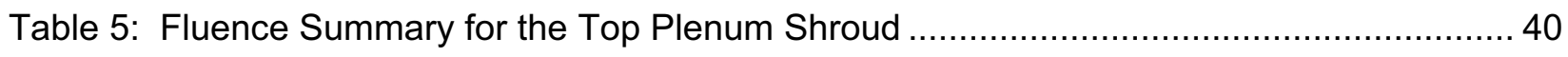

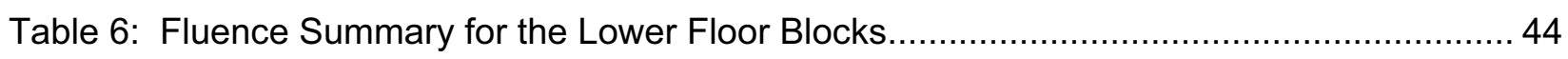

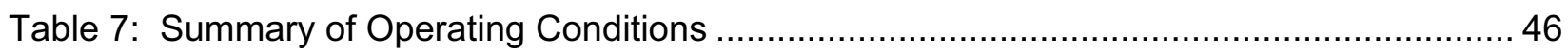

Table 8: Candidate Materials, Damage Mechanisms, and Data Needs for Design ................... 67

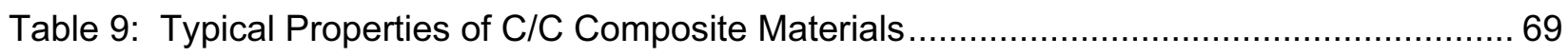

Table 10: Typical Properties of Rigid Ceramic Fiber Insulation Materials ................................ 72

Table 11: Summary of Operating Conditions, Candidate Materials and Product Forms............. 74 


\section{List of Figures}

Page

Figure 2-1: Section View of NGNP Reactor

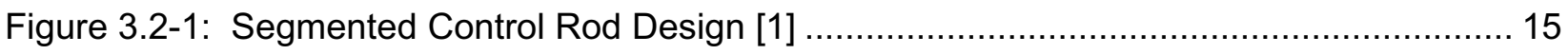

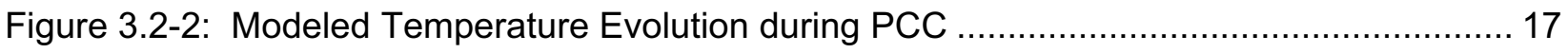

Figure 3.2-3: Temperature (Vertical Cross Section) during PCC at 60 hours ........................... 18

Figure 3.2-4: Modeled Temperature Evolution During DCC............................................. 19

Figure 3.2-5: Temperature (Vertical Cross-Section) during DCC at 109 hours ........................... 20

Figure 3.2-6: Modeled Temperature (Horizontal Cross-Section) during DCC ........................... 21

Figure 3.2-7: NGNP Maximum Temperature Evolution for Components during PCC ................ 22

Figure 3.2-8: NGNP Maximum Temperature Evolution for Components during DCC ............... 22

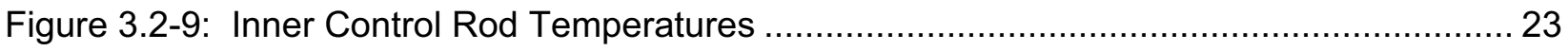

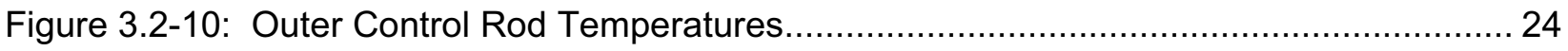

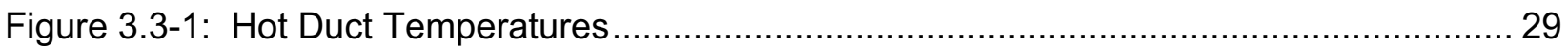

Figure 3.3-2: STAR-CD Hot Duct Model ............................................................... 30

Figure 3.3-3: Hot Inlet Coolant Temperature $\left({ }^{\circ} \mathrm{C}\right)$........................................................ 31

Figure 3.3-4: Temperature $\left({ }^{\circ} \mathrm{C}\right)$ along the Walls of the Hot Ducts ....................................... 32

Figure 3.3-5: Metallic Hot Gas Duct Design Concept [1] ................................................ 33

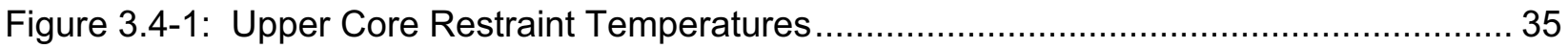

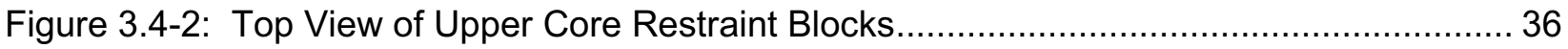

Figure 3.5-1: Upper Portion of Reactor Vessel Showing the Top Plenum Shroud ..................... 38

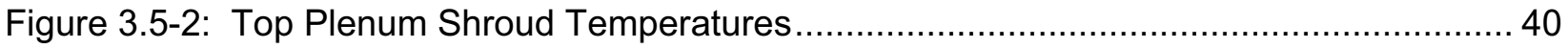

Figure 3.6-1: Lower Region of Reactor Showing Location of Lower Floor Blocks .................... 42

Figure 3.6-2: Lower Floor Block Temperatures .................................................................... 43

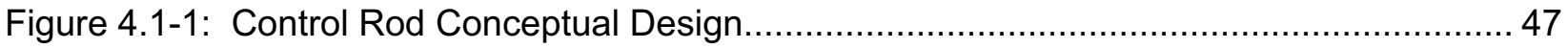

Figure 4.2-1: Ceramic-Lined Hot Duct Assembly ............................................................... 53

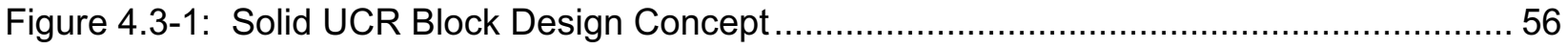

Figure 4.3-2: Hollow Box UCR Block Design Concept ..................................................... 57

Figure 4.4-1: Stress Intensity for the Inner Shell of the TPS Structure................................... 60

Figure 4.5-1: Conceptual Arrangement of Lower Floor Blocks [2] ....................................... 62 
Figure 4.5-2: Quarter-Section of the Reactor Floor Showing an Alternate LFB Arrangement

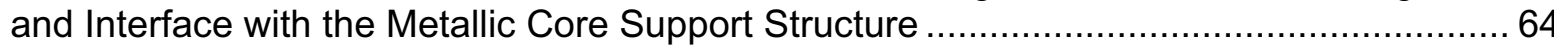

Figure 4.5-3: Potential Use of Geometric Structures in Insulation Layer to Augment Lateral

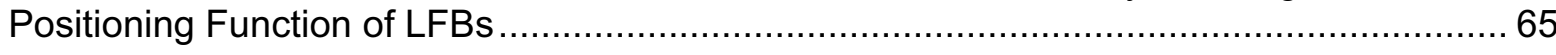

Figure 4.6-1: Effects of Neutron Dose on (A) Young's Modulus and (B) Flexural Strength of

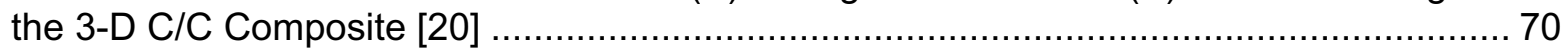

Figure 4.6-2: Effects of Neutron Dose on Volumetric Swelling and Flexural Strength of a

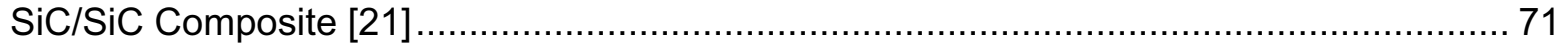




\section{Executive Summary}

This study identifies potential applications and design requirements for ceramic materials (CMs) and ceramic composite materials (CCMs) in the NGNP hightemperature gas-cooled reactor (HTGR) primary circuit. Components anticipated for fabrication from non-graphite CMs and CCMs are identified along with recommended normal and off-normal operating conditions. The evaluation defines required dimensions and material properties of the candidate materials for normal operating conditions (NOC), anticipated transients, abnormal events, and design basis events. The report also identifies additional activities required for codifying the selected materials. The activities include ASTM Standard and ASME Code development and other work to support NRC licensing of the plant.

Evaluation of the NGNP baseline design indicates components requiring either CMs or CCMs depend upon the reactor operating temperatures. For a reactor outlet temperature of $900{ }^{\circ} \mathrm{C}$, four of the five evaluated components would benefit from either CMs or CCMs. Section 4 discusses candidate materials and Section 5 discusses a recommended development and codification process. Although some thermal and mechanical data exist for most of the candidate materials, they all need additional irradiation, thermal, and mechanical testing.

Section 5.3 outlines the proposed testing program for CCMs. The recommended program will require an estimated four to six years, not including long-term tests, and cost around $\$ 80-120$ million. The codification process must take into account the type of material and the geometry of components using either CMs or CCMs. The process requires close integration of the design and the research and development (R\&D) program, which has already started by using preliminary control rod component designs as the basis for establishing specimen geometry and test conditions [13-16]. The remaining time and budget for completing the R\&D program need further assessment.

Designing the initial NGNP reactor for a lower outlet temperature (e.g., $750{ }^{\circ} \mathrm{C}$ ) would reduce development risk inherent in the R\&D process. Based on the $750{ }^{\circ} \mathrm{C}$ outlet temperature evaluation, the study recommends either CMs or CCMs for three of the five evaluated components: control rods, upper core restraint, and lower floor blocks. Designing for an initial lower outlet temperature could greatly reduce schedule and cost risks for the CM and CCM R\&D program. 


\section{Introduction}

\subsection{Objectives}

This study identifies potential applications and design requirements for ceramic materials (CMs) and ceramic composite materials (CCMs) in the NGNP hightemperature gas-cooled reactor (HTGR) primary system. It identifies components anticipated for fabrication from either non-graphite CMs or CCMs along with their recommended normal and off-normal operating conditions. It also defines required dimensions and material properties of the candidate materials for normal operating conditions (NOC), anticipated transients, abnormal events, and design basis events. It specifies additional activities required for codifying the candidate materials per ASME and ASTM codes. These activities may involve the development of a new body of code(s) to guide NGNP technology and other work to support NRC licensing of the plant.

\subsection{Process}

The evaluation of materials uses the following approach:

- Using the NGNP preconceptual design [1] as a starting point, assess and identify likely locations for the use of either CMs or CCMs based on:

$>$ Expected operating conditions

$>$ Required functions

$>$ Necessary material characteristics

- Based on the NGNP preconceptual design [1] and reference model results for thermal and core neutronics analyses, define envelopes at normal and off-normal operating conditions for:

$>$ Temperature and temperature gradients

$>$ Fluence

$>$ Applied Loads

D Environment, including air and water ingress

- Assess the need for including other component locations in the reactor vessel

- Define the characteristics for materials that satisfy the requirements

- Propose candidate materials for component applications and identify limitations

- Recommend actions for codification of the materials

\subsubsection{Selection of Potential CM and CCM Locations}

Structural components and thermal insulators exposed to high or very high temperatures in the NGNP could use either CMs or CCMs. 


\subsubsection{Estimation of Operating Conditions}

The NGNP preconceptual design [1], augmented by model results in references [3] and [4] for prismatic HTGRs of similar design and baseline operating conditions, provides the basis for estimating operating conditions.

\subsubsection{Material Selection}

The study bases the selection of materials on needs identified in the NGNP preconceptual design [1], the evaluation of HTGR materials issues by the Electric Power Research Institute [2], the Next Generation Nuclear Plant Materials Selection and Qualification Program Plan [8], and a contractor (Innovative Technologies International (NovaTech)) evaluation of candidate materials. The evaluation of thermal and physical properties of the materials determines their suitability as candidates for locations exposed to high temperatures or other adverse conditions during normal and off-normal operating conditions. The study examines materials for structural components and subassemblies needing to protect metals from hot helium gas.

\subsubsection{Proposed Codification Plan}

The proposed codification plan identifies activities needed to codify the selected materials. These activities include ASTM Standard and ASME Code development and efforts to meet NRC licensing requirements.

\section{Identification of Components}

The following components, highlighted in Figure 2-1, could use either CMs or CCMs:

- Control Rods

- Hot Duct Assembly

- Upper Core Restraint Blocks

- Top Plenum Shroud

- Lower Floor Blocks

The control rods, upper core restraint (UCR) blocks, and lower floor blocks (LFB) are considered to be structural components. The top plenum shroud (TPS) and hot duct assembly (HDA) require candidate material(s) to provide thermal insulation.

The bases for these components as potential locations for either CMs or CCMs are:

- Control rods are exposed to high temperatures during normal conditions and potentially much higher temperatures during some off-normal conditions.

- The hot duct assembly is exposed to high temperatures due to helium hot streaks in the reactor outlet stream during normal operation. The metallic support pipe in 
the hot duct assembly needs to be insulated from high temperature He to protect the support pipe and also to minimize parasitic heat loss.

- Upper core restraint blocks are exposed to high temperatures during off-normal conditions, particularly during a pressurized conduction cooldown (PCC).

- The top plenum shroud is exposed to high temperatures during off-normal conditions (primarily during a PCC).

- Lower floor blocks need to insulate the metallic core support structure from the high temperatures of the overlying graphite core support structure. The LFBs may also be exposed to high temperatures during off-normal events, particularly in the central region where the ducts to the Shutdown Cooling System (SCS) are located.

While the study focuses on the above five components, the following additional components may require CMs or CCMs:

- SCS Ducts and Inlet Shell - The ducts connecting the lower plenum to the SCS and the inlet shell will see modest temperatures during normal operating conditions. When the SCS starts during normal operation, the ducts and inlet shell will briefly see high temperatures approaching $900^{\circ} \mathrm{C}$. However, for offnormal conditions during start-up of the SCS in a conduction cooldown, the ducts and inlet shroud will experience severe thermal transients and much higher temperatures approaching $1200^{\circ} \mathrm{C}$. As a result, these components will need a ceramic insulation liner to protect the metal. Furthermore, the openings in the lower plenum for the ducts may require a CCM (e.g., C/C composite) to withstand the greater stresses during thermal transients.

- Control Rod Guide Tubes - The control rod guide tubes and the tubes for the Reserve Reactor Shutdown System (RRSS) will mostly be exposed to He at the core inlet temperature $\left(500^{\circ} \mathrm{C}\right)$. However, during PCC these components may see high temperatures greater than $1000^{\circ} \mathrm{C}$. Metal alloys such as $800 \mathrm{H}$ will be acceptable for normal conditions, but they may be damaged after exposure to such high temperatures. Alternatively, a CCM (e.g., C/C composite) should withstand the more severe conditions. 


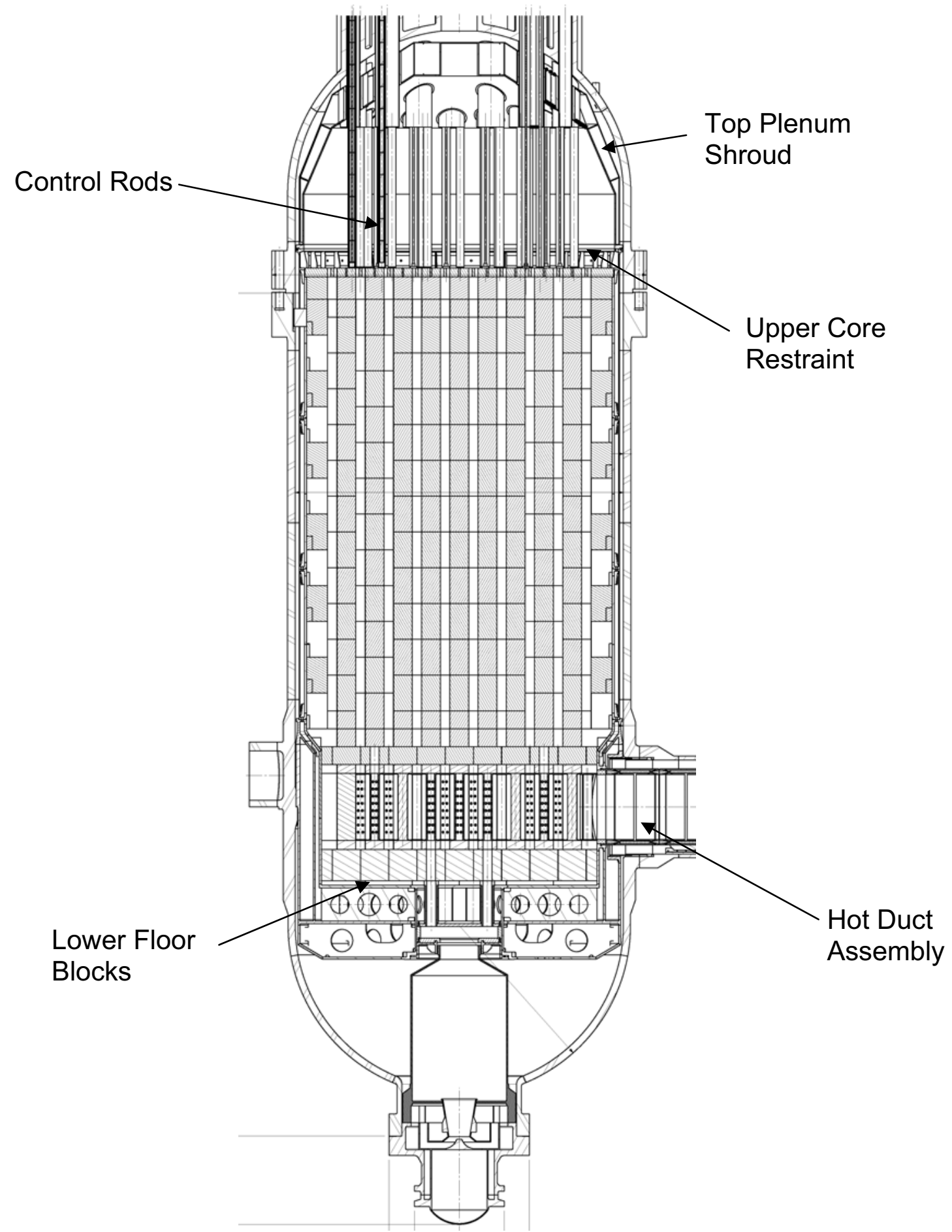

Figure 2-1: Section View of NGNP Reactor 


\section{Recommended Operating Conditions}

This section defines the baseline operating parameters and the operating conditions envelope for the NGNP HTGR specified in Reference [1].

\subsection{Design Baseline}

The NGNP has the following design baseline operating parameters:

- Very High Temperature Reactor (VHTR) Baseline

$>$ Power level 565 MWth

> Core inlet temperature $500{ }^{\circ} \mathrm{C}$

$>$ Core outlet temperature $900{ }^{\circ} \mathrm{C}$

$>$ Core Pressure $5 \mathrm{MPa}$

> Core Pressure Drop $55 \mathrm{kPa}$

- High Temperature Reactor (HTR) Baseline

$>$ Power level 600 MWth

> Core inlet temperature $350{ }^{\circ} \mathrm{C}$

$>$ Core outlet temperature $750{ }^{\circ} \mathrm{C}$

$>$ Core Pressure $5 \mathrm{MPa}$

> Core Pressure Drop $55 \mathrm{kPa}$

\subsection{Control Rods}

The NGNP reactivity control system has 12 startup rods, 18 reserve shutdown channels, and 36 control rods in reflectors. The inner control rods in the fuel region support reactor startup and shutdown. The outer control rods in the replaceable reflector region support reactor power control, reactivity margin compensation, and emergency protection. They are inserted to varying heights for control during reactor operation and are fully inserted for core protection situations. The startup control rods are only inserted during shutdown and refueling and remain fully withdrawn when the core is critical. The expected main characteristics of the NGNP control rod materials are:

- Mechanical stability at high temperature, e.g., during a conduction cooldown accident

- Corrosion resistance in the HTR environment, e.g., during normal operation and in the event of air and water ingress, if applicable

- Mechanical strength and dimensional stability after irradiation 
The control rods encapsulate the absorber material and position this material relative to the fuel. As described in the Reference [1], the initial design concepts for the control rods have a segmented column of canisters containing the absorber material and a flexible connection between each canister segment, as depicted in Figure 3.2-1.
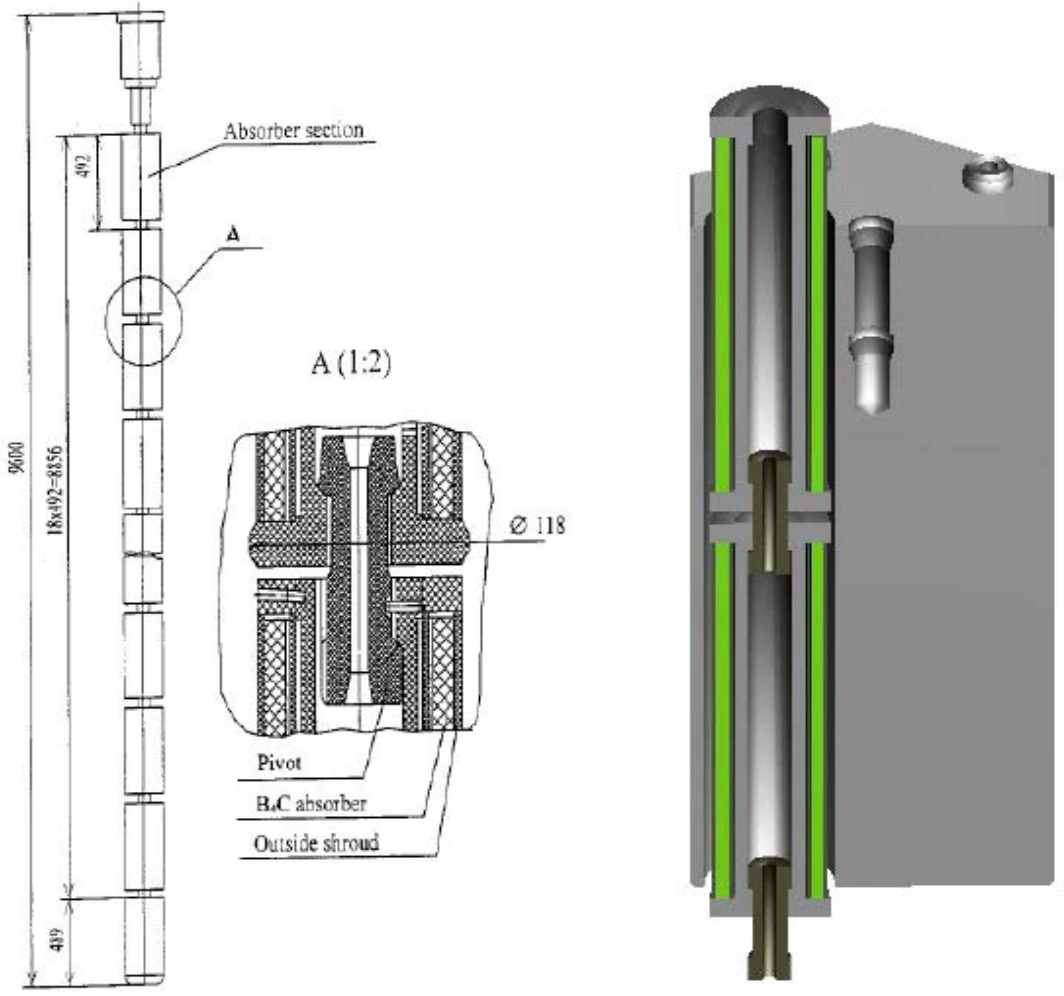

Figure 3.2-1: Segmented Control Rod Design [1]

The design concept includes annular compacts containing a neutron absorber material (e.g., $\mathrm{B}_{4} \mathrm{C}$ ) enclosed in carbon-carbon $(\mathrm{C} / \mathrm{C})$ composite or metal (e.g., Alloy $800 \mathrm{H}$ ) canisters [1, 2, 5]. A flexible connection between the canisters insures the control rods can be inserted into the core under the worst-case conditions of an earthquake, where lateral displacement may occur within the columns of graphite blocks.

Cold helium flowing through the annulus between the control rods and the channels within the graphite block removes heat from the annular compacts. Cold helium flowing through the central hole in the control rods can remove additional heat, if needed. 


\subsubsection{Operating Time}

The target operating lives of 30 years for inner control rods and 15-20 years for outer control rods fall in line with aggressive lifetime plans for next generation pressurized water reactor (PWR) control rods. The life expectancy for current PWR control rods ranges from 15 to 25 years. This study assumes an optimistic 30-year target for the NGNP control rods.

\subsubsection{Temperatures (normal and expected off-normal)}

Estimated control rod temperatures for normal and off-normal conditions are based on the NGNP design baseline with core inlet and outlet temperatures of $500{ }^{\circ} \mathrm{C}$ and $900{ }^{\circ} \mathrm{C}$, respectively. Temperatures for the control rods and other components in this study are heuristically estimated from reactor temperature maps found in model studies [3,4] of prismatic HTGRs having a reactor design and operating baseline similar to the NGNP. The reference studies examine HTGR thermal response during expected off-normal conditions, specifically, pressurized conduction cooldown (PCC) and depressurized conduction cooldown (DCC). During PCC and DCC, conduction, radiation, and natural convection passively remove heat from the reactor [3].

A PCC occurs after a reactor scram from normal operation following a loss of forced cooling. The primary system remains at full pressure and the reactor cavity cooling system continues to operate. The gas density at high system pressure enables buoyant helium to naturally circulate in the core and in the top and bottom reflectors. Hot helium from the bottom region of the core rises to the inner region of the fuel blocks and transfers heat to the upper regions of the core and to the top reflectors. The hot gas flows into the upper plenum and then downward along the core boundary where heat is transferred to side structures and to outer regions of the core. Natural circulation strongly redistributes heat in the core and in adjacent structures. As shown in Figures $3.2-2$ and $3.2-3$, relatively cold regions, e.g., the top reflector and upper core restraint, heat up and the lower hot region of the core cools down. Besides natural convection, heat transport also occurs via conduction and radiation to adjacent structures and via natural convection in the helium gas. Thus, heat is transferred from the core to adjacent structures and the pressure vessel and ultimately to the reactor cavity.

A DCC occurs after a reactor scram from normal operation following a loss of forced cooling and rapid depressurization of the primary system. The reactor cavity cooling system continues to operate. At low pressure, heat transport by natural convection in the core is negligible due to low gas density. Low buoyancy leads to negligible natural circulation in the core. Conduction and radiation, augmented by natural convection, primarily account for heat transport in the core and its adjacent structures. Heat is transferred from the core to the adjacent structures and the pressure vessel and from there to the reactor cavity cooling system. During DCC, the core heats up in the beginning, reaches maximum temperature around 70 to 110 hours, and then cools down 
slowly. As shown in Figures 3.2-4 and 3.2-5, the peak temperature approaches approximately $1600^{\circ} \mathrm{C}$.

In the reference studies, computer models were used to calculate time dependent heat conduction and temperature dependent material properties. Temperature maps (Figures 3.2-2 through 3.2-6) from the reference studies are used to heuristically estimate the NGNP temperature evolution in the vicinity of the control rods and other reactor components during DCC and PCC. Figures 3.2-7 and 3.2-8 depict the heuristically estimated evolution of temperature in the NGNP.

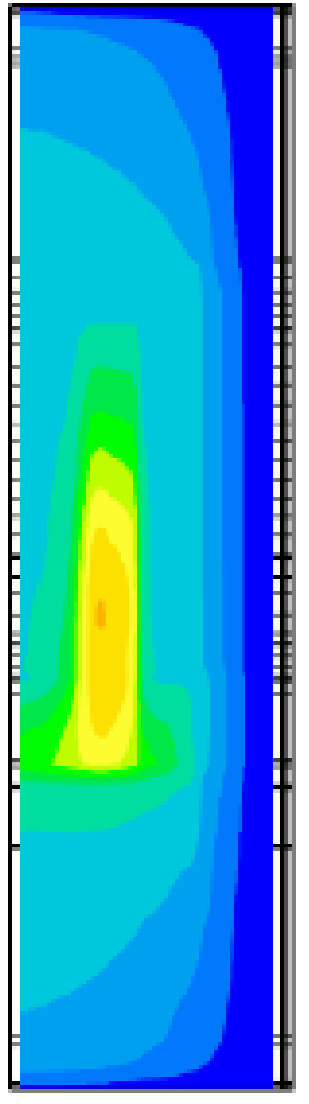

$\mathrm{t}=0$ hour

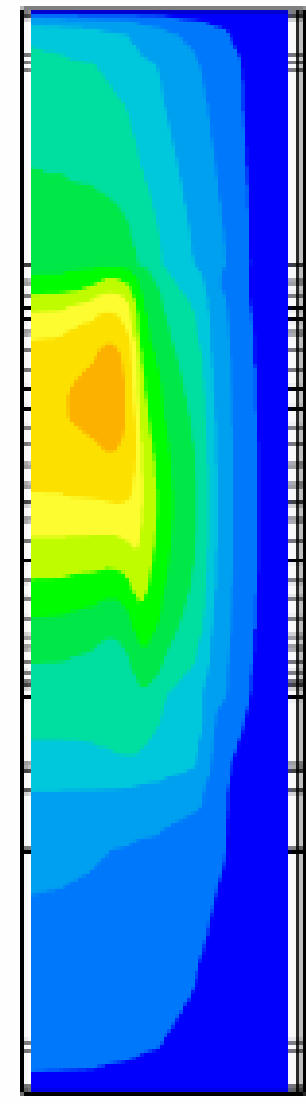

$\mathrm{t}=48$ hours
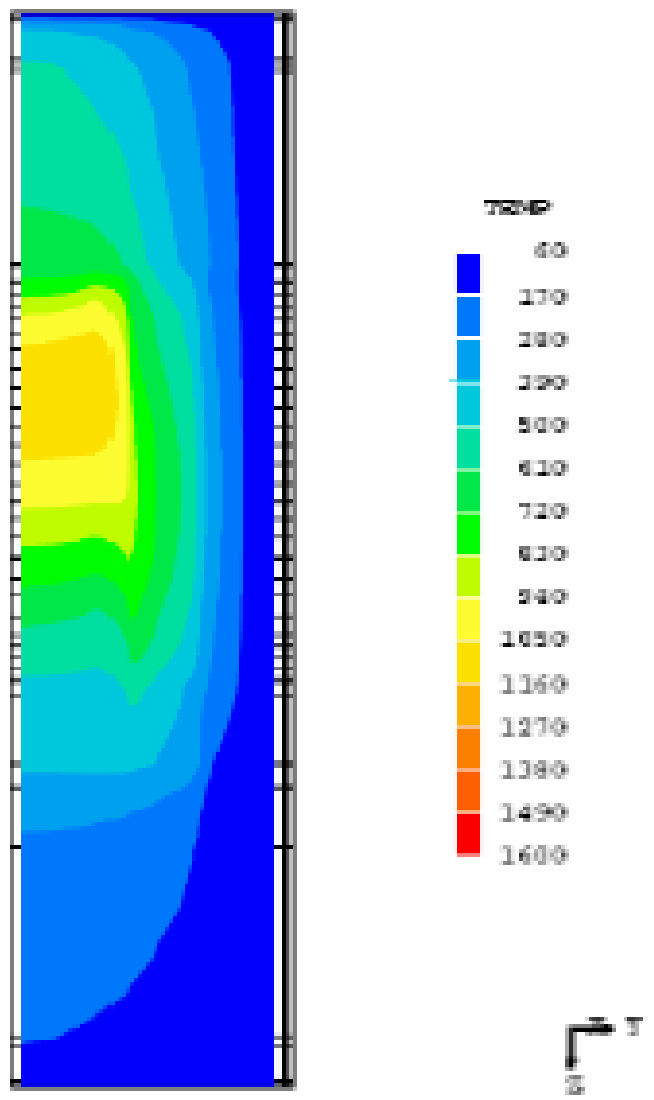

$t=100$ hours

Figure 3.2-2: Modeled Temperature Evolution during PCC 

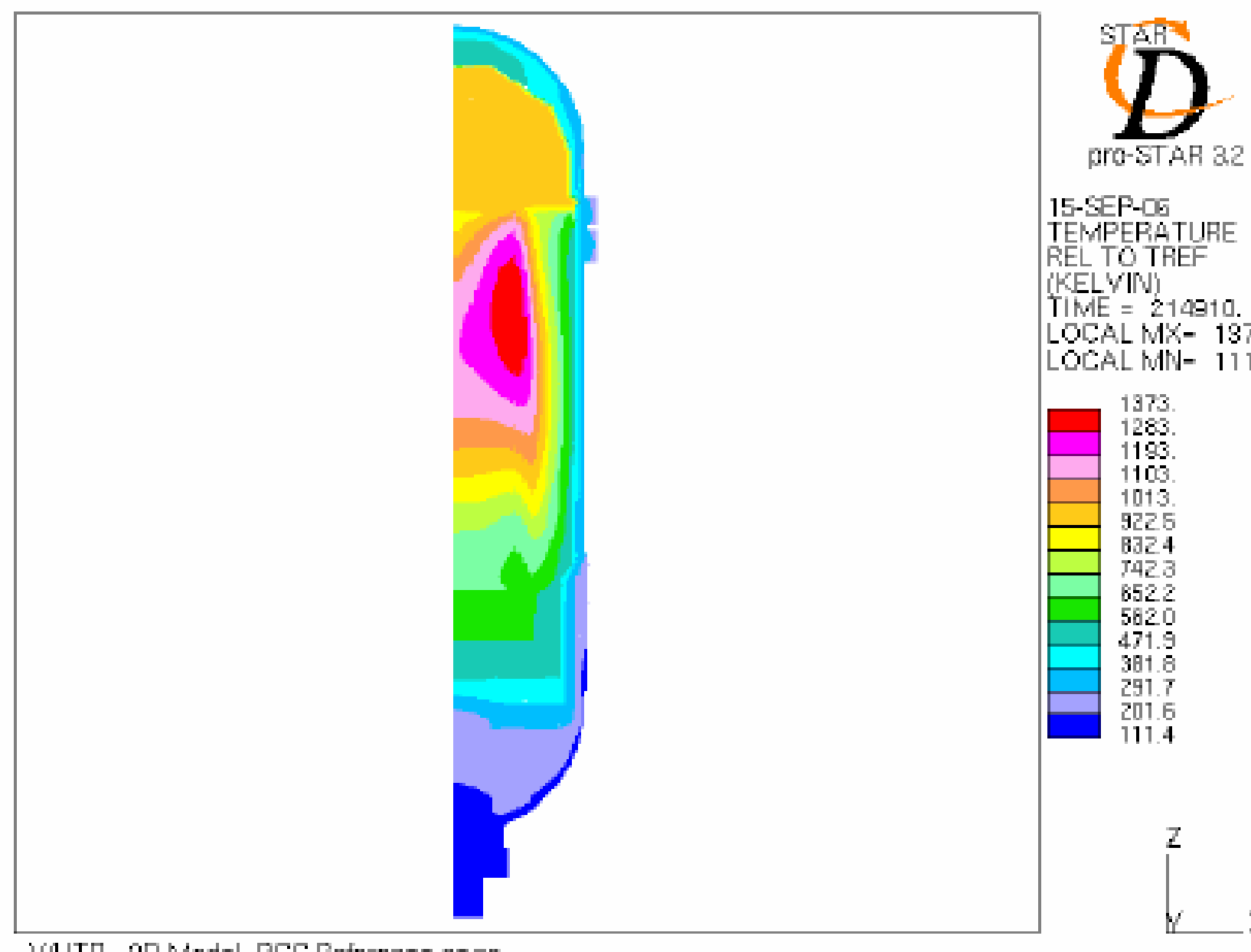

15-SEP-D5

TEMPERATURE

REL TO TREF

'KEL VIN')

TIME $=214910$.

LOCAL MX- 1373.

LOCAL MNV- 111.4

WHTR - 3D Model -PCC Reierence case

AREVA - Framatome-ANP

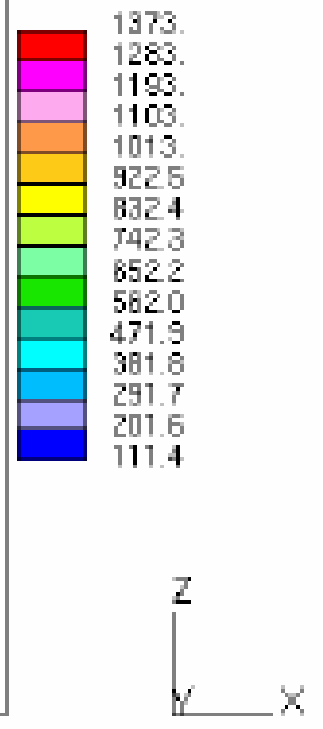

Figure 3.2-3: Temperature (Vertical Cross Section) during PCC at 60 hours 


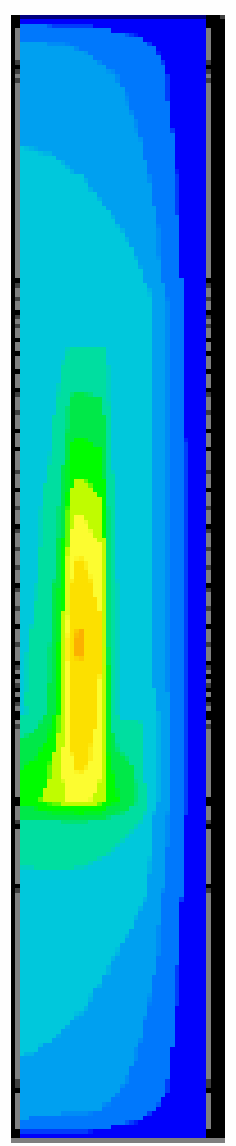

$\mathrm{t}=0$ hour

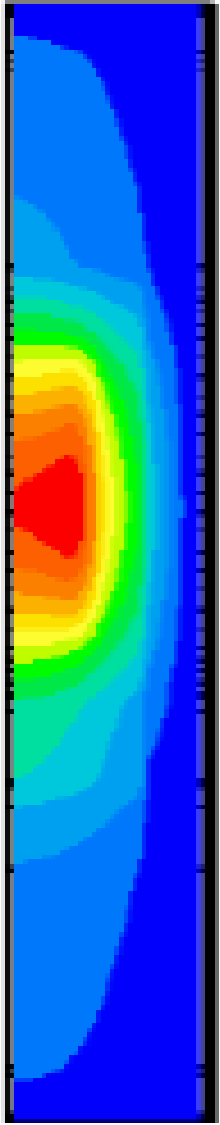

t=70 hours

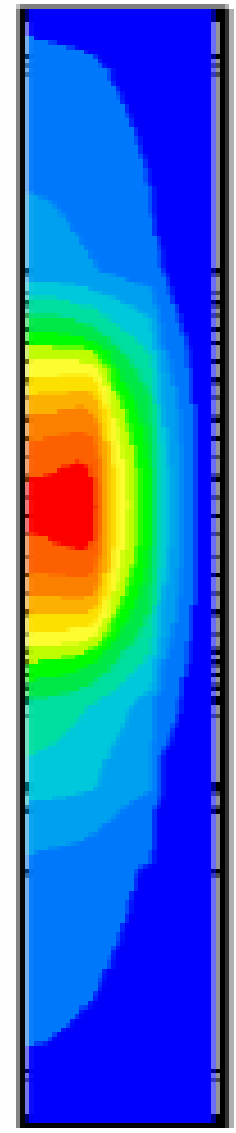

TLW

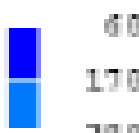

210

390

$5 \mathrm{ag}$

611

710

610

910

1051

LIA I

1971

1.2a

1497

1610

$\mathrm{t}=100$ hours

Figure 3.2-4: Modeled Temperature Evolution During DCC

This case is not limiting because the design condition will be hotter. 


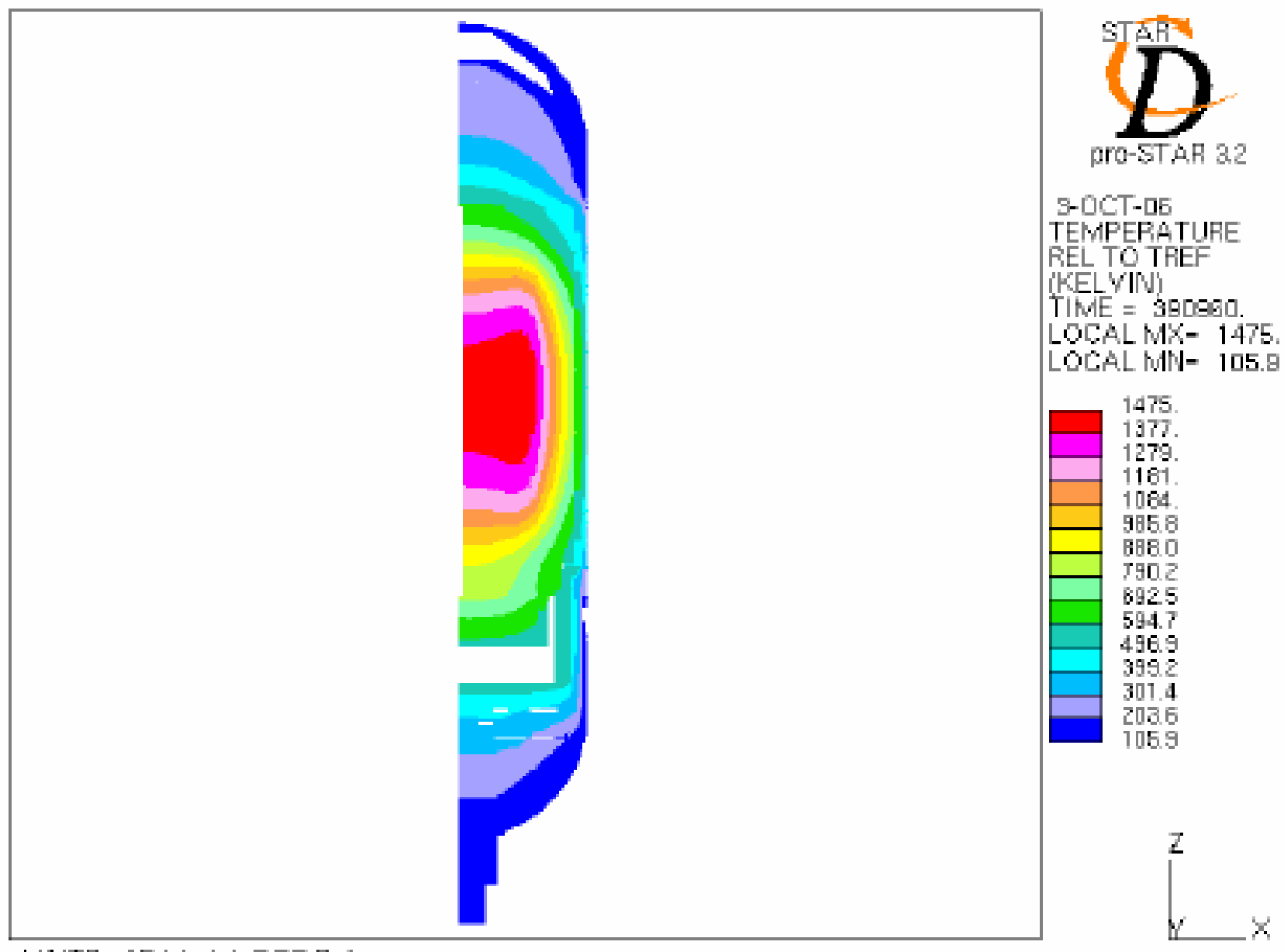

WHTR - 3D Model -DOC Reference case

SRE VA - Framatome-ANP

Figure 3.2-5: Temperature (Vertical Cross-Section) during DCC at 109 hours 

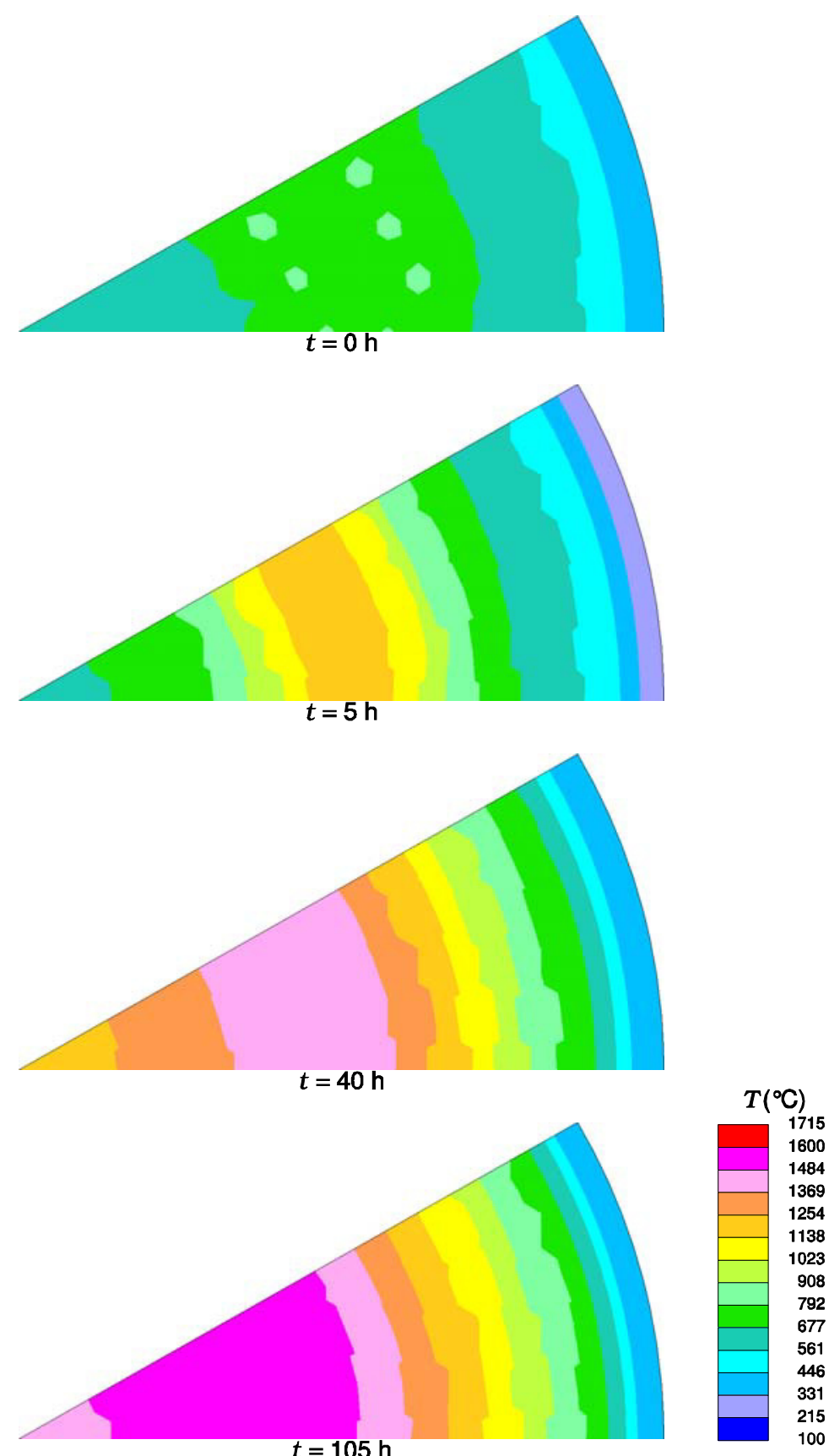

Figure 3.2-6: Modeled Temperature (Horizontal Cross-Section) during DCC 


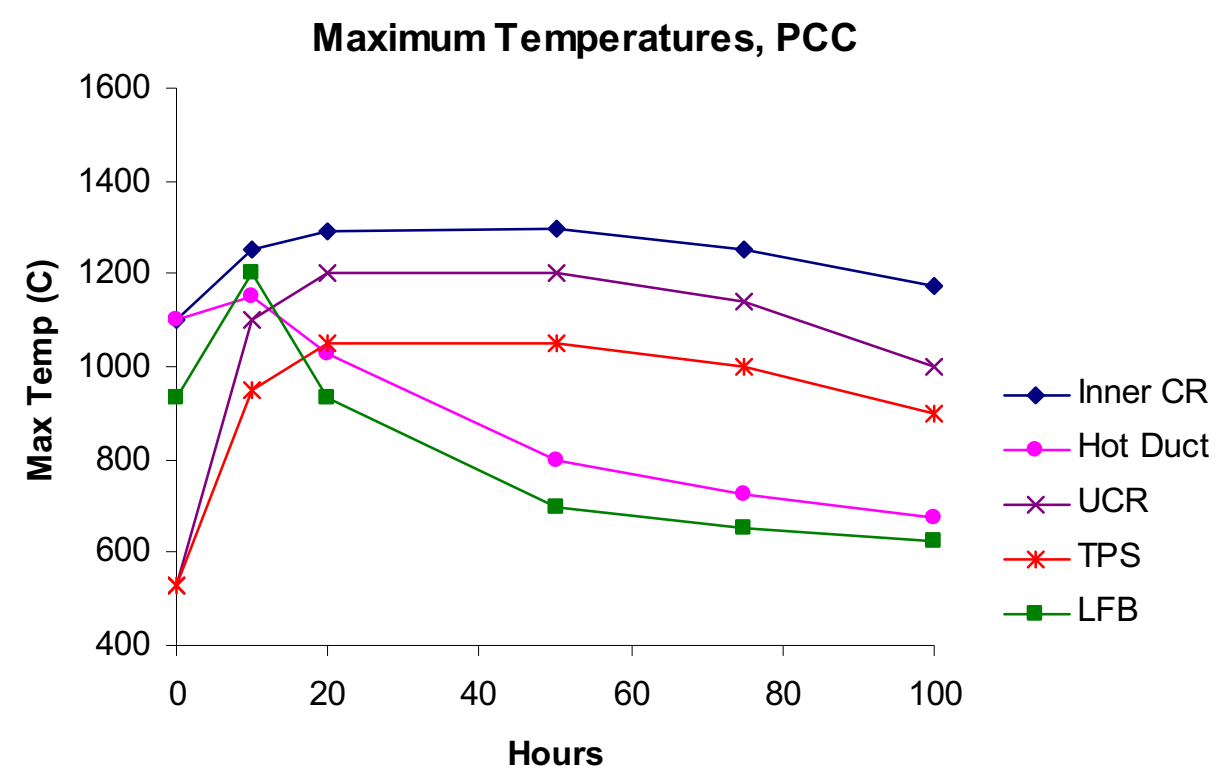

Figure 3.2-7: NGNP Maximum Temperature Evolution for Components during PCC

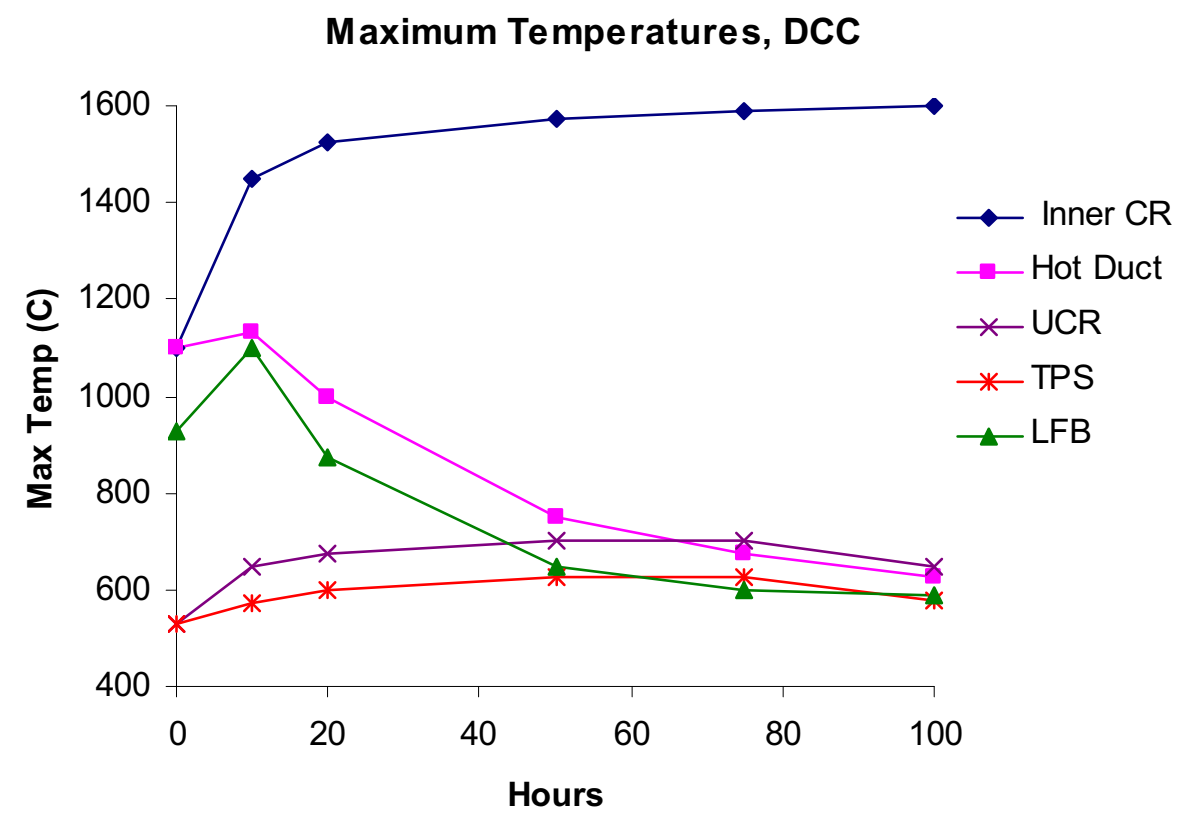

Figure 3.2-8: NGNP Maximum Temperature Evolution for Components during DCC 
The heuristically estimated control rod temperatures at NOC are based on design baseline core inlet and outlet temperatures of $500{ }^{\circ} \mathrm{C}$ and $900{ }^{\circ} \mathrm{C}$, respectively. Core temperature maps from reference studies indicate a representative maximum temperature of $1100{ }^{\circ} \mathrm{C}$ for a non-cooled control rod inserted near the location of the peak in-core temperature at NOC.

The reference study maps for accident conditions suggest a representative maximum temperature of $1200{ }^{\circ} \mathrm{C}$ for inserted outer control rods and $1600{ }^{\circ} \mathrm{C}$ for inserted inner control rods (see Figures 3.2-9 and 3.2-10).

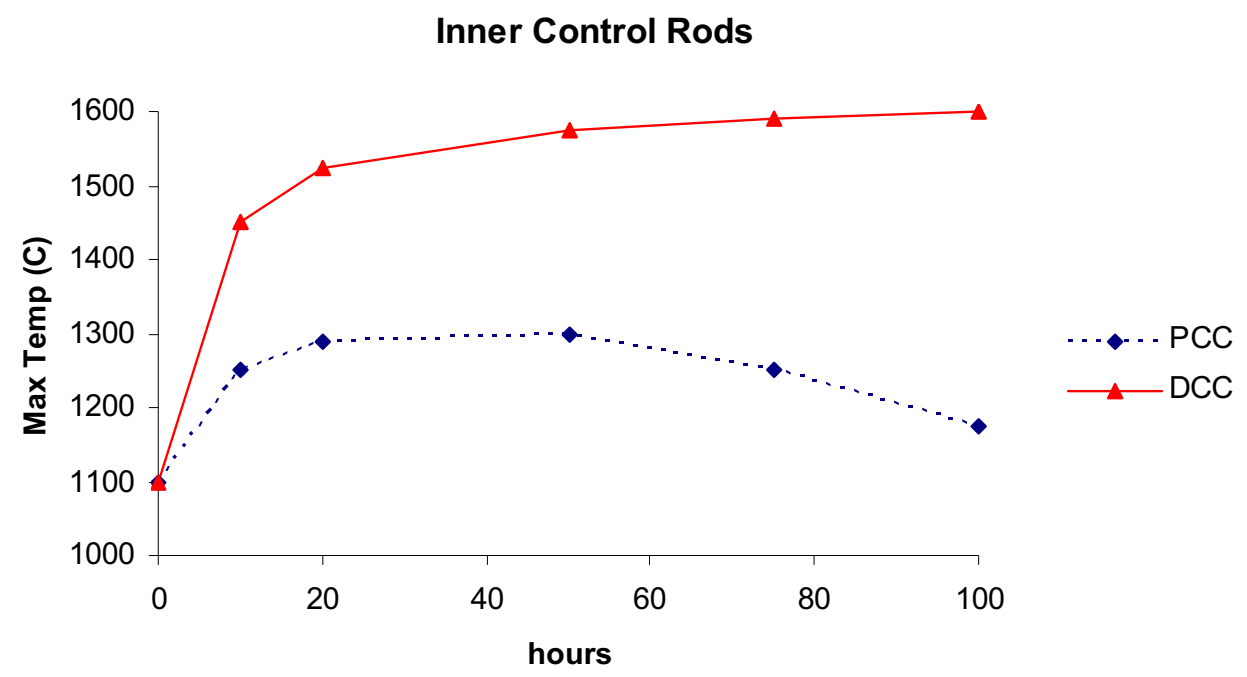

Figure 3.2-9: Inner Control Rod Temperatures 


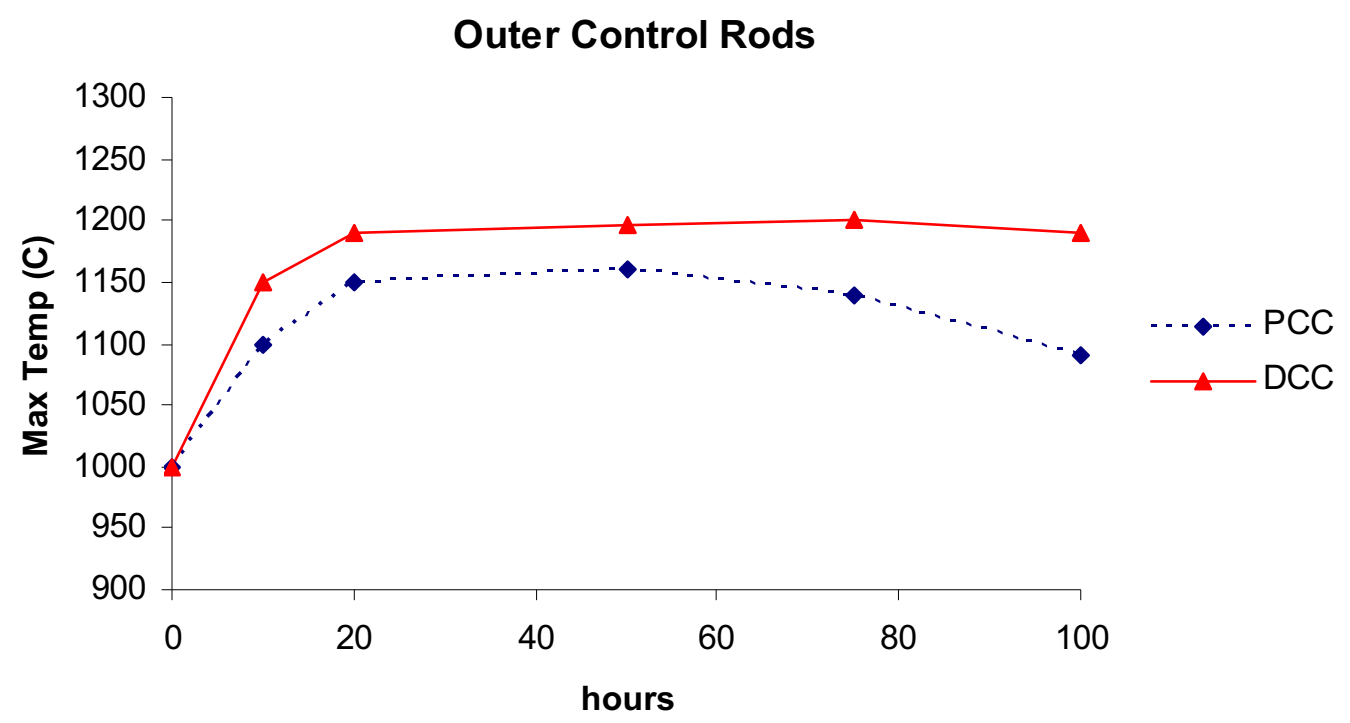

Figure 3.2-10: Outer Control Rod Temperatures

The control rod temperature ranges at NGNP operating conditions are:

- Inner control rod temperatures $\left({ }^{\circ} \mathrm{C}\right)$

$>$ Normal

$>$ Off-normal (DCC)

- Outer control rod temperatures $\left({ }^{\circ} \mathrm{C}\right)$

$>$ Normal

530-1000 (for non-cooled control rods)

$>$ Off-normal (DCC)

Reference [3] highlights the considerable variability of DCC and PCC maximum temperatures from model to model. These variations mainly stem from differences in computational methods, model resolution, and material properties. The HTGR model results show a need for further CFD and thermal-hydraulic model development, verification, and validation to support creation of a precisely defined set of benchmark problems for NGNP normal and off-normal conditions.

\subsubsection{Fluence}

Control rod fluxes in the outer cladding, $\mathrm{B}_{4} \mathrm{C}$, and inner cladding are tallied by using the MCNP5 physics code to model all six of the inserted control rods and at several axial 
levels along the rod. The results presented in Table 1 represent the highest fluence location available, e.g., the outer cladding layer on a section of the control rod assumed to be near the core mid-plane.

Table 1: Fluence Summary for the Control Rods

\begin{tabular}{|c|c|c|c|c|}
\hline \multirow{2}{*}{ Description } & \multicolumn{3}{|c|}{ Neutron Fluence $\left[\mathrm{n} / \mathrm{cm}^{2}\right]$} \\
\cline { 2 - 5 } & $\begin{array}{c}\text { Thermal } \\
{[\mathrm{E}<1 \mathrm{eV}]}\end{array}$ & $\begin{array}{c}\text { Epithermal } \\
{[1 \mathrm{eV}<\mathrm{E}<0.1 \mathrm{MeV}]}\end{array}$ & $\begin{array}{c}\text { Fast } \\
{[\mathrm{E}>0.1 \mathrm{MeV}]}\end{array}$ & Total \\
\hline Control Rods & $5.9 \mathrm{E}+22$ & $7.4 \mathrm{E}+22$ & $3.7 \mathrm{E}+22$ & $1.7 \mathrm{E}+23$ \\
\hline
\end{tabular}

The flux difference between the core mid-plane and the top of the active core is approximately a factor of ten, so the exact operating history of the control rod will significantly affect the accumulated fluence. The values in Table 1 all converged to less than $3 \%$ uncertainty and assume a very conservative 60 -year lifetime at $90 \%$ capacity factor.

\subsubsection{Applied Loads}

Mechanical and thermal loads, and resulting stresses, heavily depend on the control rod assembly design, the absorber material, and the materials of construction. The design needs to consider the following potential sources of load:

- The dead weight of the control rod assembly will introduce an axial load in the canisters and in the coupling linkages.

- Swelling of the absorber material will generate axial, radial, and hoop stresses in the canisters after the absorber material contacts the canister walls.

- At the end of a scram, an axial load will be generated as the control rod assembly decelerates from the maximum scram velocity to a rest state.

- If either a connector breaks within an assembly or a control rod assembly is released from the drive mechanism, impact loads will be imposed on the bottom canister. This load may also transmit upward though the connectors, depending on their design.

- If a cable is used in conjunction with connectors to create the flexible joints, then tensioning of the cable during fabrication of the control rod will create a pre-load in the cable and a compressive load in the column of canisters.

- Dimensional changes of control rod assembly sub-elements will result from temperature changes (e.g., expansion during ramp from ambient to normal operating conditions) and irradiation. Dimensional changes need to be analyzed when designing the control rod assembly to minimize loads and stresses. 
- Coolant flow through the control rod assembly may induce vibratory loads and displacements.

- The canisters need to be vented to the primary coolant flow so helium generated during irradiation of the absorber material will not create internal pressure within the canisters.

- The control rod assembly requires a tapered end cap for the bottom canister, along with tapered upper and lower ends for the remaining canisters, to prevent hang-up of the assembly.

The following additional sources of load will occur in off-normal conditions:

- During DCC, significant increases in temperature will result in further dimensional changes (i.e., thermal expansion). Large temperature gradients and differential thermal expansion will probably produce additional loads on the control rod assembly.

- Seismic events will produce axial loads of concern for the connections between canisters. Lateral loads should not be a factor if lateral movement of the graphite blocks is sufficiently restricted to avoid bending loads.

These potential sources of loads need to be analyzed during design of the control rod assembly. The canister design will be relatively straightforward with stresses minimized by appropriate selection of material thicknesses and clearances (e.g., between the canister ID and the OD of the annular absorber compacts). The areas of most concern are the flexible joints between the canisters and the method for sealing the canisters (e.g., lids with threaded joints).

\subsubsection{Environment}

Helium coolant in the primary loop is expected to have low levels of impurities during steady-state NOC, but over time these impurities can lead to environmental degradation of materials used for control rods and other core internals. Depending on the coolant impurity concentration and the temperature, metal alloys can undergo oxidation, carburization, or decarburization. Graphite, $\mathrm{C} / \mathrm{C}$ composites, and $\mathrm{SiC} / \mathrm{SiC}$ composites can undergo oxidation. Mild oxidation can potentially degrade the mechanical properties of these materials.

Impurity levels reported for steady-state operation of several HTGRs are shown in Table 2 , which provides information from Reference [5]. At steady-state, all reactors for which data are available show similar levels of impurities, but caution is needed in comparing data from different plants because the level of impurities varies for these plants. 
Table 2: He Coolant Impurities Reported for HTGRs [5]

\begin{tabular}{|l|c|c|c|c|c|c|c|}
\hline \multirow{2}{*}{\multicolumn{1}{c|}{ Reactor }} & \multicolumn{7}{|c|}{ He Coolant Impurities (ppm) } \\
\cline { 2 - 8 } & $\mathrm{H}_{2} \mathrm{O}$ & $\mathrm{H}_{2}$ & $\mathrm{CO}$ & $\mathrm{CO}_{2}$ & $\mathrm{CH}_{4}$ & $\mathrm{O}_{2}$ & $\mathrm{~N}_{2}$ \\
\hline Dragon & 0.1 & 0.1 & 0.05 & 0.02 & 0.01 & 0.1 & 0.05 \\
\hline Peach Bottom & 0.5 & 10 & 0.5 & $<0.05$ & 1.0 & - & 0.5 \\
\hline Fort St. Vrain & 1 & 7 & 3 & 1 & 0.1 & - & - \\
\hline AVR & 0.15 & 9 & 45 & 0.25 & 1 & & 22 \\
\hline THTR & $<0.01$ & 0.8 & 0.4 & 0.2 & 0.1 & & 0.1 \\
\hline
\end{tabular}

Air and water vapor may have entered the reactors during refueling and maintenance. Also, purging the core prior to restart and running the He purification systems reduced impurities to the levels observed in steady-state operation. Steady-state impurity levels were reached after equilibration with the graphite in the core.

At Fort St. Vrain (FSV), a key source of impurities was lubricant back streaming from the He circulators into the coolant during plant start-up. The FSV plant had high moisture levels due to ingress from the water-lubricated, steam-driven He circulators [5].

The NGNP will use a He purification system similar to those in prior HTGRs. Thus, the impurity levels in Table 2 should be representative of impurity levels expected within the baseline VHTR. In order to protect the high-temperature alloys, it is likely conditions will be controlled such that stable oxide scales will form on the alloys. For a typical Ni-based alloy, maintaining a stable oxide scale requires the following impurity levels at $950^{\circ} \mathrm{C}$ [6]:

- $\mathrm{PO}_{2}>2 \times 10^{-23}$

- $\mathrm{PH}_{2} \mathrm{O} / \mathrm{PH}_{2}>10^{-4}$

- $\mathrm{PCO}>150 \mu \mathrm{bar}$

Generation of dust and particulates in the reactor are a concern because their presence in the flowing He coolant can potentially erode core components. The sliding wear of graphite blocks produces graphite dust. Particulates can be generated by blocks rubbing against each other during refueling, vibration, seismic events, etc.

Any air and water entering the reactor during normal operation should be adequately handled by the He purification system and not pose problems for the materials. However, air and water ingress during various abnormal events, as identified in Reference [1], can harm reactor materials, e.g., graphite, C/C composites and $\mathrm{SiC} / \mathrm{SiC}$ composites. Specifically, air ingress during DCC can contribute to the degradation of control rods and other components at temperatures above $700{ }^{\circ} \mathrm{C}$. Rapid degradation occurs at temperatures above $900^{\circ} \mathrm{C}$. Similarly, water reacts with these materials at 
high temperatures. Water vapor enters the core during any air ingress, but the greatest concern for water ingress is a failure of the SCS heat exchanger. Any form of water entering the core in appreciable amounts can potentially damage core components and have a significant effect on core reactivity.

\subsection{Hot Duct Assembly}

The primary hot duct assembly (HDA) has the following functions:

- Route high-temperature helium from the core outlet plenum of the graphite core support structure to the IHX in the Process Heat Transport System or to a Steam Generator in the Main Heat Transport System within the PCS module;

- Mix the gas from the core outlet plenum to limit hot streaks;

- Provide thermal insulation to protect the support pipe from high-temperature helium and particularly hot streaks within the flow stream;

- Provide thermal insulation to minimize parasitic heat loss.

The main expected characteristics of the hot duct assembly are:

- Stability in the VHTR environment

- Thermal shock resistance

- Resistance to depressurization accidents

- Resistance to abrasion and erosion

- Mechanical stability

\subsubsection{Operating Time}

The primary hot duct assembly has a target operating life of 60 years, which is consistent with the anticipated life of the plant.

\subsubsection{Temperatures (normal and expected off-normal)}

The hot duct temperature estimates in Figure 3.3-1 are based on heuristic interpretation of the core temperature maps in Section 3.2.2 and on STAR-CD hot duct modeling performed by AREVA [7] (Figures 3.3-2 through 3.3-4).

The expected maximum temperatures for the primary hot duct assembly liner are:

- Normal

- Off-normal
$1100{ }^{\circ} \mathrm{C}$ (including hot streaks)

$1150^{\circ} \mathrm{C}$ (including hot streaks) 


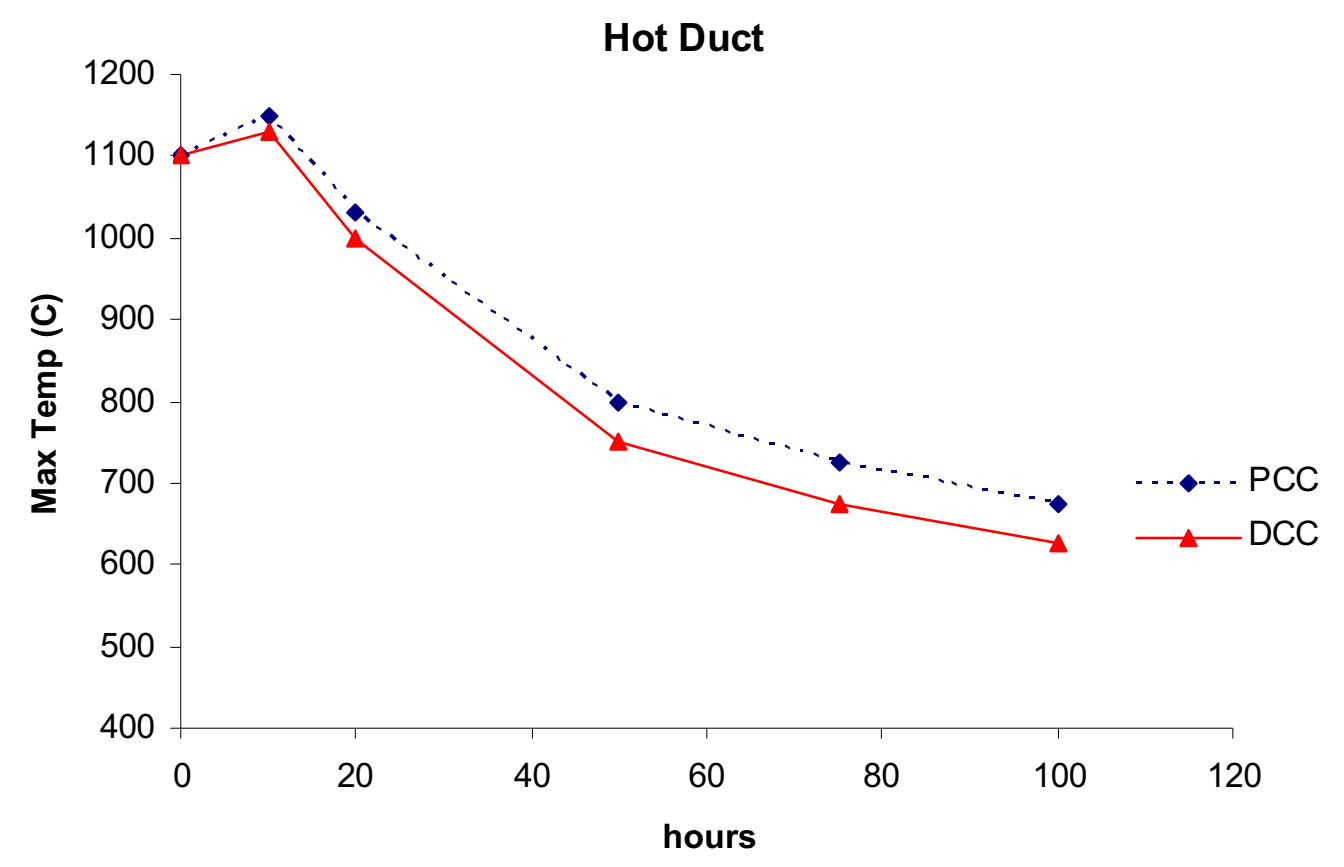

Figure 3.3-1: Hot Duct Temperatures

The next three figures show results from a STAR-CD CFD model for the lower plenum [7]. The case examined has one or two "hot" inlets adjacent to each of the three outlets as shown in the Figure 3.3-2. 

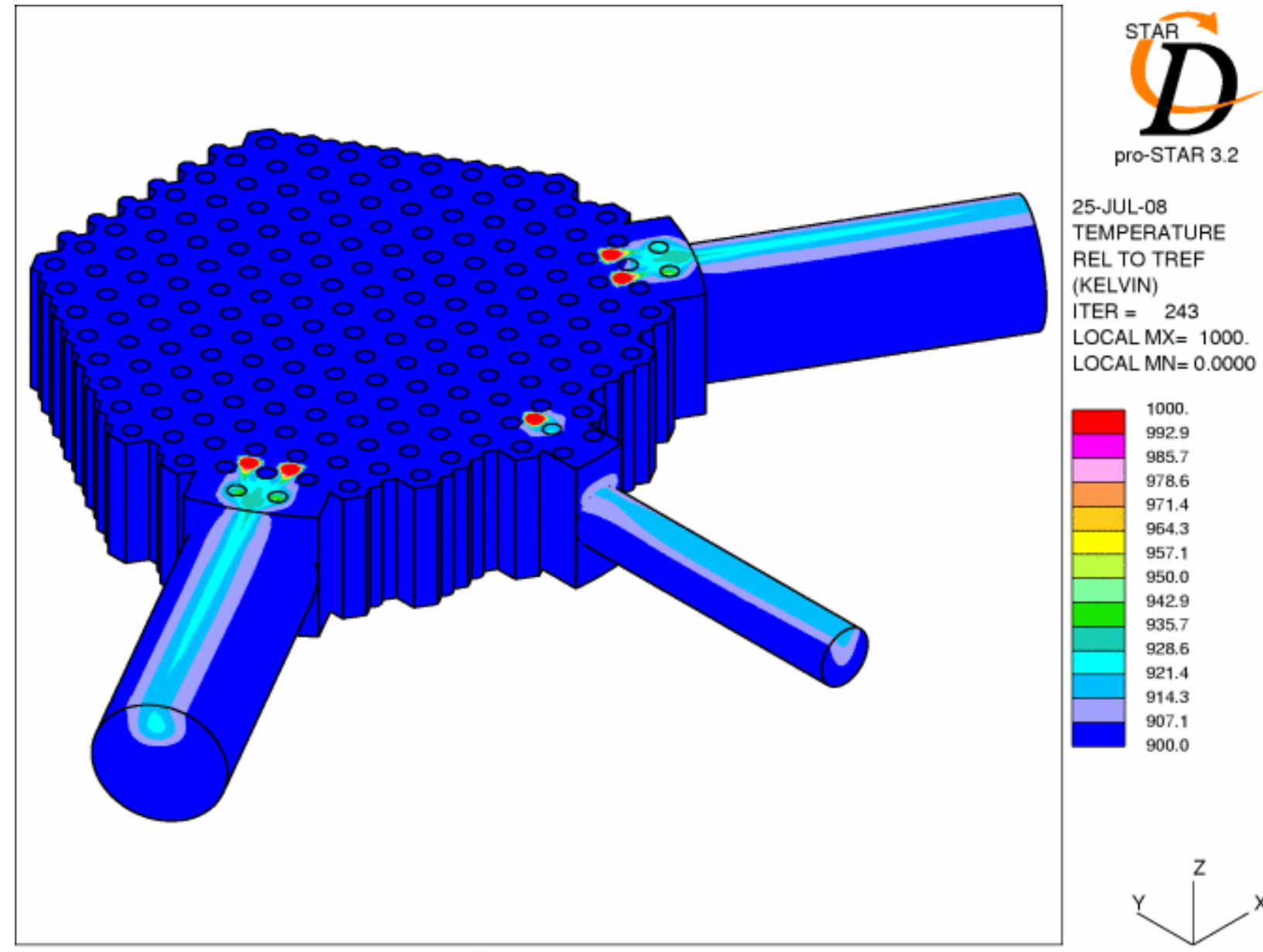

25-JUL-08

TEMPERATURE

REL TO TREF

(KELVIN)

ITER $=243$

LOCAL MX $=1000$

LOCAL MN $=0.0000$
LOCAL

Lower plenum model

Figure 3.3-2: STAR-CD Hot Duct Model

As Figure 3.3-3 shows, coolant enters the plenum through most inlets at $900{ }^{\circ} \mathrm{C}$ and "hot" inlets are about $100{ }^{\circ} \mathrm{C}$ hotter (i.e., $1000{ }^{\circ} \mathrm{C}$ ). This case, which is neither bounding nor conservative, is a parametric scoping analysis in which hot gas is mostly confined to the top spaces. The "hot" gas runs along the top surface of the hot ducts because denser coolant from the other inlets has already been pushed down and must flow under it. Furthermore, because "hot" inlets are as close as possible to the outlets, there is little room for mixing before gas enters the hot ducts. The scoping analysis case shows a heuristic $1100{ }^{\circ} \mathrm{C}$ limit is conservative for a $900{ }^{\circ} \mathrm{C}$ outlet temperature. Additional detailed analyses of the hot duct temperature need to be performed in late conceptual design and in preliminary design. 


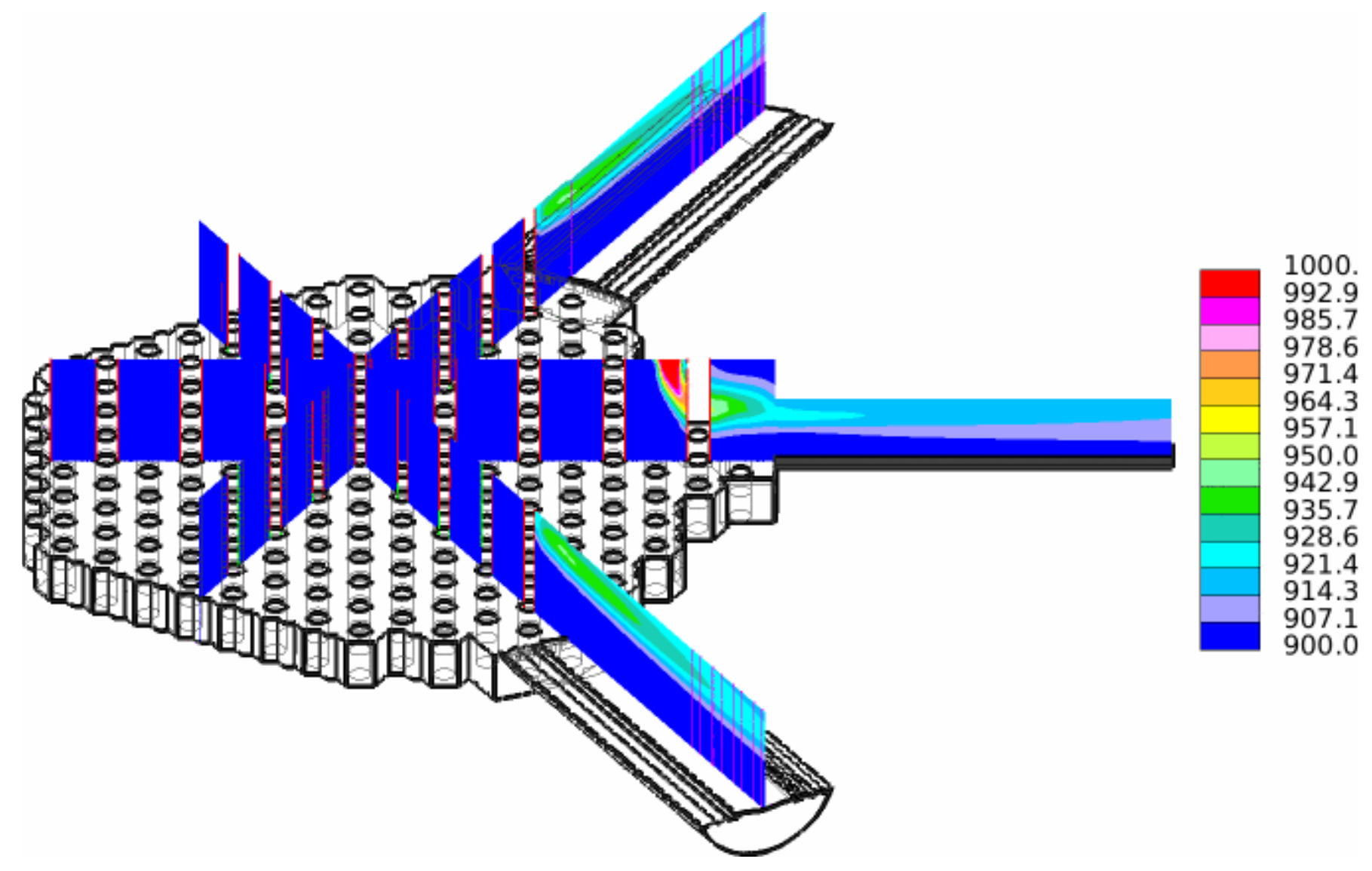

Figure 3.3-3: Hot Inlet Coolant Temperature $\left({ }^{\circ} \mathrm{C}\right)$

Figure 3.3-4 shows the temperature along the walls of the hot ducts. In each duct, a streak of hot gas flows along the top surface. The temperature reaches about $935^{\circ} \mathrm{C}$ along the top surface at the entrance of the two larger ducts. 


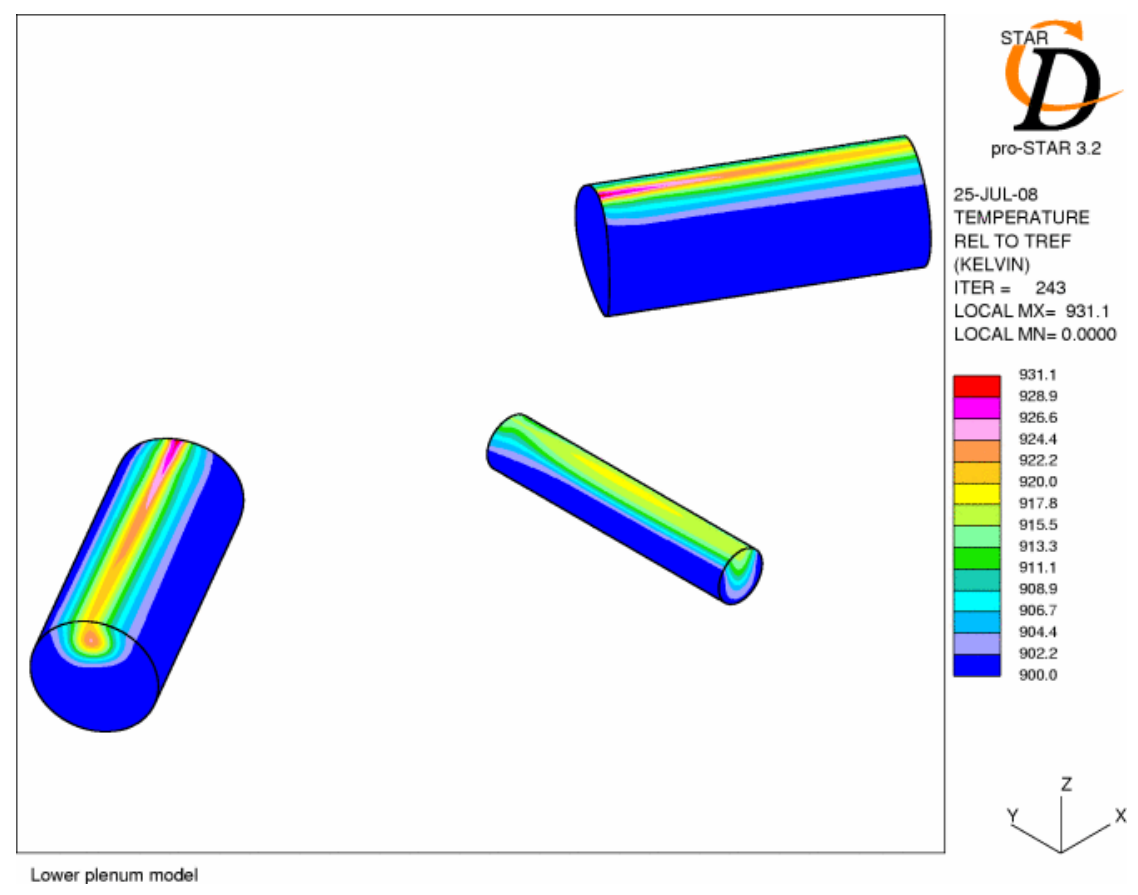

Figure 3.3-4: Temperature $\left({ }^{\circ} \mathrm{C}\right)$ along the Walls of the Hot Ducts

\subsubsection{Fluence}

The MCNP model of the duct involves only the metallic pipe with no insulation. As a surrogate for the duct insulation, flux is tallied in the inner duct pipe section nearest to the active core. The flux in the piping and insulation should be comparable and the section nearest the reactor will experience the highest fluence, ensuring a conservative calculation.

Table 3: Fluence Summary for the Primary Hot Duct Assembly

\begin{tabular}{|c|c|c|c|c|}
\hline \multirow{2}{*}{ Description } & \multicolumn{3}{|c|}{ Neutron Fluence $\left[\mathrm{n} / \mathrm{cm}^{2}\right]$} \\
\cline { 2 - 5 } & $\begin{array}{c}\text { Thermal } \\
{[\mathrm{E}<1 \mathrm{eV}]}\end{array}$ & $\begin{array}{c}\text { Epithermal } \\
{[1 \mathrm{eV}<\mathrm{E}<0.1 \mathrm{MeV}]}\end{array}$ & $\begin{array}{c}\text { Fast } \\
{[\mathrm{E}>0.1 \mathrm{MeV}]}\end{array}$ & Total \\
\hline Primary Hot Duct & $1.3 \mathrm{E}+17$ & $3.1 \mathrm{E}+16$ & $8.7 \mathrm{E}+15$ & $1.7 \mathrm{E}+17$ \\
\hline
\end{tabular}

The results in Table 3 converged to within one order of magnitude and assume 60 years of operation at a $90 \%$ load factor. 


\subsubsection{Applied Loads}

To assess potential sources for mechanical and thermal loads in the hot duct assembly, two different design concepts are evaluated. The first design has a metallic hot duct with a metal alloy structural pipe and thermal insulation in the internal cavities, as shown in Figure 3.3-5 (from Reference [1]).

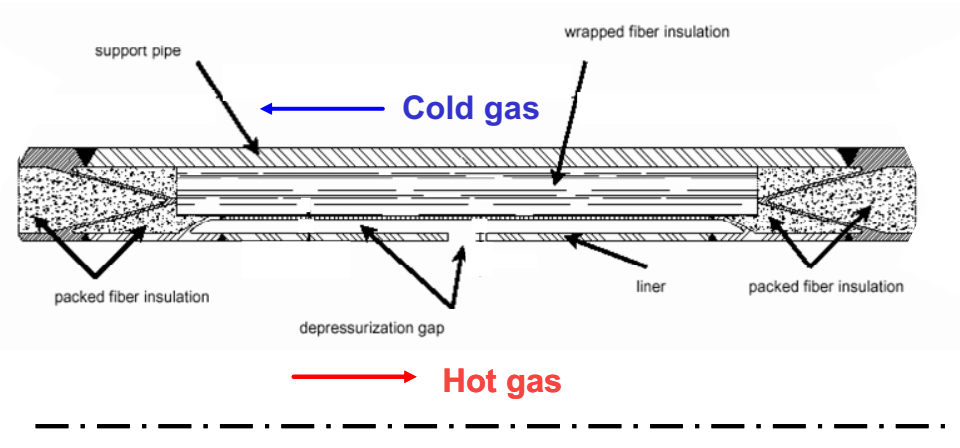

Figure 3.3-5: Metallic Hot Gas Duct Design Concept [1]

The second design has a cylindrical ceramic insulation liner within the metal support pipe. For both designs, it is assumed one end of the HDA will have a welded connection, while the other end uses a bellows connection, thus limiting the axial loads on the assembly due to differential thermal expansion.

Both designs will have the following common sources of loads at NOC:

- Radial and tangential stress in the support pipe due to the pressure gradient of about 90 psi. The stress will exist for the life of the HDA and will be cyclical.

- Acoustic and vibratory loads from the coolant pumps.

- High frequency and low amplitude vibratory loads for the PCS equipment over the lifetime of the system.

- Vibratory loads from helium flow within the HDA. Flow-induced vibration loads are expected to be low compared to rotating machinery loads.

- Bending moments due to movement of the reactor vessel and power generation vessel relative to the cross vessel. These loads would directly transfer to the hot duct through connections between the cross vessel and the metallic support pipe (both at the ends and at intermediate positions of the HDA). 
- Flow-induced loads, particularly in the elbow where flow abruptly changes direction.

Additional loads may arise in the following off-normal conditions:

- Rapid pressure changes during DCC, which might generate excessive loads for the ceramic insulation unless adequate vents provide rapid pressure equalization across the ceramic layer.

- Loads due to thermal shock and significant temperature gradients in the event of loss of pressure.

- Seismic events and loads created by acceleration and induced moments on the coupled system of interconnected vessels.

\subsubsection{Environment}

Environmental stability of the HDA insulation will depend on the materials used. Highpurity alumina insulation, as identified for the metallic HDA design, will be stable under NOC and when exposed to steam or air. However, for materials such as $\mathrm{C} / \mathrm{C}$ composites, exposure to air or steam at high temperatures $\left(>700{ }^{\circ} \mathrm{C}\right)$ would lead to rapid degradation unless given a protective coating.

Erosion is the greatest environmental concern for HDA insulation. It is expected hot helium flowing out of the reactor will contain a small amount of graphite powder. The entrained graphite may erode the inner surface of the HDA, particularly at the elbow where flow abruptly changes direction. This erosion is a greater concern for a ceramic liner and will probably require the inner surface of the liner to be constructed of a more durable grade of material.

\subsection{Upper Core Restraint Blocks}

The functions of the upper core restraint (UCR) blocks are to:

- Limit the lateral movement of the replaceable reflector and fuel columns at the upper end of the reactor core.

- Ensure uniform flow of primary coolant into the active core.

- Provide access and insertion alignment for the Neutron Control Assemblies

- Minimize parasitic flow of primary coolant through gaps between the fuel columns.

The main expected characteristics for the upper core restraints are:

- Mechanical integrity at high temperature, especially during conduction cooldown

- Thermal expansion coefficient similar to graphite

- Include design features to permit the operation of the Fuel Handling System. 


\subsubsection{Operating Time}

The UCR has an expected operating life of 30 years.

\subsubsection{Temperatures (normal and expected off-normal)}

The UCR temperature estimates in Figure 3.4-1 are based on the core temperature maps in Section 3.2.2.

The expected temperatures for the upper core restraints at operating conditions are:

- Upper surface temperature $\left({ }^{\circ} \mathrm{C}\right)$

$>$ Normal 530

$>$ Off-normal (PCC) 1200

- Lower surface temperature $\left({ }^{\circ} \mathrm{C}\right)$

$>$ Normal 530

$>$ Off-normal (PCC) 1150

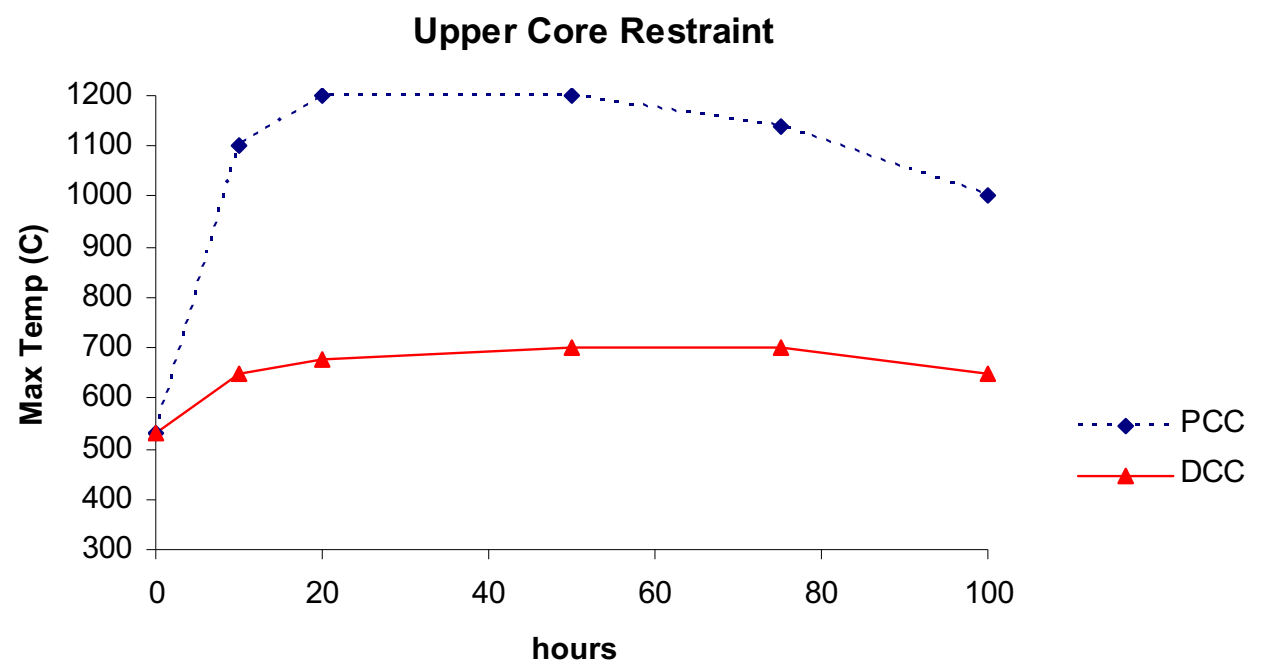

Figure 3.4-1: Upper Core Restraint Temperatures

\subsubsection{Fluence}

The UCR is modeled as a pair of graphite plates between the upper graphite reflector and the upper plenum. Table 4 lists the average flux values in the lower restraint plate. 
Fluences for the lower restraint plate are given for conservatism as they are approximately a factor of three greater than those for the upper restraint plate.

Table 4: Fluence Summary for the Upper Core Restraint

\begin{tabular}{|c|c|c|c|c|}
\hline \multirow{2}{*}{ Description } & \multicolumn{4}{|c|}{ Neutron Fluence [n/cm $\left.{ }^{2}\right]$} \\
\cline { 2 - 5 } & $\begin{array}{c}\text { Thermal } \\
{[\mathrm{E}<1 \mathrm{eV}]}\end{array}$ & $\begin{array}{c}\text { Epithermal } \\
{[1 \mathrm{eV}<\mathrm{E}<0.1 \mathrm{MeV}]}\end{array}$ & $\begin{array}{c}\text { Fast } \\
{[\mathrm{E}>0.1 \mathrm{MeV}]}\end{array}$ & Total \\
\hline Upper Core Restraint & $1.2 \mathrm{E}+21$ & $1.8 \mathrm{E}+19$ & $1.5 \mathrm{E}+17$ & $1.2 \mathrm{E}+21$ \\
\hline
\end{tabular}

The thermal flux value converges to less than $2 \%$ uncertainty for an assumed 60 years of operation and $90 \%$ capacity. Assuming a 30-year operating life of the upper core restraint will halve the fluence values in the table.

\subsubsection{Applied Loads}

The UCR is an assembly of interlocking blocks, each expected to have hexagonal shape and to interface with the upper surface of the reflector elements as shown in Figure 3.4$2[1,2]$. Keys maintain the lateral position of the UCR blocks and lock adjacent blocks to each other. Keys around the perimeter of the UCR lock the blocks to the core barrel. Dowels maintain the lateral position of the graphite reflector blocks and, thus, the columns of fuel and reflector blocks. Prior UCR block designs are based on Alloy $800 \mathrm{H}$, as in Reference [9], but more recent studies consider the use of carbon/carbon (C/C) composites, as in References [1, 2].

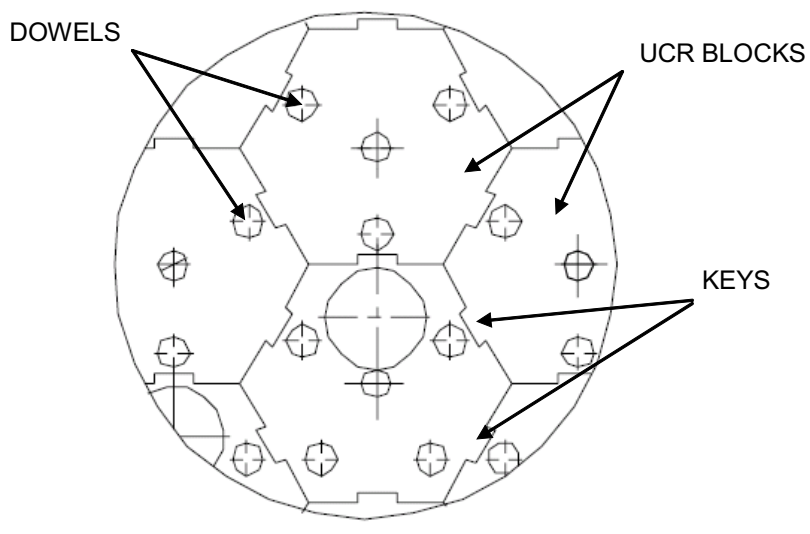

Figure 3.4-2: Top View of Upper Core Restraint Blocks 
The dowel and key positioning features for the UCR blocks will see tensile and shear loads as a result of their function to constrain the lateral movement core. The degree of stress within the UCR blocks and pins depends on various factors, which include:

- Differential expansion between the UCR blocks and the graphite blocks due different coefficients of thermal expansion (CTE);

- Differential expansion between the core barrel and the UCR blocks due to CTE differences;

- Dimensional changes in the UCR blocks and mating components due to irradiation;

- Dimensional tolerances in the keys and dowels and in their mating features.

The UCR blocks also interface with control rod guide tubes and the RRSS tubes. Because the blocks will presumably restrain and position these tubes, loads will be imposed around the mating holes in the UCR blocks.

The UCR blocks will not be constrained in the axial direction. Thus, the UCR blocks will be free to move vertically and will not be subjected to vertical loads except for a small load due to coolant pressure drop through the blocks and to friction between adjacent blocks.

Keys and dowels for lateral positioning need to be evaluated for fatigue due to cyclical loads. Also, coolant flow will probably produce flow-induced vibration causing repetitive impacts between adjacent blocks and keys and between the dowels and holes.

Thermal and mechanical loads increase during off-normal conditions as a result of higher temperatures, lateral temperature gradients across the blocks, and differential thermal expansion due to axial temperature gradients in the blocks.

Seismic activity is also a concern as it may subject keys and dowels to shear (keys and dowels) and tensile loads (keys).

\subsubsection{Environment}

The UCR blocks will normally be exposed to flowing helium at the core inlet temperature of $500{ }^{\circ} \mathrm{C}$. If nominal He purity is maintained, the high-temperature metal alloys and $\mathrm{C} / \mathrm{C}$ composite materials being considered for UCR block fabrication should be stable against corrosion. However, erosion of the blocks around the coolant flow holes may be an issue for long-term performance and needs to be considered in the design and materials selection process.

Steam or air ingress should not be a threat to the UCR blocks at normal operating temperatures and below. However, exposure to either steam or air during a hightemperature accident condition (e.g., $\mathrm{T}>700^{\circ} \mathrm{C}$ for a $\mathrm{C} / \mathrm{C}$ composite) could lead to rapid degradation of the UCR blocks. 
For $\mathrm{C} / \mathrm{C}$ composites, the use of a hard, dense protective coating, such as $\mathrm{SiC}$, would improve the resistance of the material to corrosion and erosion.

\subsection{Top Plenum Shroud}

The top plenum shroud (TPS) provides thermal and radiation shielding for the reactor pressure vessel (RPV) and pressure vessel head. The main expected characteristics of the top plenum shroud are:

- Thermal performance - structural stability under normal and off-normal operating conditions

- Neutron shielding for the RPV head

The top plenum shroud connects to the top of the metallic core support inner structural shell. As shown in Figure 3.5-1, the TPS has through-thickness penetrations to accommodate control rods, instrumentation, and fuel handling equipment. The main helium flow exits the core barrel annular channel into a plenum formed by the upper core restraint blocks and the TPS. Stagnant flow outside the top plenum shroud reduces parasitic heat loss.

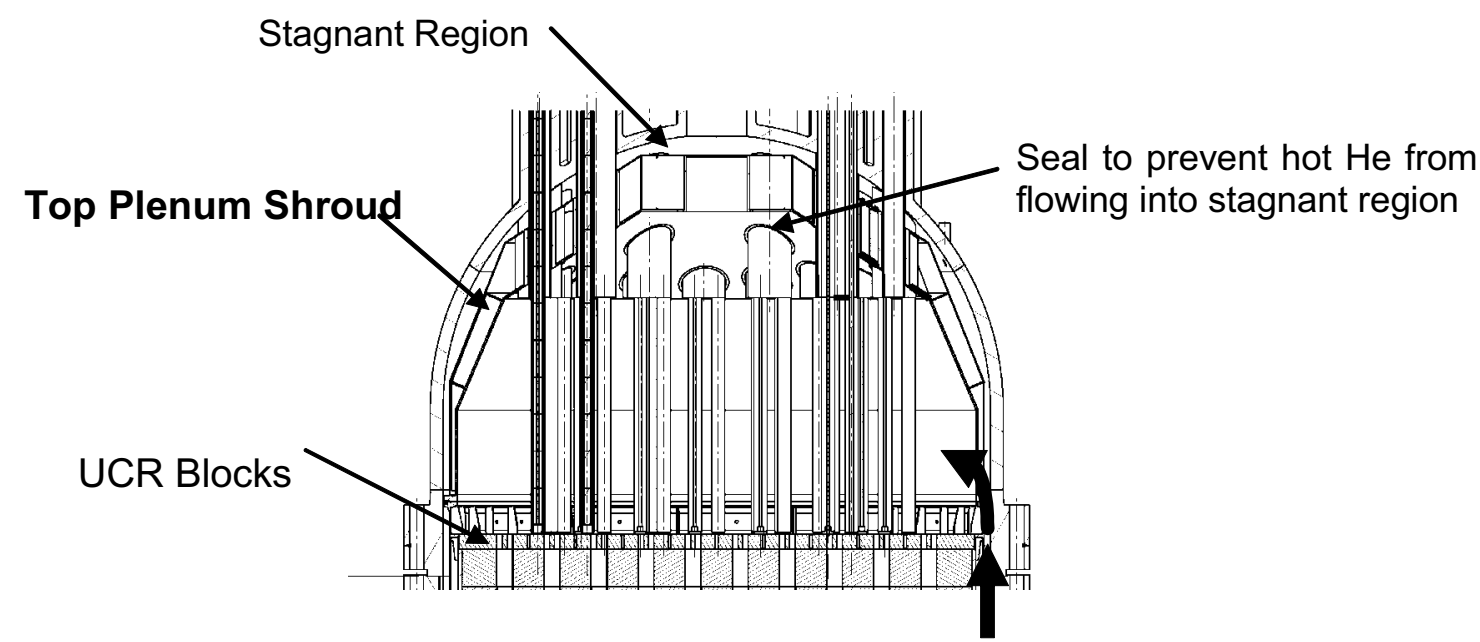

Helium flow

Figure 3.5-1: Upper Portion of Reactor Vessel Showing the Top Plenum Shroud

Prior designs for the top plenum shroud, as in References [1, 9], use metal alloy (e.g., $800 \mathrm{H}$ ) for the inner and outer shells and include stiffening ribs on the inner shell. 
Insulation and shielding materials resides in the space between the two shells. Seals are required around the shroud penetrations to prevent helium from flowing into the stagnant region. However, these seals are not expected to be completely leaktight and thus will need a baffle of some kind to minimize leakage.

The functions of thermal and radiation shielding are somewhat mutually exclusive. An effective neutron shield must be relatively dense to maximize the amount of absorber material per unit volume, but a thermal insulation material generally has very low density.

To provide neutron shielding, either a hydrogenous or an absorber material may be used. The most likely hydrogenous material candidate is $\mathrm{ZrH}$. The most likely absorber material candidate is boron in the form of either $\mathrm{B}_{4} \mathrm{C}$ or borosilicate glass.

The shielding function is expected to only apply to the upper, thicker part of the TPS structure. For the more vertical, thinner lower sections of the TPS joining the core barrel, both insulation and shielding functions probably cannot coexist. Because the lower TPS section is coaxial with the core, the neutron flux there will be lower. Thus, the lower section of the TPS only needs to provide thermal insulation.

\subsubsection{Operating Time}

The TPS has an expected operating life of 60 years, which requires no burnout of the shielding absorber material.

\subsubsection{Temperatures (normal and expected off-normal)}

Temperature estimates for the top plenum in Figure 3.5-2 are based on reactor temperature maps in Section 3.2.2.

Expected temperatures for the top plenum shroud at operating conditions are:

- Outer surface temperature $\left({ }^{\circ} \mathrm{C}\right)$

$>$ Normal 350

$>$ Off-normal (PCC) 380-500

- Inner surface temperature $\left({ }^{\circ} \mathrm{C}\right)$

$>$ Normal 530

$>$ Off-normal (PCC) 930-1050 


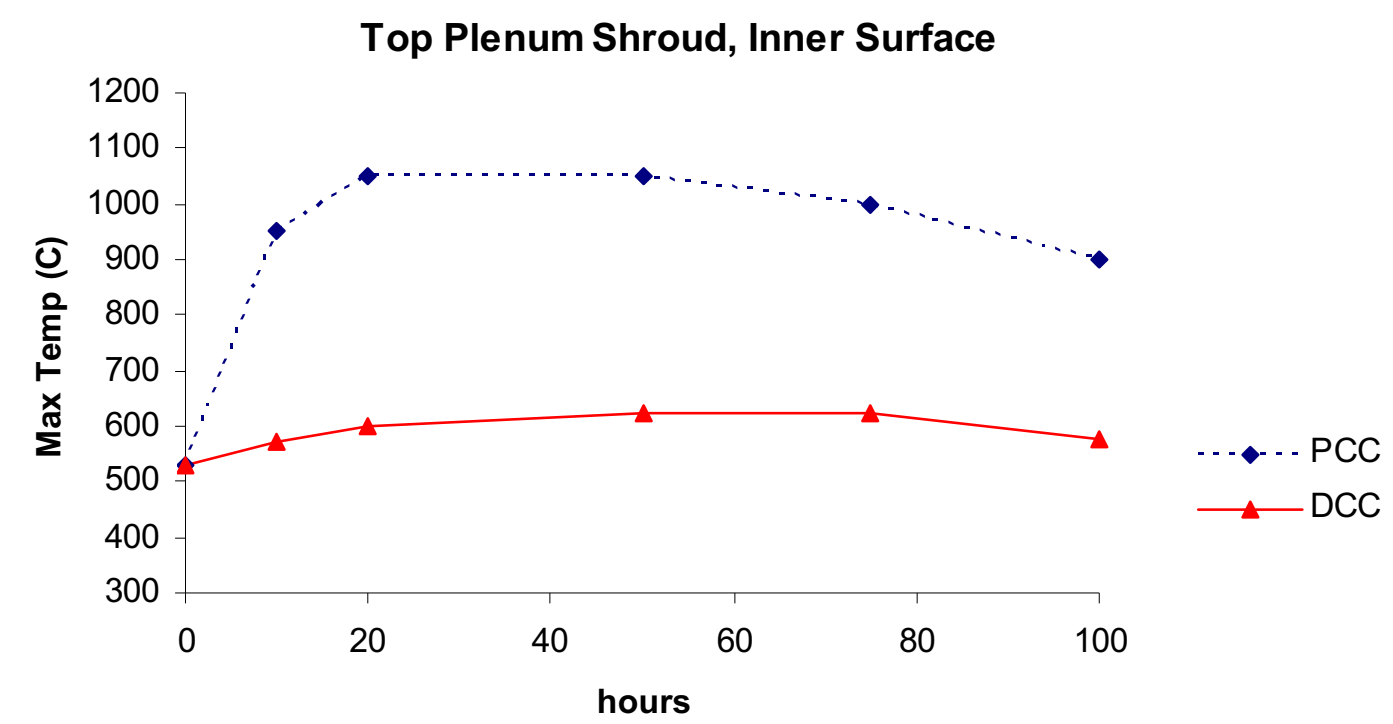

Figure 3.5-2: Top Plenum Shroud Temperatures

\subsubsection{Fluence}

The top plenum shroud is modeled in an MCNP5 physics model as four sections tallied individually. Table 5 shows the results from the four tallies.

Table 5: Fluence Summary for the Top Plenum Shroud

\begin{tabular}{|c|c|c|c|c|}
\hline \multirow{2}{*}{ Description } & \multicolumn{4}{|c|}{ Neutron Fluence $\left[\mathrm{n} / \mathrm{cm}^{2}\right]$} \\
\cline { 2 - 5 } & $\begin{array}{c}\text { Thermal } \\
{[\mathrm{E}<1 \mathrm{eV}]}\end{array}$ & $\begin{array}{c}\text { Epithermal } \\
{[1 \mathrm{eV}<\mathrm{E}<0.1 \mathrm{MeV}]}\end{array}$ & $\begin{array}{c}\text { Fast } \\
{[\mathrm{E}>0.1 \mathrm{MeV}]}\end{array}$ & Total \\
\hline Top Plenum Shroud & $1.3 \mathrm{E}+20$ & $1.4 \mathrm{E}+17$ & $3.4 \mathrm{E}+16$ & $1.3 \mathrm{E}+20$ \\
\hline
\end{tabular}

Only the results for the thermal energy range converged well. The thermal groups have an average error of less than $5 \%$ but average errors in the epithermal and fast groups range from 10 to $100 \%$. Thermal neutron dominance in the upper plenum leads to sparse sampling and statistics for the higher-energy groups 


\subsubsection{Applied Loads}

Load concerns for the top plenum shroud are:

- Stress resulting from temperature gradients

- Mechanical loads resulting from the weight of the TPS

Flow-induced loads have not yet been identified but are probably insignificant due to low coolant density and the upper plenum's large volume.

For the baseline design from References [1,9], the most likely source of thermal gradients during NOC will be the different levels of thermal insulation for the TPS. Specifically, the inner, thinner shell sections will be cooler than the upper, thicker sections due to the smaller thickness of insulation for the former. Similarly, the outer perimeter will be warmer for the thinner sections. The most severe through-thickness thermal gradients are expected to occur in the thinner sections.

While temperature gradients during NOC are not expected to lead to significant thermal loads on the TPS structure, the much higher temperatures in the upper plenum during PCC will produce much higher thermal gradients. As a result, these higher thermal loads will need to be assessed when designing the TPS.

Last, it is assumed the Neutron Control Assemblies and the refueling machine will not impart loads on the TPS as they will be fully supported above the TPS and only interface with the TPS through the baffle seals.

\subsubsection{Environment}

Steam and air ingress are not expected to be a concern for the TPS, particularly if the outer shell is the primary structural member and the inner shell contains the insulation and radiation shielding materials.

\subsection{Lower Floor Blocks}

The lower floor blocks (LFBs) are located toward the bottom of the reactor vessel and directly contact the graphite core support structure (above) and the metallic core support (MCS, below), as shown in Figure 3.6-1.

Prior studies generally describe the LFBs as ceramic plates having a thickness on the order of $100 \mathrm{~mm}$ (thickness to be determined by thermal insulation requirements). Dowels and sockets maintain the lateral position of the graphite support blocks in contact with the LFBs and also the position of graphite columns within the core [1]. Dowels and sockets or some other method may also be needed to maintain the position of the LFBs relative to the metallic core support structure [2]. 
Lower floor blocks have the following functions:

- Protect the metallic core support from the high temperatures of the graphite core support structure

- Transfer loads from the core to the metallic support structures

- Maintain the axial and radial alignment of the core

The lower floor blocks have the following expected main characteristics:

- Compressive strength

- Very low thermal conductivity

- Good sliding and wear behavior between the ceramic LFB material and the metallic core support structure

- Corrosion resistance in the VHTR environment

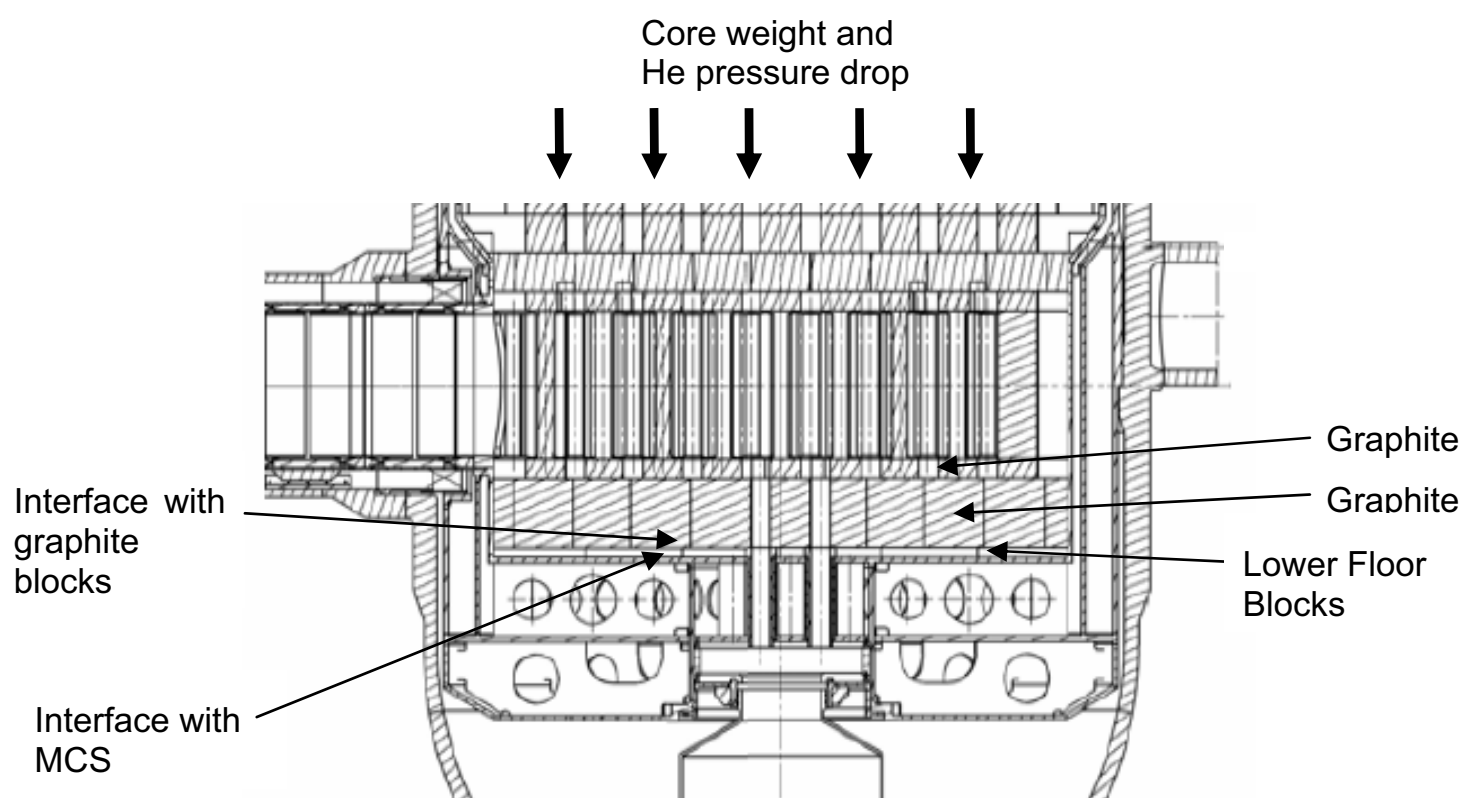

Figure 3.6-1: Lower Region of Reactor Showing Location of Lower Floor Blocks

\subsubsection{Operating Time}

The lower floor blocks have an expected operating lifetime of 60 years. 


\subsubsection{Temperatures (normal and expected off-normal)}

The lower floor block temperature estimates in Figure 3.6-2 are based on reactor temperature maps in Section 3.2.2.

The lower floor blocks have the following expected temperatures:

- Upper surface temperature $\left({ }^{\circ} \mathrm{C}\right)$

$\begin{array}{ll}>\text { Normal } & 930 \\ >\text { Off-normal } & 1200\end{array}$

- Lower surface temperature $\left({ }^{\circ} \mathrm{C}\right)$

$>$ Normal 530

$>$ Off-normal (PCC) 1200

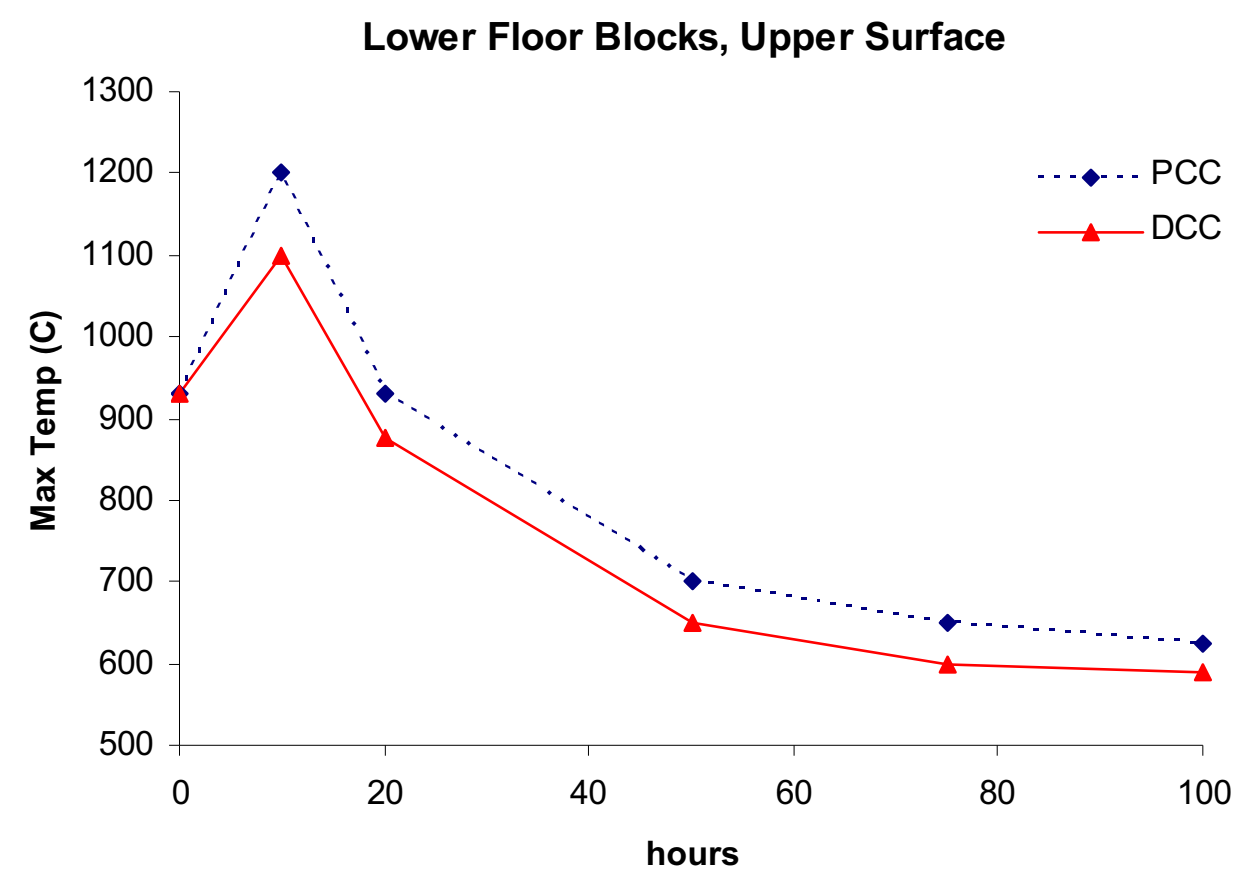

Figure 3.6-2: Lower Floor Block Temperatures 
The temperatures listed above are for expected worst-case off-normal conditions, which occur either during a nominal reactor trip with rapid cooldown of the lower metallic region or during recovery from conduction cooldown when starting the SCS system.

\subsubsection{Fluence}

The lower floor blocks are not explicitly modeled with the MCNP code, so the metallic core support plates are used as a surrogate. Flux tallies at the top of the core support plate should accurately represent the flux at the bottom of the core support plate. This assumption is slightly non-conservative, although the effect is mitigated by the slight flux gradient across the lower floor blocks, which are approximately $10 \mathrm{~cm}$ thick.

Table 6: Fluence Summary for the Lower Floor Blocks

\begin{tabular}{|c|c|c|c|c|}
\hline \multirow{2}{*}{ Description } & \multicolumn{4}{|c|}{ Neutron Fluence $\left[\mathrm{n} / \mathrm{cm}^{2}\right]$} \\
\cline { 2 - 5 } & $\begin{array}{c}\text { Thermal } \\
{[\mathrm{E}<1 \mathrm{eV}]}\end{array}$ & $\begin{array}{c}\text { Epithermal } \\
{[1 \mathrm{eV}<\mathrm{E}<0.1 \mathrm{MeV}]}\end{array}$ & $\begin{array}{c}\text { Fast } \\
{[\mathrm{E}>0.1 \mathrm{MeV}]}\end{array}$ & Total \\
\hline Lower Floor Blocks & $4.4 \mathrm{E}+16$ & $1.1 \mathrm{E}+14$ & $1.7 \mathrm{E}+13$ & $4.4 \mathrm{E}+16$ \\
\hline
\end{tabular}

The results in Table 6 are calculated assuming 60 years of operation at a $90 \%$ load factor and converged to within one order of magnitude.

\subsubsection{Applied Loads}

Load concerns for the lower floor blocks are:

- Compressive load due to the weight of the core and the He pressure drop through the core. The weight of the core is approximately 720 metric tons. If this weight is uniformly distributed over the core (diameter $\sim 7000 \mathrm{~mm}$ ), the resulting compressive load is about $184 \mathrm{kPa}(27 \mathrm{psi})$. The He pressure drop through the core will be $55 \mathrm{kPa}(8 \mathrm{psi})$. Thus, the compressive load transferred through the LFBs to the metallic core support will be about $240 \mathrm{kPa}$ (35 psi).

- Stress resulting from differential thermal expansion of the LFB material(s) due to temperature gradients during NOC. The upper surface of the LFBs has a temperature on the order of $900{ }^{\circ} \mathrm{C}$ while the lower surface has a temperature of approximately $500^{\circ} \mathrm{C}$.

- Stress resulting from differential thermal expansion due to CTE differences between the LFBs and the adjacent graphite blocks (above) and metallic core support structure (below). The resulting loads will be concentrated at connection points between LFBs and adjacent materials and structures. Shear loads may also be present between the LFBs and the metallic core support (i.e., the metal will expand more during heat-up to normal operation). 
- Bending loads due to surface irregularities and potential bow of the metallic core support structure.

- Fatigue may be a factor due to cyclical loading during start-up and shutdown. Fatigue due to vibration of the core may also need to be assessed although such loads should be relatively small.

Besides the potential loads during NOC, other significant loads may occur during the following off-normal conditions:

- DCC and PCC are not expected to pose any thermal problems for the LFBs. However, relatively rapid thermal transients and high temperature exposure up to about $1200^{\circ} \mathrm{C}$ may occur upon starting the SCS during conduction cooldown. The primary area of concern will be the LFBs adjacent to the holes in the lower floor leading to the SCS. Also, the interface between the LFBs and the insulation material within the SCS ducting will be subjected to thermal loads under these conditions.

- Seismic events will produce lateral and axial loads on the LFBs. Lateral loads will be concentrated at the connection points, while the axial loads will act over the blocks.

\subsubsection{Environment}

Lower floor blocks are not expected to be exposed to flowing He coolant but will simply need to be stable in exposure to the reducing $\mathrm{He}$ atmosphere.

Air and water ingress will not generally be a problem for the lower floor blocks. Any issues associated with air or water will likely exist in the SCS ducts and in the LFBs adjacent to SCS holes in the lower floor. The SCS will operate during refueling when the core is exposed to air and also during certain accidents where air will be present (e.g., DCC).

\subsection{Summary of Operating Conditions}

Table 7 provides a summary of the normal and off-normal operating conditions for the five components evaluated in this study. 
Table 7: Summary of Operating Conditions

\begin{tabular}{|c|c|c|c|c|c|c|c|}
\hline \multirow[b]{2}{*}{ Component } & \multicolumn{4}{|c|}{ Normal Operating Conditions } & \multicolumn{3}{|c|}{ Off-Normal Conditions } \\
\hline & $\begin{array}{c}\text { Max } \\
\text { Temp } \\
\left({ }^{\circ} \mathrm{C}\right)\end{array}$ & $\begin{array}{c}\text { Fast } \\
\text { Fluence } \\
\left(\mathrm{n} / \mathrm{cm}^{2}\right)\end{array}$ & $\begin{array}{l}\text { Load } \\
\text { Sources }\end{array}$ & Environ. & $\begin{array}{c}\text { Max } \\
\text { Temp } \\
\left({ }^{\circ} \mathrm{C}\right)\end{array}$ & Load Sources & Environ. \\
\hline $\begin{array}{l}\text { Inner Control } \\
\text { Rod }\end{array}$ & 1100 & & $\begin{array}{l}\text { Dead weight, } \\
\text { Differential } \\
\text { expansion, } \\
\text { Vibration }\end{array}$ & $\begin{array}{l}\text { Purified } \\
\text { helium }\end{array}$ & 1600 & $\begin{array}{l}\text { Scram impact, } \\
\text { Seismic, } \\
\text { Temperature } \\
\text { gradients, } \\
\text { Depressurization }\end{array}$ & $\begin{array}{l}\text { Air, Water } \\
\text { Vapor }\end{array}$ \\
\hline $\begin{array}{l}\text { Outer } \\
\text { Control Rod }\end{array}$ & 1000 & $3.7 \times 10^{22}$ & $\begin{array}{l}\text { Dead weight, } \\
\text { Differential } \\
\text { expansion, } \\
\text { Vibration }\end{array}$ & $\begin{array}{l}\text { Purified } \\
\text { helium }\end{array}$ & 1200 & $\begin{array}{l}\text { Scram impact, } \\
\text { Seismic, } \\
\text { Temperature } \\
\text { gradients, } \\
\text { Depressurization }\end{array}$ & $\begin{array}{l}\text { Air, Water } \\
\text { Vapor }\end{array}$ \\
\hline $\begin{array}{l}\text { Hot Duct } \\
\text { Assembly }\end{array}$ & 1000 & $8.7 \times 10^{15}$ & $\begin{array}{l}\text { Bending, } \\
\text { Differential } \\
\text { expansion, } \\
\text { Vibration }\end{array}$ & $\begin{array}{l}\text { Purified } \\
\text { helium, } \\
\text { Erosion }\end{array}$ & 1150 & $\begin{array}{l}\text { Seismic, } \\
\text { Temperature } \\
\text { gradients, } \\
\text { Depressurization }\end{array}$ & $\begin{array}{l}\text { Air, Water } \\
\text { Vapor }\end{array}$ \\
\hline UCR Blocks & 500 & $1.5 \times 10^{17}$ & $\begin{array}{l}\text { Lateral } \\
\text { restraint, } \\
\text { Differential } \\
\text { expansion, } \\
\text { Vibration }\end{array}$ & $\begin{array}{l}\text { Purified } \\
\text { helium, } \\
\text { Erosion }\end{array}$ & 1200 & $\begin{array}{l}\text { Seismic, } \\
\text { Temperature } \\
\text { gradients }\end{array}$ & $\begin{array}{l}\text { Air, Water } \\
\text { Vapor }\end{array}$ \\
\hline $\begin{array}{l}\text { Top Plenum } \\
\text { Shroud }\end{array}$ & 500 & $3.4 \times 10^{16}$ & $\begin{array}{l}\text { Dead weight, } \\
\text { Differential } \\
\text { expansion }\end{array}$ & $\begin{array}{l}\text { Purified } \\
\text { helium }\end{array}$ & 1050 & $\begin{array}{l}\text { Seismic, } \\
\text { Temperature } \\
\text { gradients } \\
\end{array}$ & $\begin{array}{l}\text { Water } \\
\text { Vapor }\end{array}$ \\
\hline $\begin{array}{l}\text { Lower Floor } \\
\text { Blocks }\end{array}$ & 900 & $1.7 \times 10^{13}$ & $\begin{array}{l}\text { Dead weight, } \\
\text { Differential } \\
\text { expansion, } \\
\text { Lateral } \\
\text { restraint, } \\
\text { Bending }\end{array}$ & $\begin{array}{l}\text { Purified } \\
\text { helium }\end{array}$ & 1200 & $\begin{array}{l}\text { Seismic, } \\
\text { Temperature } \\
\text { gradients near } \\
\text { SCS ducts }\end{array}$ & $\begin{array}{l}\text { Air, Water } \\
\text { Vapor }\end{array}$ \\
\hline
\end{tabular}

\section{Required Material Properties}

This section provides initial conceptual designs and candidate CM and CCM materials for each component and representative dimensions for each component, as available. It also summarizes material properties, as available, for the candidate CMs and CCMs. The material properties evaluation includes thermal stability, thermal conductivity, coefficient of thermal expansion, Young's modulus, strength, creep, and other properties 
needed in order to determine the viability of the candidate materials for NGNP NOC, anticipated transients, abnormal events, and design basis events.

\subsection{Control Rods}

\subsubsection{Control Rod Conceptual Design}

For this study, each control rod assembly (CRA) is assumed to consist of a column of individual canisters and flexible connectors to maintain conformance to the control rod channels in the graphite fuel blocks and reflector blocks (illustrated in Figure 3.2-1). A CRA has 18 canisters, each with a diameter of approximately $100 \mathrm{~mm}$ and a length of about $400 \mathrm{~mm}$.

Figure 4.1-1 shows a conceptual design of the NGNP control rod.

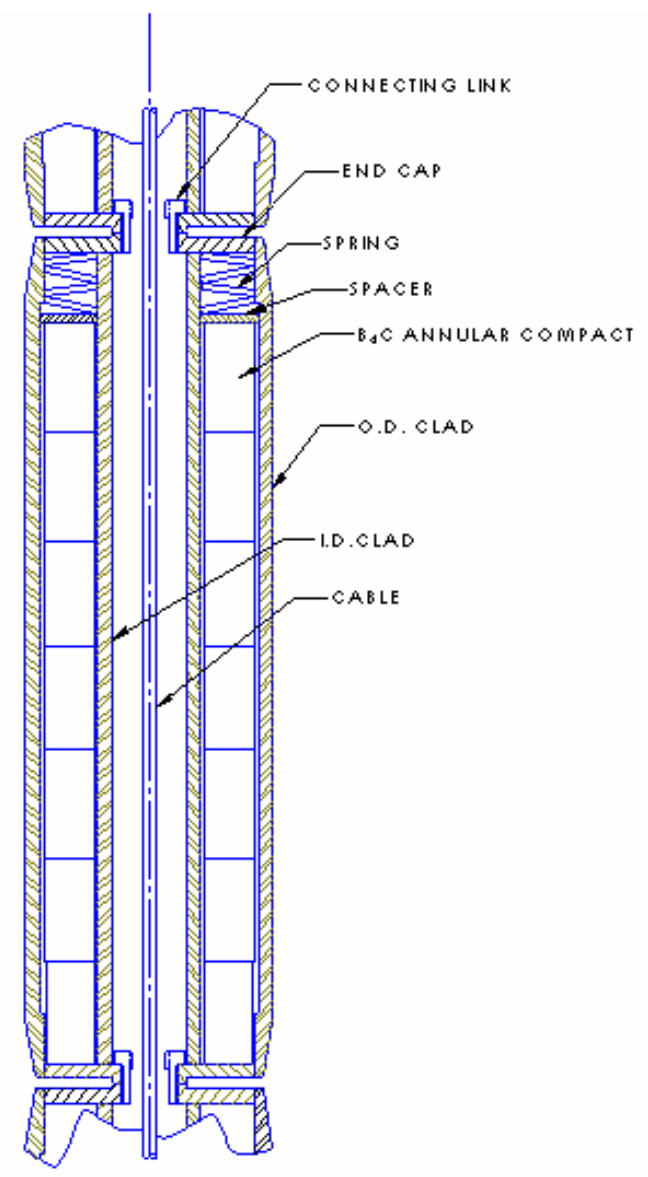

CONTROL ROD CANNISTER

Figure 4.1-1: Control Rod Conceptual Design 
The control rod conceptual design assumes the following:

- Canister - Design concepts thus far [1, 2, 5, 8, 9] are based on the use of metallic (e.g., Alloy $800 \mathrm{H}$ ) and CCM (e.g., C/C composite or SiC/SiC composite) canisters. While Alloy $800 \mathrm{H}$ may be acceptable for NOC, this material will not be suitable at the temperatures expected during conduction cooldown. Conversely, $\mathrm{C} / \mathrm{C}$ and $\mathrm{SiC} / \mathrm{SiC}$ composites will be stable in helium to temperatures exceeding $1500^{\circ} \mathrm{C}[5,8]$. As further discussed below, the present design concept assumes the use of a CCM for the canisters.

- Flexible Joints - There are various options for the design of a flexible joint between the canisters. The design in Figure 4.1-1 assumes a CCM end cap with a raised lug at the center will help articulate the canister column during rod insertion and removal.

- Metal Cable - Rather than rely solely on CCM joints to connect the string of canisters, it is assumed a metal cable (e.g., Alloy $800 \mathrm{H}$ ) will be strung through the center of the column. The top of the cable connects to the control rod drive mechanism, while the bottom will be connected to the nose cap on the bottom canister. A spring-loaded mechanism within the drive will be used to place the cable in tension. Cable tension will help keep the column of canisters straight during insertion of the rod assembly and during its removal from the core and thus minimize the possibility of canister "jack-knifing".

- Absorber - It is assumed annular absorber compacts consisting of $\mathrm{B}_{4} \mathrm{C}$ and graphite will be used. The height of the compact and the number of compacts required will be determined when designing the CRA. The inner and outer diameter of the compacts must provide clearance inside the canister to accommodate swelling of the absorber compacts during irradiation and thus to avoid deleterious interference.

- Absorber Cavity Spring - It is assumed a spring within the absorber cavity will limit movement of the absorber compacts during shipment and allow for swelling of the compacts during irradiation.

- Nose Cap - At the bottom of the CRA, it is assumed a nose cap and cable anchor, not shown in the figure, will facilitate the insertion of the assembly into the control rod channel. The nose cap will be attached to the bottom canister.

Additionally, the following design considerations need to be evaluated:

- Canister Outer Diameter - The outer diameter of the canisters relative to the inner diameter of the control element channels within the graphite blocks will need to include the following: (a) clearance to minimize mechanical drag during rod movement and to compensate for distortion of the channels due to irradiation, 
differential thermal expansion, seismic events, etc.; and (b) clearance to prevent rod jamming within the channels due to the presence of foreign particles.

- Canister Walls - The thickness of the inner and outer walls of the canister will be designed to withstand anticipated normal and off-normal load conditions and to prevent the loss of absorber material to the primary coolant. The inner wall will also include holes or other features to vent the interior of the canisters of the helium gas generated by the absorber material during irradiation.

- Ballast - The lowermost canister may be ballasted, if necessary, to accelerate the CRA into the core and satisfy trip time requirements during accident conditions. For this purpose, hafnium may be used as an optional absorber material.

The above design concept represents one of several options available for future evaluation. Other CRA options [1, 2, 5, 9] that need to be considered are:

- Metallic - Alloy $800 \mathrm{H}$ annular cans on a cable

- Composite - C/C or SiC/SiC composite annular cans with composite joints (no cable)

- Hybrids - Metallic annular cans with ceramic jackets on a cable

\subsubsection{Candidate Materials}

Possible materials for control rods are:

- Alloy $800 \mathrm{H}$

- C/C composite

- $\mathrm{SiC} / \mathrm{SiC}$ composite

Alloy $800 \mathrm{H}$ (Incoloy) - Alloy $800 \mathrm{H}$ is an austenitic iron based alloy with substantial nickel $(32 \%)$ and chromium $(21 \%)$. It has useful tensile and creep strength and oxidation resistance up to $850{ }^{\circ} \mathrm{C}$. This alloy was used in the fabrication of control rods in the Fort St. Vrain (FSV) reactor and in the High Temperature Test Reactor (HTTR) in Japan. The normal operating temperatures in these reactors were $477^{\circ} \mathrm{C}$ and $550{ }^{\circ} \mathrm{C}$, respectively, and the maximum accident temperature was $900^{\circ} \mathrm{C}$.

Alloy $800 \mathrm{H}$ resists corrosion in a VHTR environment, but there are concerns about a loss of ductility, particularly at temperatures above $400^{\circ} \mathrm{C}$. Ductility also decreases as temperature and fluence increase. Furthermore, helium produced by the nuclear transmutation reaction of thermal neutrons with boron and nickel in Alloy $800 \mathrm{H}$ forms bubbles at the grain boundaries. Under tensile loading, the bubbles grow and cause intergranular cracking.

The maximum temperature allowed by the ASME code for Alloy $800 \mathrm{H}$ material is $760{ }^{\circ} \mathrm{C}$. This temperature needs to be extended to at least $900{ }^{\circ} \mathrm{C}$ for this material is to be used 
in control rod structural components in the NGNP, but even this may not suffice for very high temperatures of more than $1200^{\circ} \mathrm{C}$ expected during conduction cooldown.

C/C Composites - C/C composites, the production of which is relatively mature, have been used for many years in high-temperature components for military and aerospace applications. These materials offer a wide variety of optional structures (fiber and matrix types) and optional methods for fabricating fiber performs and thus for creating different fiber architectures. Many domestic companies manufacture $\mathrm{C} / \mathrm{C}$ composite components and should provide the infrastructure needed to support component development for the NGNP [5].

$\mathrm{C} / \mathrm{C}$ composite materials have many advantages over graphite for core structural components and metal alloys for the CRA in the NGNP. These advantages include [2]:

- Chemical stability in the NGNP environment in the absence of oxidizing contaminants in the helium coolant (e.g., air or steam);

- High tensile and flexural strength and modulus values over the entire range of temperatures of interest;

- Good fracture toughness, impact resistance, and abrasion resistance;

- High thermal conductivity;

- Low coefficient of thermal expansion;

- Excellent thermal shock resistance due to high thermal conductivity and low thermal expansion;

- Excellent thermal creep resistance (over the temperature range of interest); and

- Acceptable radiation resistance (up to about $8 \mathrm{dpa}$ ).

The fact that $\mathrm{C} / \mathrm{C}$ composites are considered to be an engineered material system [2, 5], becomes a key complicating factor for their use in NGNP structural components. As such, the raw materials, composite structure, and processing method all affect the physical, thermal and mechanical properties of the final component. Thus, the canister and connector components of the CRA need to be designed to optimize their performance relative to the anticipated loads and environmental conditions. Specimens fabricated for the purpose of evaluating material properties will need to properly reflect the NGNP component design.

As discussed in Section 4.6, a substantial body of property data at room temperature and at elevated temperature is available for a range of $\mathrm{C} / \mathrm{C}$ composites. Property data as a function of exposure time at elevated temperatures are limited, particularly for the environmental conditions expected over lengthy periods in high-temperature reactors. Limited data are available for radiation effects on key properties. 
Failure of a $\mathrm{C} / \mathrm{C}$ composite component in the NGNP will likely result from radiationinduced instabilities and oxidation during off-normal conditions. Based on the available information, it seems that 3-D composites (woven or braided fiber architecture) and random fiber composites, fabricated using a pitch-based fiber and a pitch-based matrix, are most suitable for control rod components. The following details are noted [2, 5, 10]:

- Irradiated carbon fibers undergo highly anisotropic dimensional changes as they shrink along the length of the fibers and swelling along the diameter. Thus, a more complex fiber architecture improves dimensional stability. C/C composites of 1-D architecture are significantly anisotropic and the least dimensionally stable while those of 3-D (or random fiber) architecture are nearly isotropic and more stable.

- $\mathrm{C} / \mathrm{C}$ composites fabricated with pitch-based fibers and pitch-based matrices are more stable than those fabricated with polyacrylonitrile (PAN)-based fibers and resin-based matrices. In particular, pitch-based $\mathrm{C} / \mathrm{C}$ composites irradiated at $800^{\circ} \mathrm{C}$ have shown a $40 \%$ increase in strength over non-irradiated materials.

Carbon/Carbon composites fabricated using pitch-based fibers and matrices are expected to be stable in the NGNP environment. However, extended exposure to oxidizing conditions (e.g., air ingress or water ingress) at elevated temperatures may cause excessive degradation. Thus, it may be necessary to apply a protective coating such as SiC.

$\mathrm{SiC} / \mathrm{SiC}$ Composites - SiC/SiC composites are an alternate material for structural components of the control rod assembly. Composites fabricated with high-purity beta$\mathrm{SiC}$ fibers and a beta-SiC matrix produced via chemical vapor infiltration have shown excellent room-temperature and elevated-temperature properties. This material has several advantages over $\mathrm{C} / \mathrm{C}$ composites:

- Superior stability during irradiation. Swelling has been measured to be about $0.6 \%$ at fluences of $6 \mathrm{dpa}$ and temperatures of $1000^{\circ} \mathrm{C}[5,10,11]$. Moreover, when subjected to radiation in doses above $10 \mathrm{dpa}$, the ultimate strength remains unaffected, although there is a small reduction in elastic modulus $[5,10,12]$.

- The properties of $\mathrm{SiC} / \mathrm{SiC}$ composites appear to be less sensitive to the details of the manufacturing process. Two suppliers' materials fabricated with high-purity beta-SiC fibers and the same matrix densification process have shown similar properties, including changes due to irradiation. This contrasts with $\mathrm{C} / \mathrm{C}$ composites where minor changes in materials and processing methods by different suppliers can have significant impacts on properties [19].

- Superior oxidation resistance due to formation of $\mathrm{a} \mathrm{SiO}_{2}$ protective scale.

$\mathrm{SiC} / \mathrm{SiC}$ composites have the following perceived disadvantages: 
- $\mathrm{SiC} / \mathrm{Sic}$ composite products are relatively immature and available only from a limited number of commercial suppliers. Moreover, the supply of high-purity, fully crystallized beta-SiC fibers is in the developmental stage. Substantial effort and investment will be required to meet NGNP program needs and future VHTR commercialization.

- Given the limited supply base for $\mathrm{SiC} / \mathrm{SiC}$ composites, it is expected control rod components will be more expensive than equivalent $\mathrm{C} / \mathrm{C}$ composite components. In addition to more expensive raw materials, capacity constraints exist for both the beta-SiC fibers and composite manufacturing.

- Limited property data exist at room temperature and as a function of temperature, particularly for the new class of $\mathrm{SiC} / \mathrm{SiC}$ composites fabricated using high-purity beta-SiC fibers, such as Hi-Nicalon Type-S and Tyranno-SA. While existing data show promising irradiation stability for $\mathrm{SiC} / \mathrm{SiC}$ composites fabricated using these fibers and a CVI matrix, the available data are limited.

- $\mathrm{SiC} / \mathrm{SiC}$ composites have relatively low thermal conductivity $(20-30 \mathrm{~W} / \mathrm{m}-\mathrm{K})$ versus $\mathrm{C} / \mathrm{C}$ composites. Moreover, irradiation reduces the thermal conductivity to about 3-5 W/m-K [10, 12]. For the control rod application, low thermal conductivity may not be an issue as no requirement for heat dissipation has been identified.

Further evaluation of $\mathrm{SiC} / \mathrm{SiC}$ composites may be warranted, particularly given the potential of a 60-year lifetime for a $\mathrm{SiC} / \mathrm{SiC}$ composite control rod [8]. Significant investment in the design, manufacture, and testing of $\mathrm{SiC} / \mathrm{SiC}$ composites for control rod components will be needed in the near future to meet the current NGNP schedule.

\subsection{Hot Duct Assembly}

\subsubsection{Hot Duct Assembly Conceptual Designs}

As discussed in Section 3.3, two conceptual designs are under consideration for the hot duct assembly (HDA): (1) an existing design using a metallic liner and ceramic insulation, and (2) an alternate design using a ceramic liner.

\section{Metallic Design:}

The metallic hot duct design is based on the use of a metal alloy structural pipe in conjunction with thermal insulation contained within internal cavities, as shown in Figure 3.3-5. These pipes are welded assemblies created in approximately $1200 \mathrm{~mm}$ segments. To evaluate this type of design, the material selections are divided into structural vessel materials and insulation materials. Material selection for the metal vessel has been limited to two candidates: Alloy $800 \mathrm{H}$ and Alloy ChS-57 (CrNi55MoWZr) [2, 9]. Each material appears to be in either testing or certification at the proposed 
NGNP operating conditions. Selection of a material will be based on results from these tests and other evaluations for the expected loading conditions. This approach is needed because conditions for some metal parts of the tube near the insulation cavity surface may exceed current ASME code limits (Alloy $800 \mathrm{H}$ is limited to $760{ }^{\circ} \mathrm{C}$ ). Efforts are under way to extend the temperature limit to $850^{\circ} \mathrm{C}$ or higher. Additional data are also needed on material performance such as fatigue at NGNP operating temperatures.

The internal insulation for use inside the metallic hot duct design will include both packed and wrapped forms of fiber insulation. While a number of high-temperature refractory fiber insulation materials are commercially available, the best material for longterm performance in the hot duct will be a high-purity oxide fiber such as $\mathrm{Al}_{2} \mathrm{O}_{3}$ (alumina), $\mathrm{ZrO}_{2}$ (zirconia), or mullite.

\section{Rigid Ceramic Liner Design:}

A hot duct with a rigid ceramic liner is shown in Figure 4.2-1. This hot duct design depends upon having a rigid ceramic material capable of withstanding the anticipated environmental conditions and the applied loads during the life cycle of the hot duct. This material is paired with a metal support pipe as in the metal duct design. The ceramic liner provides the primary flow path for the hot coolant and therefore experiences the greatest thermal and flow induced loads. Also, a ceramic fiber thermal insulation blanket will be used to augment thermal isolation of the two coolant flows and to provide additional support and vibration dampening for the rigid liner. Finally, spacers made of the same material as the liner position the liner at the desired location and retain the proper location of the blanket insulation.

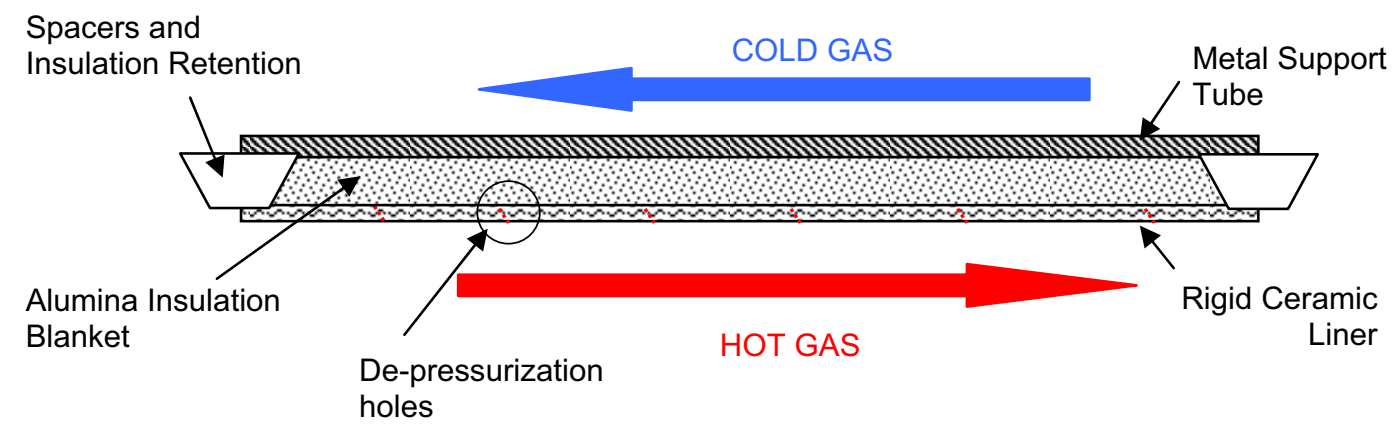

Figure 4.2-1: Ceramic-Lined Hot Duct Assembly 


\subsubsection{Candidate Materials}

The candidate materials and approximate dimensions for the ceramic-lined HDA design concept are provided below.

\section{Metal support pipe:}

- Alloy $800 \mathrm{H}$ or Alloy ChS-57 (CrNi55MoWZr)

$>$ Segments with a length equal to manufactured length of ceramic liner (about 1000-1200 mm long)

> Thickness - sized to meet structural requirements

\section{Rigid ceramic liner:}

- Carbon/Carbon composite liner

> Dimensions - Approximately $1500 \mathrm{~mm}$ inner diameter and $10 \mathrm{~mm}$ wall thickness; wall thickness established to allow handling of liner. Length dependent on manufacturing capability.

$>$ Other required properties:

- Holes formed into the $\mathrm{C} / \mathrm{C}$ composite liner to allow rapid pressure equalization in the event of depressurization

- Long-term thermal stability through the full range of normal, off-normal, and accident conditions $\left(900^{\circ} \mathrm{C}\right.$ to $\left.1100^{\circ} \mathrm{C}\right)$

- Flexural strength $>100 \mathrm{MPa}$ desired

- High surface hardness for the inner surface to limit erosion - may require addition of SiC coating to inner surface

- Corrosion resistance during air or steam ingress conditions - may require addition of $\mathrm{SiC}$ coating to inner surface

- Alumina $\left(\mathrm{Al}_{2} \mathrm{O}_{3}\right)$ or zirconia $\left(\mathrm{ZrO}_{2}\right)$ rigidized fiber refractory casting or formed Liner

> Dimensions - Approximately $1500 \mathrm{~mm}$ inner diameter and $25 \mathrm{~mm}$ wall thickness; length dependent on manufacturing capability (on the order of 1000 $\mathrm{mm}$ ).

$>$ Other required properties:

- Porosity sufficient to allow rapid pressure equalization (in the event of a depressurization event)

- Long-term thermal stability through the full range of normal, off-normal, and accident conditions $\left(900^{\circ} \mathrm{C}\right.$ to $\left.1100^{\circ} \mathrm{C}\right)$ 
- Flexural strength $>20 \mathrm{MPa}$ desired

- Moderate to high hardness for the liner inner surface to limit erosion - may require treatment of liner surface

- Low Thermal Conductivity - $<2 \mathrm{~W} / \mathrm{m}-\mathrm{K}$ for rigid liner

- Acceptable resistant to fatigue

Several commercial suppliers of $\mathrm{C} / \mathrm{C}$ composite and alumina or zirconia cast fiber refractories should be able to produce larger cylindrical liners. Further evaluation is needed to assess the manufacturing capabilities and properties for each candidate material. This evaluation would allow better definition of the approximate dimensions and key characteristics for each material.

\section{Fiber insulation batting and blankets:}

- High-purity Alumina $\left(\mathrm{Al}_{2} \mathrm{O}_{3}\right)$ or Zirconia $\left(\mathrm{ZrO}_{2}\right)$

$>$ Standard manufactured lengths and widths and cut to length and width and layered to the desired thickness of approximately $100 \mathrm{~mm}$ (thickness will be based on selection of material and requirement for a $2{ }^{\circ} \mathrm{C}$ temperature drop along the length of the HDA)

$>$ Thermal Conductivity $<1.0 \mathrm{~W} / \mathrm{m}-\mathrm{K}$ for alumina and $<0.5 \mathrm{~W} / \mathrm{m}-\mathrm{K}$ for zirconia

\subsection{Upper Core Restraint Blocks}

\subsubsection{UCR Block Conceptual Design}

The upper core restraint (UCR) subsystem is an assembly of interlocking blocks. It is assumed the blocks will have hexagonal shape and interface with the upper surface of the reflector elements. In this design, dowels connect each UCR block to one reflector block. Keys maintain the lateral position of the UCR blocks by locking adjacent blocks to each other, as shown in Figure 3.4-2 [1, 2]. Keys at the perimeter of the UCR subsystem lock UCR blocks to the core barrel. Prior designs for the UCR blocks use Alloy $800 \mathrm{H}$ [9] while more recent studies consider the use of $\mathrm{C} / \mathrm{C}$ composites [1,2].

Two conceptual designs have been generated for the UCR blocks: one based on a solid block of material and the other based on a hollow shell structure. The solid UCR blocks shown in Figure 4.3-1 are fabricated from a solid piece of raw material by machining or other methods to fabricate the key slots, the handling feature, the holes for coolant flow, and the holes for the dowels. Keys will be added during block fabrication.

The hollow box UCR block shown in Figure 4.3-2 will likely be fabricated as two primary components (lower plate and upper shell) to be joined during block fabrication. Keys and key slots, the handling feature, and the dowel sockets will also be fabricated using methods similar to those used for the solid block. The coolant holes will be fabricated 
into the individual components (bottom plate and top shell) prior to assembly and will permit the use of different sized holes and patterns for the two components. The holes in the bottom plate will be aligned with the coolant holes in the upper reflector blocks (for columns requiring coolant flow), while the holes in the upper shell will simply serve to supply coolant to the internal plenum (within the shell).

Each of the two design concepts has advantages and disadvantages. For example, the solid block will be robust and relatively thin $(200 \mathrm{~mm}$ thickness) but will require machining of the coolant flow holes. On the other hand, the more complex and costly hollow box design will have a plenum to ensure uniform coolant flow through the core even if debris falls onto the top of the block (blocking one or more feed holes in the upper shell). Moreover, if the blocks are fabricated from a $\mathrm{C} / \mathrm{C}$ composite, it may be possible to form the flow holes in the plate and upper shell without machining. This approach would avoid cutting the reinforcing fibers, thereby maximizing the structural integrity of the composite structure.

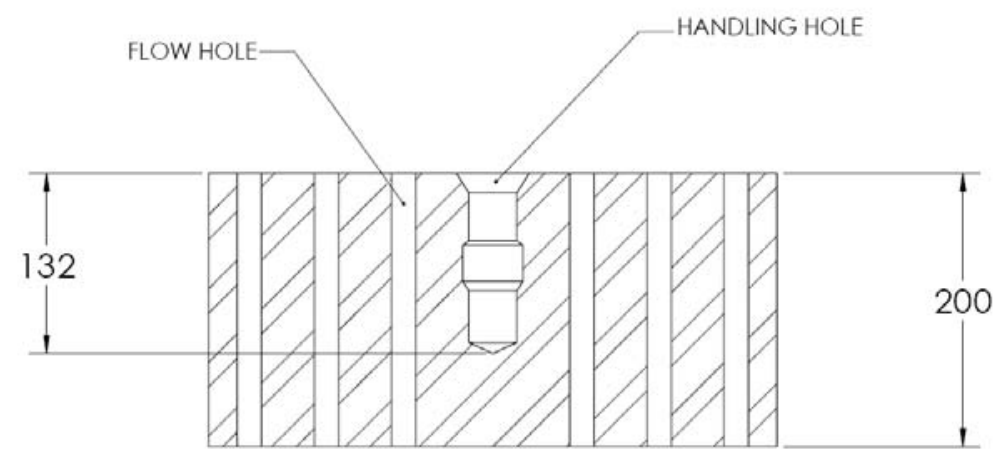

Figure 4.3-1: Solid UCR Block Design Concept 


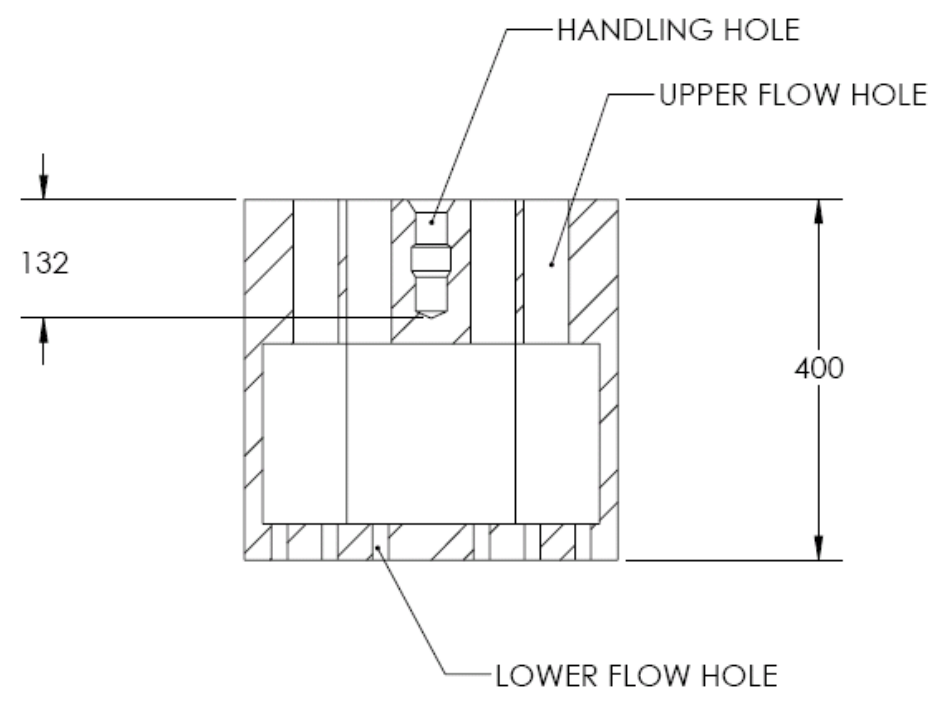

Figure 4.3-2: Hollow Box UCR Block Design Concept

Detailed design analysis will be needed to determine which approach best meets the required UCR block functions. Regardless of the design, the following fit-up and interface aspects will need to be addressed:

- UCR Block - Upper Reflector Block: Each individual UCR block will interface with a corresponding upper reflector block positioned directly below the UCR block. Three or four graphite pins will connect the blocks to each other. To achieve the desired position tolerances, dowel pins will fit tightly into the UCR blocks. To maintain lateral restraint of the core, one of the pins will have a tight fit with the upper reflector block.

- UCR Block - UCR Block: Each UCR block will be keyed to the surrounding UCR blocks as illustrated in Figure 3.4-2 (flow holes not shown for clarity). The key design will be determined at a further stage in design development. Because the keys will be a primary location of stresses, they should be integral features of the block itself, particularly if the blocks are formed using $\mathrm{C} / \mathrm{C}$ composites. The final of keying design will depend on the design of the UCR-core barrel restraint and the fuel element gap sealing options (see below). The shape of the keys and corresponding key slots will depend on the material selected for UCR block construction. For example, to minimize stress, the $\mathrm{C} / \mathrm{C}$ composite blocks will require keys to have rounded features instead of the sharp corners shown in Figure 3.4-2.

- UCR Block Fit-up: To facilitate installation and removal of the UCR blocks, it is likely the dowel pins will need to be engaged with the upper reflector block prior to engaging the UCR block keys. This approach will ensure the UCR blocks are 
properly positioned, thereby minimizing the potential for damaging the keys during installation.

- Core Barrel Connection (Lateral Constraint): A primary function of the UCR blocks is to restrain lateral (radial) motion of the fuel and reflector columns. To do so, the UCR blocks located above the permanent reflector columns will be connected to the core barrel by keying (not necessarily similar to the block-toblock connection). The design needs to allow free vertical motion between each connected block and the core barrel.

It is expected the outer UCR blocks will be fabricated from the same material as other UCR blocks. An alternate design is to make the outer UCR blocks from a metallic alloy having a higher coefficient of thermal expansion than the other UCR blocks. For example, if the UCR blocks are fabricated from $\mathrm{C} / \mathrm{C}$ composites, then the outer blocks could be fabricated from the same metallic alloy used for the core barrel. The thermal expansion of the metallic alloy would be much higher than for graphite and $\mathrm{C} / \mathrm{C}$ composites during heat-up of the core to normal operating conditions. The differential expansion may fill the gap between the core barrel and the array of outer UCR blocks, provide lateral restraint, and simultaneously compress the interior $\mathrm{C} / \mathrm{C}$ composite UCR blocks together to create a seal above the fuel and reflector columns. The material selected for the outer UCR blocks should have relatively low yield strength at elevated temperatures to allow plastic deformation of the blocks if subjected to extreme temperatures in accident conditions. For this design option, block-to-block keying may not be needed.

- Bypass Flow Control: The design has a gap of approximately $2 \mathrm{~mm}$ between adjacent fuel and reflector columns. During heat-up of the core, this gap will partially close due to thermal expansion of the graphite blocks in the columns, but by-pass flow may still occur if the expanded UCR blocks do not completely seal. To create a seal, the UCR blocks should form a very tight lateral fit, which may be accomplished by:

- Tightening dimensions and tolerances for the envelope of the blocks

- Appropriate keying design

- Implementing the core barrel lateral restraint option mentioned above

\subsubsection{Candidate Materials}

Prior designs for the upper core restraint blocks have been based on Alloy $800 \mathrm{H}$ [9], while more recent design studies have considered alternate materials such as $\mathrm{C} / \mathrm{C}$ composites as core outlet temperature has increased [1, 2]. The use of Alloy $800 \mathrm{H}$ is acceptable for NOC because the UCR blocks will be at the coolant inlet temperature. This material may also be acceptable for brief exposures during worst-case accident 
conditions. For the GT-MHR, the peak temperature for the UCR blocks during a PCC is estimated to be about $982^{\circ} \mathrm{C}$ (for a core outlet temperature of $850{ }^{\circ} \mathrm{C}$ ) [9].

However, for the higher operating temperatures of the NGNP core and for worst-case UCR block temperatures approaching $1200^{\circ} \mathrm{C}$, it may not be feasible to use Alloy $800 \mathrm{H}$. Thus, the recommended material for the UCR blocks is a 3-D C/C composite. This material has the necessary high-temperature strength and stiffness to provide the required lateral location functions. In particular, the high strength, on the order of 200$300 \mathrm{MPa}$, will be needed to ensure reliable performance when subjected to the stresses associated with the keys and dowels. The coefficient of thermal expansion, about $0.2 \mathrm{x}$ $10^{-6} / \mathrm{K}$, is much lower than for graphite, about $5 \times 10^{-6} / \mathrm{K}$. This difference can be accommodated during the design of the UCR blocks. Moreover, C/C composites will allow the fabrication of more complex shapes such as the hollow box design. Flow holes and keys will be incorporated during the preform fabrication stage prior to matrix densification.

Further discussion of the available material properties for 3-D C/C composites and the property data required to support the design of UCR blocks is provided in Section 4.6.

\subsection{Top Plenum Shroud}

\subsubsection{Conceptual Design}

The conceptual design of the top plenum shroud in Figure 3.5-1 has a structural inner shell with external stiffening ribs and an outer shell to contain the insulating and shielding materials. This arrangement requires the inner shell to be the structural member, thus requiring it to maintain strength in accident conditions that may impose a temperature as high as $1025^{\circ} \mathrm{C}$. Data for Incoloy 800 generally do not go above $871^{\circ} \mathrm{C}$ $\left(1600^{\circ} \mathrm{F}\right)$, but there are isolated data up to $982^{\circ} \mathrm{C}\left(1800^{\circ} \mathrm{F}\right)$. Isolated data indicate Alloy $800 \mathrm{H}$ retains up to $55 \mathrm{MPa}(8 \mathrm{ksi})$ short-term yield strength at $982^{\circ} \mathrm{C}\left(1800{ }^{\circ} \mathrm{F}\right)$ and a 1000 -hour creep rupture strength of $10.3 \mathrm{MPa}(1.5 \mathrm{ksi})$. Data for Alloy $800 \mathrm{H}$ above $982^{\circ} \mathrm{C}\left(1800^{\circ} \mathrm{F}\right)$ have not been located. As a structural material, Alloy $800 \mathrm{H}$ would have to be acceptable from an ASME Code standpoint at the maximum temperatures.

To assess the acceptability of the baseline design, a simple finite element analysis was performed for a $25 \mathrm{~mm}$ thick inner metal shell and an $\mathrm{Al}_{2} \mathrm{O}_{3}$ insulation board (Zircar ZAL15AA). Figure 4.4-1 shows the calculated stress profile for the estimated dead weight of the shell and insulation. The maximum stress intensity is 336 psi. Because the estimated stress intensity is about five times less than the creep rupture strength and much less than the short-term yield strength at $982^{\circ} \mathrm{C}\left(1800^{\circ} \mathrm{F}\right)$, the design may be acceptable if the use temperature in the ASME Code is extended to $900^{\circ} \mathrm{C}$ or higher.

An alternate approach proposes using the outer shell as the primary structural member and the inner shell only to contain the insulation and shielding materials. The inner shell 
would still have to support its own weight and potentially the weight of the insulation and shielding material. However, the latter materials could be supported by recessed ties through the insulation at various points such that the temperature of the ties remains within the existing ASME Code limits for Alloy $800 \mathrm{H}$. The ties could also be refractory metals, in which case the temperature would be well within their capability. Further, to reduce or eliminate thermal stresses, the thermal shell can be segmented with sections overlapping and refractory metal ties can be used to support the insulation, shielding materials, and inner panels. This approach should allow the inner panels to no longer be considered structural materials and, therefore, eliminate the need to extend the Code temperature data for the material, at least for this application.

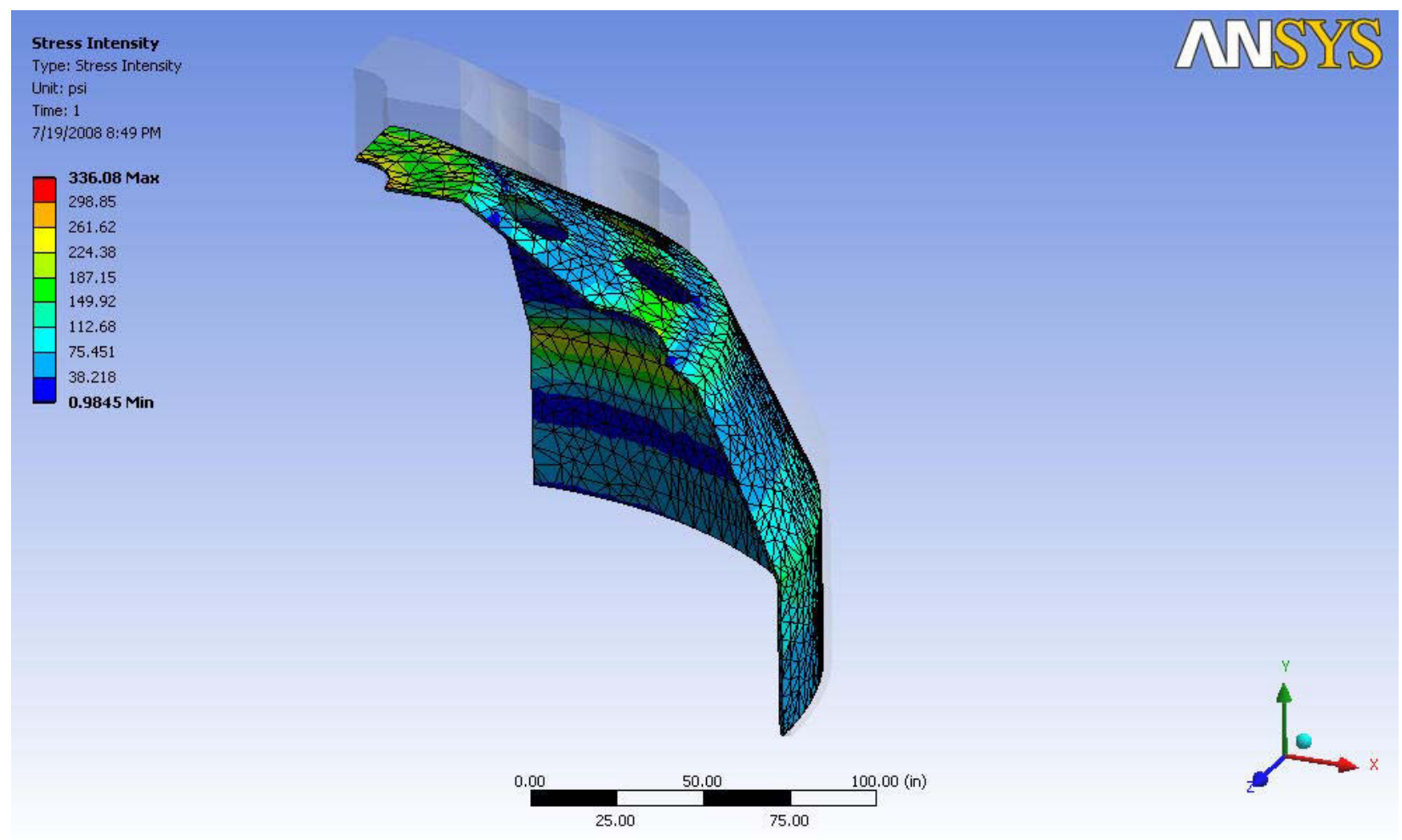

Figure 4.4-1: Stress Intensity for the Inner Shell of the TPS Structure

\subsubsection{Candidate Materials}

Structural Material - The structural materials must maintain sufficient strength to support their own weight and the weight of the insulation and shielding materials during 
normal and off-normal conditions. In both design concepts, the structural member is metallic (probably Alloy $800 \mathrm{H}$ ). The use of this material at the high temperatures expected for the TPS and other core internals is being addressed apart from the present study.

Insulation Material - The allowable heat loss through the head has not been defined. Therefore, the required thermal conductivity for the insulation material cannot be determined. The temperature drop across the stagnant helium zone exterior to the TPS will insulate the upper head. As such, the thermal conductivity of the insulation material will only need to be low enough to limit the outer shell to existing Code temperature limits during accident conditions, if the alternate concept described above is used. If the baseline concept is retained, the Code temperature range for Incoloy $800 \mathrm{H}$ will need to be extended, in which case the insulation value will only affect the heat loss through the upper head.

Candidate insulation materials are:

- Molded $\mathrm{Al}_{2} \mathrm{O}_{3}$ shapes and standard $\mathrm{Al}_{2} \mathrm{O}_{3}$ board

- $\mathrm{Al}_{2} \mathrm{O}_{3}$ fiber batt

- $\mathrm{ZrO}_{2}$ board and molded shapes

These materials can be nearly any size because they are sandwiched between the inner and outer shell. However, they will likely be made as large as possible, which is on the order of one meter across.

Shielding Material - Specific shielding requirements have not been defined. Thus, the actual shielding efficiency requirement cannot yet be determined. However, the shielding material used must not burn out during the 60 year life of the TPS.

Candidate shielding materials include:

- $\mathrm{B}_{4} \mathrm{C}$ (probably combined with graphite or other material)

- Borosilicate glass

- $\mathrm{ZrH}$

These materials can be nearly any size because they are sandwiched between the inner and outer shell or dispersed in the insulation. However, as with the insulation, if they are rigid materials, they will likely be made in the form of large sheets on the order of 0.5 meters across. 


\subsection{Lower Floor Blocks}

\subsubsection{Conceptual Design}

The lower floor blocks (LFBs) are located toward the bottom of the reactor vessel and directly contact the graphite core support structure (above) and the metallic core support structure (below). The LFBs must support the weight of the core and provide vertical and lateral positioning of the core. The blocks must also insulate the metallic core support structure from high temperatures in the core outlet plenum.

Prior studies have generally described the LFBs as ceramic plates with a thickness on the order of $100-200 \mathrm{~mm}$ (thickness to be determined by thermal insulation requirements). Dowels and sockets or some other means are included to maintain the position of the LFBs relative to the metallic core support structure [2]. Additionally, dowels and sockets are used to ensure the lateral position of the graphite support blocks in contact with the LFBs and the graphite columns within the core [1].

One conceptual arrangement for the LFBs is illustrated in Figure 4.5-1 [2]. This design subdivides the floor into pie-shaped segments and uses large ceramic insulation plates with a maximum dimension of about $2000 \mathrm{~mm}$. Locking pins position the ceramic plates with respect to the metallic core support structure. The overall thickness of the LFB is about $200 \mathrm{~mm}$ of $\mathrm{C} / \mathrm{C}$ composite material. No further information is provided for the proposed $\mathrm{C} / \mathrm{C}$ composite material [2].

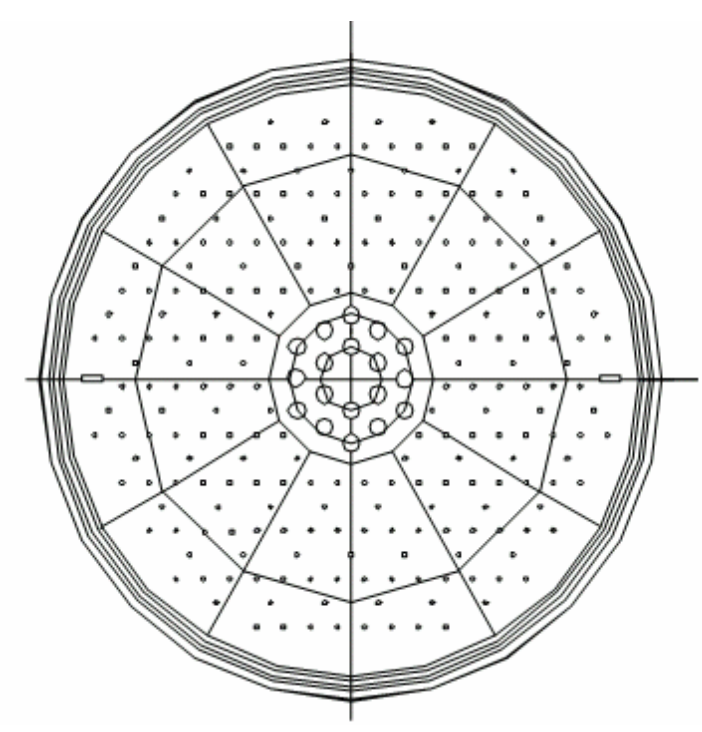

Figure 4.5-1: Conceptual Arrangement of Lower Floor Blocks [2] 
The selection of material for the LFBs must address two key requirements that generally create opposing demands on the material. First, the material must have sufficient strength to withstand stresses generated by the imposed thermal and mechanical loads. Also, the material must provide the thermal insulation to protect the metallic core support structure. Insulation materials of low thermal conductivity (e.g., $<1 \mathrm{~W} / \mathrm{m}-\mathrm{K}$ ) generally have low compressive and tensile strength $(<0.5 \mathrm{MPa})$. Conversely, structural materials generally have much higher compressive and tensile strength (>100 MPa) but also have higher thermal conductivity $(>10 \mathrm{~W} / \mathrm{m}-\mathrm{K})$. Clearly, the selection of the material for the LFBs must balance these two characteristics if a single material is used.

Alternatively, multiple materials may be used in a layered structure to simultaneously provide lateral positioning and insulation. For example, a three-layered engineered structure might be used with each layer having the following characteristics:

- Upper Layer - This layer will contact the graphite core support structure and will use dowels and slots to maintain the lateral position of the graphite columns in the core. The normal operating temperature for this material will be about $900^{\circ} \mathrm{C}$. The maximum off-normal temperature may approach $1200^{\circ} \mathrm{C}$ toward the center of the lower floor near the SCS ducts. The material may be subjected to rapid thermal transients (thermal shock) if the SCS is started during conduction cooldown. The material selected for the upper layer needs to be relatively strong at temperatures approaching $1200^{\circ} \mathrm{C}$ and to have thermal shock resistance.

- Intermediate Layer - The primary function of this layer will be to insulate the LFB structure. To accommodate a $400{ }^{\circ} \mathrm{C}$ temperature difference $\left(900{ }^{\circ} \mathrm{C}\right.$ upper surface and $500^{\circ} \mathrm{C}$ lower surface) for a thickness of about $100 \mathrm{~mm}$, the thermal conductivity will need to be about $2.0 \mathrm{~W} / \mathrm{m}-\mathrm{K}$ or less. The material will also need to have sufficient strength to support compressive loads from the core and any additional loads resulting from the lateral positioning function of the LFB structure.

- Bottom Layer - This layer will contact the metallic core support structure and will use dowels and slots to maintain lateral positioning. Because this layer will be below the intermediate insulation layer, the temperatures will generally be on the order of $500{ }^{\circ} \mathrm{C}$. The material will need to have sufficient strength to serve the positioning function and will also need to have sufficient hardness to withstand contact with the core support. Differential thermal expansion between this bottom layer and the metal floor may generate wear and shear loads at the interface.

To have the desired lateral positioning of the bottom portion of the core the LFB structure will need design features that allow transmission of the lateral restraining force from the metallic core support structure through the LFBs to the graphite core support blocks. One approach to achieving this function is using dowels and mating holes and slots, as shown in Figure 4.5-2. For this design, the LFBs are on the order of 500-1000 $\mathrm{mm}$ in size. A single pin tightly fitting inside a hole within the bottom layer of each block 
positions the block. Slots in each block and pins attached to the metal support plate prevent rotation of the blocks but allow differential thermal expansion.

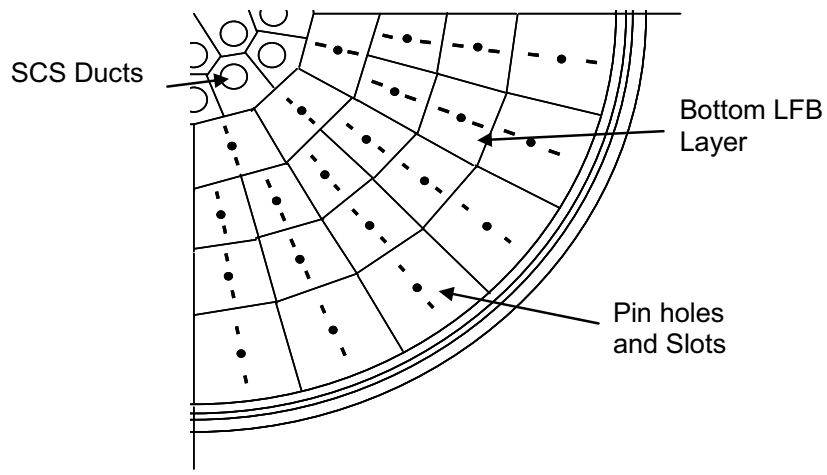

Figure 4.5-2: Quarter-Section of the Reactor Floor Showing an Alternate LFB Arrangement and Interface with the Metallic Core Support Structure

A combination of holes and slots with dowels can be used to connect and laterally align the upper layer of LFBs with the graphite core support structure. The pins and slots will likely need to be offset relative to the pins and slots in the bottom layer.

This concept of using dowel pins with holes and slots in the upper and lower surfaces of the LFBs to provide lateral positioning will require the restraining force to be transmitted through the insulation layer. It is possible the insulation material will have sufficient strength to withstand restraining forces imposed by the two sets of pins. However, it may be necessary to include $\mathrm{C} / \mathrm{C}$ composite ligaments or other structures between the upper and lower layers. Alternatively, geometric design features may be included to transmit the forces. An example of this geometric concept is shown in Figure 4.5-3. Insulation blocks attached to the upper and lower layers of the LFB structure fit together to create an interlocking structure. 


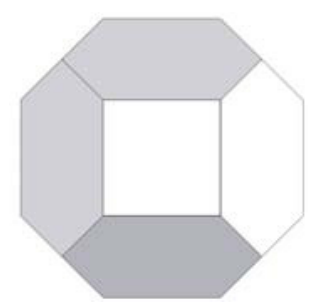

TOP View
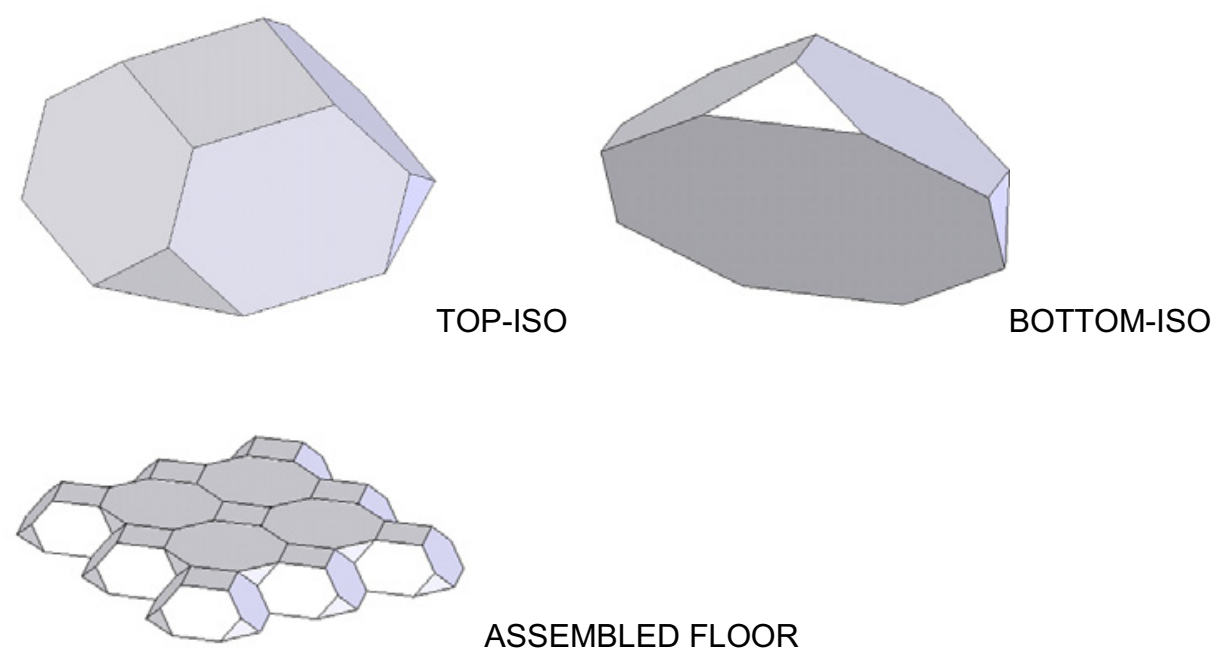

ASSEMBLED FLOOR

Figure 4.5-3: Potential Use of Geometric Structures in Insulation Layer to Augment Lateral Positioning Function of LFBs

\subsubsection{Candidate Materials}

Meeting all LFB requirements will likely require the use of a layered structure. A typical alumina refractory insulation board has excellent thermal insulation characteristics (conductivity $<1.5 \mathrm{~W} / \mathrm{m}-\mathrm{K})$ but may have relatively low strength $(<0.5 \mathrm{MPa})$. Conversely, a $\mathrm{C} / \mathrm{C}$ composite will have sufficient strength to withstand imposed loads but will have higher thermal conductivity. The use of a 2-D C/C composite with a throughthickness conductivity of $5-10 \mathrm{~W} / \mathrm{m}-\mathrm{K}$ might require a design with plates having a total thickness of $200-250 \mathrm{~mm}$ to provide the required thermal insulation.

For the purpose of defining candidate materials for the LFBs, a three-layered engineered structure is assumed. The candidate materials for each layer are as follows:

- Upper Layer - To perform the desired functions, a structural ceramic or ceramic composite material will be needed. For this layer, monolithic structural ceramics (e.g., alumina or mullite) might be acceptable materials for the floor away from the 
SCS ducts. However, thermal transients near the SCS ducts during conduction cooldown and start-up of the SCS might damage such materials via thermal shock. Conversely, 3-D and 2-D C/C composites appear to have all desired characteristics for the upper layer. Also, the use of a 2-D composite might provide some thermal insulation as the through-thickness thermal conductivity $(\sim 5-10$ $\mathrm{W} / \mathrm{m}-\mathrm{K})$ is relatively low compared to the in-plane conductivity $(30-100 \mathrm{~W} / \mathrm{m}-\mathrm{K})$.

- Intermediate Layer - There are many types of commercially available ceramic fiber insulation materials. Many of these materials use fibers containing free silica and bonding agents containing silica or other materials that are not suitable for the reducing $\mathrm{He}$ coolant environment. High-purity oxide ceramic fiber insulation materials appear to be the most promising candidates for the intermediate layer. Such materials use high-purity alumina, zirconia, and mullite $\left(\mathrm{Al}_{2} \mathrm{O}_{3}-\mathrm{SiO}_{2}\right)$. These materials can generally be used for continuous operation at temperatures in the range of $1200-1400^{\circ} \mathrm{C}$. In addition, low-density carbon fiber and foam insulation materials are also available and can be used at temperatures in excess of $1500^{\circ} \mathrm{C}$ in inert environments like the NGNP. Therefore, these materials should be included in the list of candidate materials.

- Bottom Layer - If the intermediate insulation layer has sufficient strength to withstand the restraining forces, then the primary function of the bottom layer will be to protect the insulation from wear due to differential expansion between the LFB structure and the metallic support plate. In this case, a thin layer of 2-D C/C composite or Grafoil ${ }^{\mathrm{TM}}$ may be sufficient. Grafoil is a commercially available sheet form of graphite that has low thermal conductivity in the direction perpendicular to the sheet and is often used for high-temperature gaskets. However, if the insulation material has a low strength then a thicker layer of 3-D or 2-D C/C composite will be required. A thin sheet of Grafoil may still be used to reduce wear between the metal support plate and the $\mathrm{C} / \mathrm{C}$ composite.

\subsection{Summary of Material Properties}

This section summarizes candidate materials and key issues for five NGNP components. The available property data for each class of materials is summarized and followed by a discussion of the required data to support detailed design of the components for the NGNP.

Table 8 summarizes the candidate materials for each component along with the primary damage mechanisms. In addition, the primary data needed to support future detailed design work and the approaches for obtaining such data are identified. The available property data and the data required to support detailed design work for each component are discussed in more detail below. 
Table 8: Candidate Materials, Damage Mechanisms, and Data Needs for Design

\begin{tabular}{|c|c|c|c|c|c|}
\hline Component & Sub-Unit & $\begin{array}{c}\text { Candidate } \\
\text { Material }\end{array}$ & $\begin{array}{c}\text { Primary } \\
\text { Damage } \\
\text { Mechanisms }\end{array}$ & $\begin{array}{l}\text { Data Needs } \\
\text { for Design }\end{array}$ & $\begin{array}{l}\text { Approaches } \\
\text { to Obtain } \\
\text { Design Data }\end{array}$ \\
\hline \multirow[t]{2}{*}{ Control Rod } & Canister & $\begin{array}{l}\text { 3-D C/C } \\
\text { Composite } \\
\text { (pitch-based } \\
\text { fibers and } \\
\text { matrix) }\end{array}$ & $\begin{array}{l}\text { Radiation, } \\
\text { corrosion from air } \\
\text { and steam }\end{array}$ & $\begin{array}{l}\text { Long-term } \\
\text { elevated } \\
\text { temperature } \\
\text { properties, } \\
\text { deterioration due } \\
\text { to radiation \& } \\
\text { oxidation }\end{array}$ & $\begin{array}{l}\text { Extensive } \\
\text { testing of 3-D } \\
\text { specimens } \\
\text { and prototype } \\
\text { components }\end{array}$ \\
\hline & Connector & $\begin{array}{l}\text { 3-D C/C } \\
\text { Composite } \\
\text { (pitch-based } \\
\text { fibers and } \\
\text { matrix) }\end{array}$ & $\begin{array}{l}\text { Scram loads, } \\
\text { radiation, } \\
\text { corrosion from air } \\
\text { and steam }\end{array}$ & As above & As above \\
\hline \multirow[t]{3}{*}{$\begin{array}{l}\text { Hot Duct } \\
\text { Assembly }\end{array}$} & $\begin{array}{l}\text { Ceramic } \\
\text { Insulation }\end{array}$ & $\begin{array}{l}\text { High-purity oxide } \\
\text { fiber insulation } \\
\left(\mathrm{Al}_{2} \mathrm{O}_{3}, \mathrm{ZrO}_{2} \text {, }\right. \\
\text { mullite })\end{array}$ & Thermal fatigue & $\begin{array}{l}\text { Aging due to } \\
\text { thermal cycling }\end{array}$ & $\begin{array}{l}\text { Long-term } \\
\text { tests with } \\
\text { thermal cycling }\end{array}$ \\
\hline & \multirow[t]{2}{*}{$\begin{array}{l}\text { Ceramic } \\
\text { Liner }\end{array}$} & $\begin{array}{l}\text { High-Density } \\
\text { Cast } \mathrm{Al}_{2} \mathrm{O}_{3}\end{array}$ & Fatigue, erosion & $\begin{array}{l}\text { Long-term aging } \\
\text { at elevated } \\
\text { temperature and } \\
\text { thermal cycles }\end{array}$ & $\begin{array}{l}\text { Long-term } \\
\text { testing under } \\
\text { prototypic } \\
\text { conditions } \\
\end{array}$ \\
\hline & & C/C Composite & $\begin{array}{l}\text { Fatigue, erosion, } \\
\text { corrosion from air } \\
\text { and steam }\end{array}$ & $\begin{array}{l}\text { Long-term } \\
\text { elevated } \\
\text { temperature } \\
\text { properties, } \\
\text { deterioration due } \\
\text { to cycling \& } \\
\text { oxidation }\end{array}$ & As above \\
\hline UCR Blocks & & $\begin{array}{l}\text { 3-D C/C } \\
\text { Composite }\end{array}$ & $\begin{array}{l}\text { Failure from off- } \\
\text { normal loads, } \\
\text { Fatigue, } \\
\text { corrosion from air } \\
\text { and steam }\end{array}$ & $\begin{array}{l}\text { Long-term } \\
\text { elevated } \\
\text { temperature } \\
\text { properties, } \\
\text { deterioration due } \\
\text { to oxidation }\end{array}$ & $\begin{array}{l}\text { Extensive } \\
\text { testing of 3-D } \\
\text { specimens } \\
\text { and prototype } \\
\text { components }\end{array}$ \\
\hline $\begin{array}{l}\text { Top Plenum } \\
\text { Shroud }\end{array}$ & Insulation & $\begin{array}{l}\text { High-purity oxide } \\
\text { fiber insulation } \\
\left(\mathrm{Al}_{2} \mathrm{O}_{3}, \mathrm{ZrO}_{2} \text {, }\right. \\
\text { mullite) }\end{array}$ & None & None & None \\
\hline $\begin{array}{l}\text { Lower Floor } \\
\text { Blocks }\end{array}$ & $\begin{array}{l}\text { Upper } \\
\text { Layer }\end{array}$ & $\begin{array}{l}\text { 2-D } \\
\text { C/C Composites }\end{array}$ & $\begin{array}{l}\text { Failure from off- } \\
\text { normal loads, } \\
\text { fatigue, corrosion } \\
\text { from air and } \\
\text { steam }\end{array}$ & $\begin{array}{l}\text { Long-term } \\
\text { elevated } \\
\text { temperature } \\
\text { properties, } \\
\text { deterioration due } \\
\text { to oxidation } \\
\end{array}$ & $\begin{array}{l}\text { Long-term } \\
\text { testing under } \\
\text { prototypic } \\
\text { conditions }\end{array}$ \\
\hline
\end{tabular}




\begin{tabular}{|l|l|l|l|l|l|}
\hline \multicolumn{6}{|c|}{ Table 8 (continued) } \\
\hline Component & Sub-Unit & \multicolumn{1}{|c|}{$\begin{array}{c}\text { Candidate } \\
\text { Material }\end{array}$} & $\begin{array}{l}\text { Primary } \\
\text { Damage } \\
\text { Mechanisms }\end{array}$ & $\begin{array}{l}\text { Data Needs } \\
\text { for Design }\end{array}$ & $\begin{array}{c}\text { Approaches } \\
\text { to Obtain } \\
\text { Design Data }\end{array}$ \\
\hline & $\begin{array}{l}\text { Insulation } \\
\text { Layer }\end{array}$ & $\begin{array}{l}\text { High-purity oxide } \\
\text { fiber insulation } \\
\left(\mathrm{Al}_{2} \mathrm{O}_{3}, \mathrm{ZrO}_{2},\right. \\
\text { mullite) }\end{array}$ & $\begin{array}{l}\text { Failure from off- } \\
\text { normal loads, } \\
\text { fatigue }\end{array}$ & $\begin{array}{l}\text { Long-term aging } \\
\text { at elevated } \\
\text { temperature and } \\
\text { cyclic loads }\end{array}$ & As above \\
\hline & $\begin{array}{l}\text { Low-density } \\
\text { carbon fiber } \\
\text { insulation }\end{array}$ & $\begin{array}{l}\text { Failure from off- } \\
\text { normal loads, } \\
\text { fatigue, corrosion } \\
\text { from air and } \\
\text { steam }\end{array}$ & $\begin{array}{l}\text { Long-term aging } \\
\text { at elevated } \\
\text { temperature and } \\
\text { cyclic loads, and } \\
\text { oxidation }\end{array}$ & As above \\
\hline & $\begin{array}{l}\text { Bottom } \\
\text { Layer }\end{array}$ & $\begin{array}{l}\text { 2-D } \\
\text { C/C Composites }\end{array}$ & $\begin{array}{l}\text { Failure from off- } \\
\text { normal loads, } \\
\text { fatigue, abrasion }\end{array}$ & $\begin{array}{l}\text { Aging due to } \\
\text { cyclic loads and } \\
\text { wear }\end{array}$ & As above \\
\hline
\end{tabular}

\subsubsection{C/C Composites}

Carbon/Carbon composite materials have been used for many years in hightemperature components for military and aerospace applications. The production of $\mathrm{C} / \mathrm{C}$ composites is relatively mature and offers a wide variety of material options (fiber and matrix types) and methods for fabricating fiber performs and for creating different fiber architectures. Many domestic companies now manufacture $\mathrm{C} / \mathrm{C}$ composite components. As a result, an infrastructure to support component development for the NGNP exists [5]. However, current manufacturing capabilities may present practical limitations to the size and shape of components that can be manufactured. For example, it may be difficult and expensive to manufacture a thin-wall $1500 \mathrm{~mm}$ diameter, $1200 \mathrm{~mm}$ long cylindrical liner for the hot duct assembly.

While $\mathrm{C} / \mathrm{C}$ composites can be manufactured with a wide range of fiber architectures, it is likely the components evaluated in this study will use either 3-D or 2-D reinforcement. Three-dimensional reinforcement may be achieved by either weaving or braiding the fiber preform or vacuum to form a random fiber composite (RFC) preform. Typical properties for 2-D and 3-D C/C composites are summarized in Table 9 and, for completeness, include typical properties for fine-grained isotropic graphite. The density of the composite material generally depends on the fiber density in the preform and the number of matrix impregnation cycles. Higher density generally increases the strength, Young's modulus, and thermal conductivity. 
Table 9: Typical Properties of C/C Composite Materials

\begin{tabular}{|l|c|c|c|c|}
\hline \multirow{2}{*}{\multicolumn{1}{c|}{ Property }} & \multirow{2}{*}{\begin{tabular}{c} 
Composite Grade \\
\cline { 3 - 5 }
\end{tabular}} & $\begin{array}{c}2-\mathrm{D} \\
\text { Insulation }\end{array}$ & $\begin{array}{c}\text { 3-D } \\
\text { Densits }\end{array}$ & $\begin{array}{c}\text { Fined-Grained } \\
\text { Graphite }\end{array}$ \\
\hline Thermal Conductivity & $\mathrm{g} / \mathrm{cm}^{3}$ & 1.49 & $1.7-1.9$ & $1.75-1.85$ \\
& $\mathrm{~W} / \mathrm{m}-\mathrm{K}$ & $\begin{array}{c}32(/ /) \\
7(\perp)\end{array}$ & $100-200$ & $90-200$ \\
\hline CTE & $10-6 / \mathrm{K}$ & $\begin{array}{c}0.5(/ /) \\
7.0(\perp)\end{array}$ & $0.1-2.0$ & $2-5$ \\
\hline Young's Modulus & $\mathrm{GPa}$ & $100(/ /)$ & $75-150$ & $10-15$ \\
\hline Flexural Strength & $\mathrm{MPa}$ & $170(\perp)$ & $75-200$ & \\
\hline Flexural Modulus & $\mathrm{GPa}$ & $63(\perp)$ & $40-80$ & $40-60$ \\
\hline Tensile Strength & $\mathrm{MPa}$ & $133(/ /)$ & $100-400$ & $100-200$ \\
\hline $\begin{array}{l}\text { Compressive } \\
\text { Strength }\end{array}$ & $\mathrm{MPa}$ & $135(/ /)$ & $100-200$ & $\mathrm{~N} / \mathrm{A}$ \\
\hline $\begin{array}{l}\text { Inter-laminar Shear } \\
\text { Strength }\end{array}$ & $\mathrm{MPa}$ & 13.2 & $\mathrm{~N} / \mathrm{A}$ & $<1$ \\
\hline Fracture Toughness & $\mathrm{MPa}-\mathrm{m}^{1 / 2}$ & & $4-6$ & \\
\hline
\end{tabular}

As shown in Table 9, the strength and fracture toughness for $\mathrm{C} / \mathrm{C}$ composites are much higher than for graphite. Composite materials and graphite have similar compressive strength. In general, 3-D composites have mostly isotropic properties isotropic, but 2-D composites have significant anisotropy. Strength, stiffness, and thermal conductivity are much greater in the plane of the 2-D fabric than in the direction perpendicular to the fabric plane. Conversely, thermal expansion is lower in the fabric plane.

While there are extensive room-temperature property data for $\mathrm{C} / \mathrm{C}$ composite materials, elevated temperature data are limited, particularly for the pitch-based fiber and pitchbased matrix composites required for the reactor core components. Furthermore, data for key thermal and mechanical properties do not exist for the effects of long-term exposure of these materials to high temperatures, radiation, and representative environments. Such data are essential to support the design and qualification of components with an expected operating lives of 30 to 60 years.

The stability of $\mathrm{C} / \mathrm{C}$ composites under neutron irradiation only matters for control rod components as the fast neutron fluence will not be high enough to appreciably affect the properties of other components. As discussed in Section 4.1.1, the results of early studies for $\mathrm{C} / \mathrm{C}$ composite materials indicate mechanical properties and dimensional stability are acceptable up to fast neutron dose levels of 6-8 dpa [2, 5, 10]. However, results from recent exposure tests show anisotropic dimensional changes for a 3-D composite [20], possibly as a result of the combined effects of the fiber architecture and specimen geometry. Overall volumetric swelling for rectangular bars was about $9 \%$ after a fast neutron dose of $9.5 \mathrm{dpa}$. The anisotropic dimensional changes distorted the rectangular bars after $4 \mathrm{dpa}$ and partially delaminated the surface layer after $7.3 \mathrm{dpa}$. 
Even with the anisotropic dimensional changes, flexural strength was not adversely affected by irradiation, as shown in Figure 4.6-1, at least up to $7.3 \mathrm{dpa}$. These results confirm the operating life for $\mathrm{C} / \mathrm{C}$ composites is limited by fast neutron irradiation to dose levels of $8 \mathrm{dpa}$ or less. The results also clearly demonstrate the specimen geometry must be carefully chosen to best represent the actual component design and associated fiber architecture, as some of the observed dimensional changes and distortions may be been due to these factors.
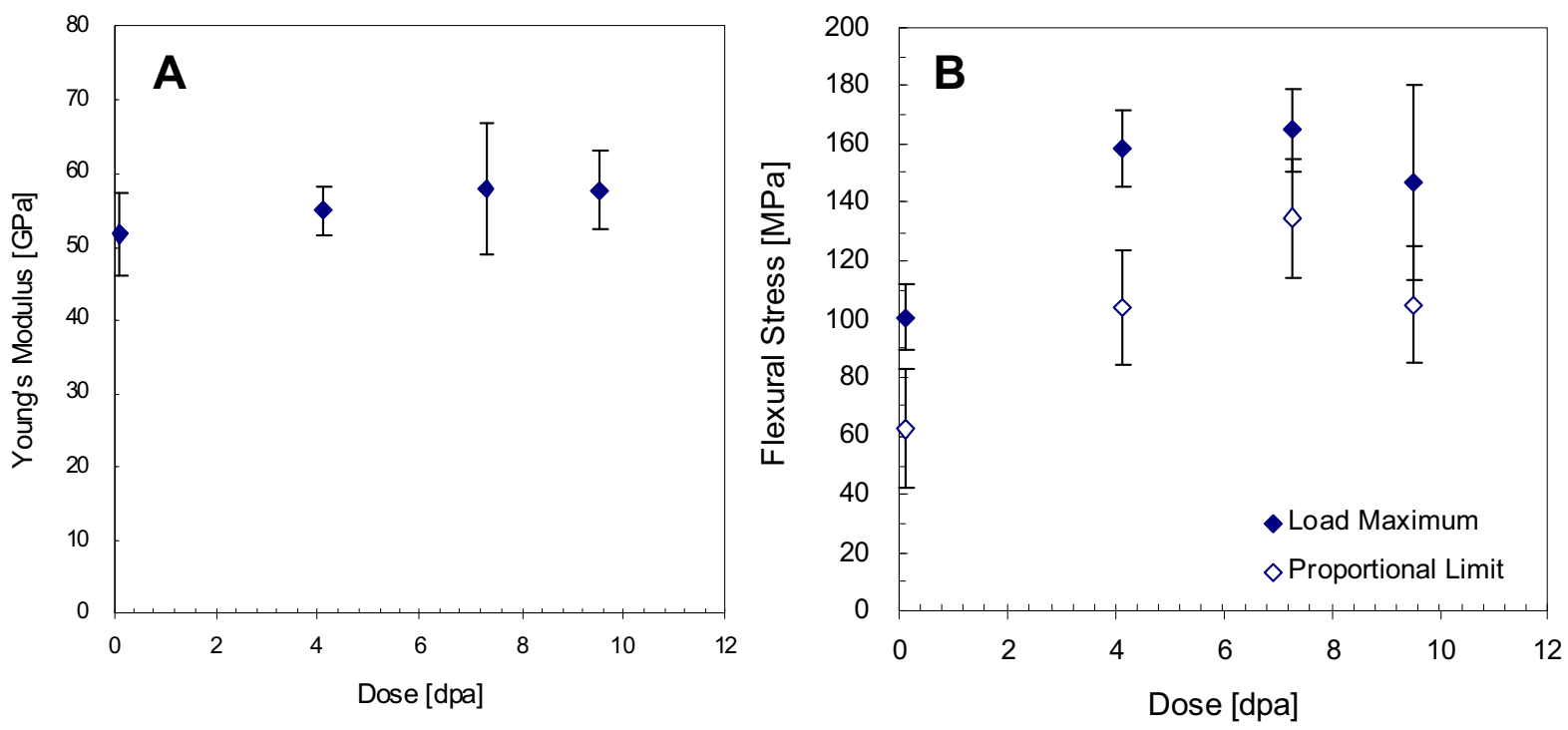

Figure 4.6-1: Effects of Neutron Dose on (A) Young's Modulus and (B) Flexural Strength of the 3-D C/C Composite [20]

\subsection{2 $\mathrm{SiC} / \mathrm{SiC}$ Composites}

$\mathrm{SiC} / \mathrm{SiC}$ composites are an alternate material to $\mathrm{C} / \mathrm{C}$ composites for the control rod assembly [5, 8], but these materials are relatively immature. This is particularly true for $\mathrm{SiC} / \mathrm{SiC}$ composites such as Hi-Nicalon Type-S and Tyranno-SA, which are based on recently developed high-purity beta-SiC fibers.

Many of the property data generated for $\mathrm{SiC} / \mathrm{SiC}$ composites have used relatively simple, small-scale components from which test specimens were cut. Consequently, while such data may provide general properties and useful insights regarding material behavior, the data cannot be used for component design. For the tubular control rod components for which $\mathrm{SiC} / \mathrm{SiC}$ composites are considered to be a candidate material, the specimen geometry and fiber architecture must properly address the design and 
fiber architecture of the tubular component. This important consideration has been the focus of significant effort in the NGNP R\&D program [13-16].

$\mathrm{SiC} / \mathrm{SiC}$ composite materials have experienced rapid development over the past ten years, particularly with respect to high-purity beta-SiC fibers and composites fabricated using chemical vapor infiltration (CVI) for matrix densification that exhibit excellent hightemperature properties and stability when exposed to radiation [5, 8, 10-12]. More recent results have confirmed the excellent stability of $\mathrm{SiC} / \mathrm{SiC}$ composites [21]. As shown in Figure 4.6-2, irradiation at $800^{\circ} \mathrm{C}$ resulted in about $0.6 \%$ volumetric swelling, with saturation being observed after about $1 \mathrm{dpa}$. Flexural strength and the proportional limit stress (PLS) showed no significant reduction in values up to $4.6 \mathrm{dpa}$. This stability is the primary reason for considering $\mathrm{SiC} / \mathrm{SiC}$ composites over $\mathrm{C} / \mathrm{C}$ composites for control rod components.

The paucity of data for the new class of radiation-resistant $\mathrm{SiC} / \mathrm{SiC}$ composites, plus the anticipated time and cost to develop the required manufacturing infrastructure and the data to the support the design and qualification of structural components for nuclear applications, present difficult challenges to the NGNP program. Significant investment in the design, manufacture, and testing of $\mathrm{SiC} / \mathrm{SiC}$ composites for control rod components will be needed in the near future to meet the current NGNP schedule.
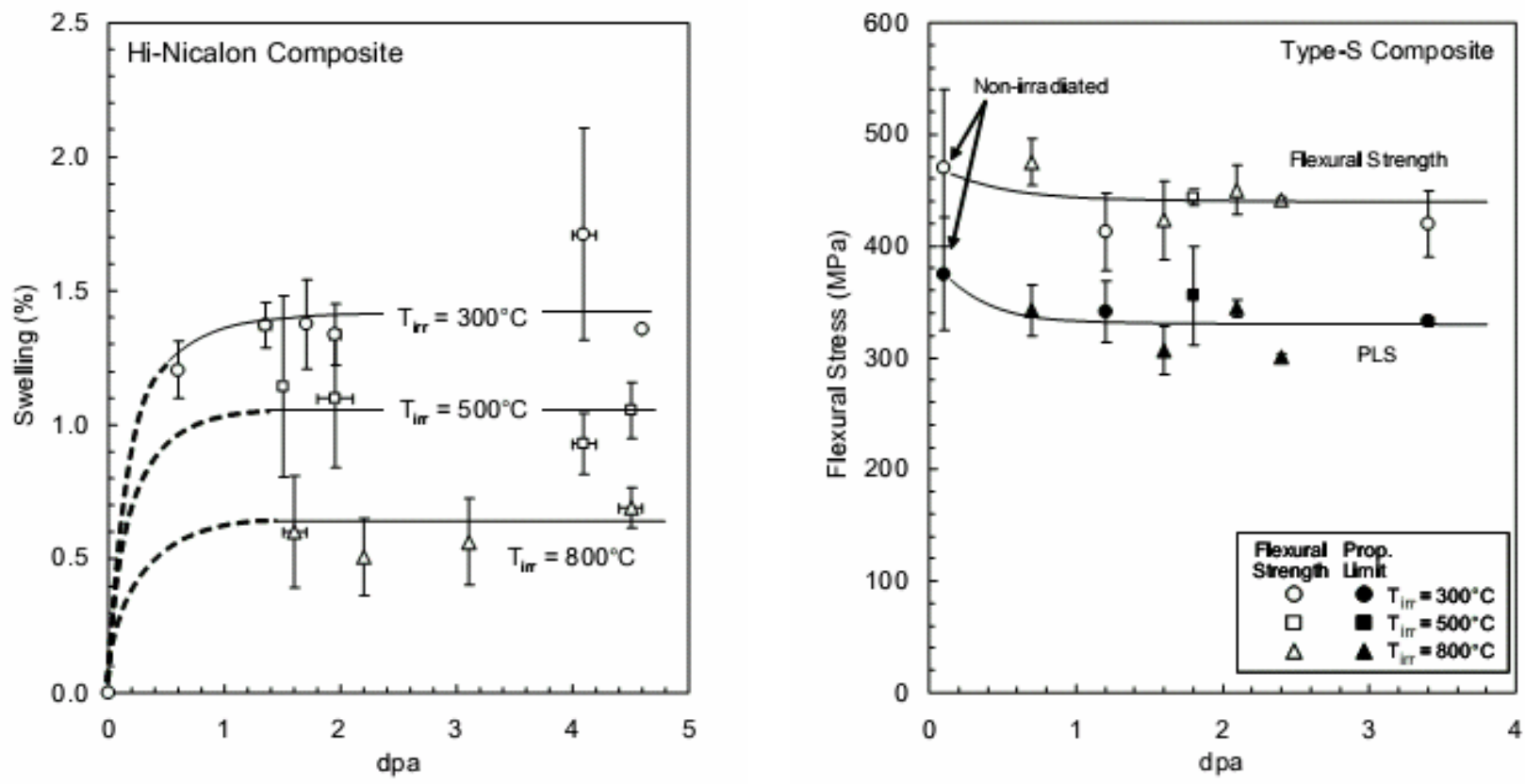

Figure 4.6-2: Effects of Neutron Dose on Volumetric Swelling and Flexural Strength of a $\mathrm{SiC} / \mathrm{SiC}$ Composite [21] 


\subsubsection{Alumina and Other Refractory Fiber Insulation Materials}

Numerous commercial suppliers produce ceramic insulation materials in many forms, e.g., bricks, castable cements, fiber blankets and boards. Ceramic insulation for the NGNP will likely be high-purity, ceramic fiber-based insulation materials in the form of fiber blankets, vacuum formed and cast cylinders, and vacuum formed and cast plates. The most promising oxide ceramic insulation materials are high-purity alumina $\left(\mathrm{Al}_{2} \mathrm{O}_{3}\right)$, zirconia $\left(\mathrm{ZrO}_{2}\right)$, and mullite $\left(\mathrm{Al}_{2} \mathrm{O}_{3}-\mathrm{SiO}_{2}\right)$. High purity is needed to minimize long-term changes in material properties, to limit undesired impurities in the He environment, and to limit the possible transport of impurities to other parts of the reactor (i.e., vapor phase transport). Also, carbon fiber blanket insulation may be suitable for the hot duct assembly and top plenum shroud.

Table 10 provides typical property data for the selected rigid ceramic fiber insulation materials, which are candidates for the lower floor blocks. These materials have a wide range of properties. Typically, low-density materials (e.g., AA-30 and ZYFB-6) have low thermal conductivity and relatively low strength. Higher density insulation materials (e.g., RS-99R) have higher compressive and flexural strength but also have higher thermal conductivity. The properties of the material generally can be tailored to obtain the desired mix of properties (e.g., strength and thermal conductivity) for a specific application. Moreover, these materials generally can be provided as boards in sizes up to about 1 meter square and $50 \mathrm{~mm}$ thickness. They can also come in cylindrical form with diameters of $1-1.5$ meters.

Table 10: Typical Properties of Rigid Ceramic Fiber Insulation Materials

\begin{tabular}{|c|c|c|c|c|}
\hline \multirow[b]{2}{*}{ Property } & \multirow[b]{2}{*}{ Units } & \multicolumn{3}{|c|}{ Insulation Material } \\
\hline & & $\begin{array}{c}\text { T-Cast AA-30 } \\
\text { Board }\end{array}$ & Type RS-99R & $\begin{array}{c}\text { Type } \\
\text { ZYFB-6 }\end{array}$ \\
\hline Composition & & $98 \% \mathrm{Al}_{2} \mathrm{O}_{3}$ & $99+\% \mathrm{Al}_{2} \mathrm{O}_{3}$ & $\mathrm{ZrO}_{2}-\mathrm{Y}_{2} \mathrm{O}_{3}$ \\
\hline Max. Use Temperature & ${ }^{\circ} \mathrm{C}$ & 1630 & 1650 & 1650 \\
\hline Density & $\mathrm{g} / \mathrm{cm}^{3}$ & 0.5 & 2.1 & .96 \\
\hline $\begin{array}{l}\text { Max. Initial Use } \\
\text { Shrinkage }\end{array}$ & & $\begin{array}{c}5 \% \text { Max @ } \\
\text { Use T }\end{array}$ & $\begin{array}{c}.3 \%(1 \mathrm{hr} @ \\
\left.1200^{\circ} \mathrm{C}\right)\end{array}$ & $\begin{array}{c}1.7 \%(24 \mathrm{hr} @ \\
\left.1650^{\circ} \mathrm{C}\right)\end{array}$ \\
\hline Thermal Conductivity & $\mathrm{W} / \mathrm{m}-\mathrm{K}$ & 0.18 & .65 & .20 \\
\hline CTE & $10-6 / \mathrm{K}$ & 7.0 & 7.0 & 10.7 \\
\hline Young's Modulus & $\mathrm{GPa}$ & & & \\
\hline Flexural Strength & $\mathrm{MPa}$ & 1.9 & 21.8 & 2.1 \\
\hline Compressive Strength & $\mathrm{MPa}$ & $\begin{array}{c}1.0 @ 10 \% \\
\text { Strain }\end{array}$ & 30.1 & $\begin{array}{c}1.6 @ 10 \% \\
\text { Strain }\end{array}$ \\
\hline
\end{tabular}

Table 10 Notes: T-Cast AA supplied by Refractory Specialties Inc. Type RS-99R and ZYFB-6 supplied by Zircar Refractory Composites, Inc ZYFB-6 supplied by Zircar Zirconia, Inc. 
Fiber insulation materials can also be obtained in blanket form. These materials have very low bulk densities and low thermal conductivities. For the NGNP, they are primary candidates for insulation in the hot duct assembly and the top plenum shroud.

To support component design for the NGNP, most material properties data needed to design the insulation for the HDA and TPS appear to be available. Also, data are available for the candidate rigid insulation materials likely to be used for the lower floor blocks and the HDA ceramic liner. However, the actual rigid insulation for these two components will require development to achieve the most favorable mix of thermal and structural properties for each application. The manufacturing process for producing the desired insulation blocks and HDA liner may also need to be optimized. A complete set of physical, thermal, and structural property data for these tailored materials is needed.

Because the lower floor blocks support the core and also maintain the lateral position of the graphite columns in the core, the insulation material used for the LFBs might have to be treated as a structural component. If so, much more testing and analysis will be needed to qualify the design and constituent materials for the LFBs.

\section{Anticipated Codification Requirements}

This section addresses anticipated codification requirements for candidate CMs and CCMs identified for the five NGNP components evaluated. The required testing, determination of the required material properties, and codification activities for NRC approval are summarized. An estimated timeline and costs for testing to obtain the necessary material property data are provided.

Any ceramic or ceramic composite structural material in the NGNP reactor will require acceptance by the NRC prior to implementation for safety significant applications. Final NRC acceptance requires extensive qualification activities for any new material system presently having no nuclear performance or design basis. These activities entail development of ASTM international testing standards, ASME performance specifications, ASME design rules, and ASME inspection requirements [5].

Table 11 summarizes candidate materials, operating conditions, and product forms for the five NGNP components evaluated. The primary structural materials identified for these components are $\mathrm{C} / \mathrm{C}$ composites. The product forms used for each component will likely require a unique fiber architecture engineered for the application. The remaining candidates are insulation materials and thus will not be subject to the extensive qualification effort. However, testing may be required for these materials to verify long-term functional performance. 
Table 11: Summary of Operating Conditions, Candidate Materials and Product Forms

\begin{tabular}{|c|c|c|c|c|c|c|c|c|}
\hline \multirow[b]{2}{*}{ Component } & \multirow[b]{2}{*}{ Sub-Unit } & \multirow[b]{2}{*}{$\begin{array}{c}\text { Design } \\
\text { Life } \\
(y r)\end{array}$} & \multicolumn{3}{|c|}{ Normal Operating Conditions } & \multirow[b]{2}{*}{$\begin{array}{l}\text { Off-Normal } \\
\text { Conditions }\end{array}$} & \multirow[b]{2}{*}{$\begin{array}{l}\text { Candidate } \\
\text { Material }\end{array}$} & \multirow[b]{2}{*}{$\begin{array}{l}\text { Product } \\
\text { Form }\end{array}$} \\
\hline & & & $\begin{array}{l}\text { Max. } \\
\text { Temp. } \\
\left({ }^{\circ} \mathrm{C}\right)\end{array}$ & $\begin{array}{c}\text { Fast } \\
\text { Fluence } \\
\left(\mathrm{n} / \mathrm{cm}^{2}\right)\end{array}$ & Environment & & & \\
\hline \multirow{4}{*}{$\begin{array}{l}\text { Outer Control } \\
\text { Rod }\end{array}$} & Canister & $15-60$ & $\begin{array}{c}800-1000 \\
(\text { Note a) }\end{array}$ & $\begin{array}{c}9 \times 10^{21} \\
\text { to } \\
3.6 \times 10^{21}\end{array}$ & $\mathrm{He}$ & $1200^{\circ} \mathrm{C}^{b}$ & $3 \mathrm{D} C / \mathrm{C}$ & Tube \\
\hline & Connecter & & & & & & $\mathrm{C} / \mathrm{C}$ & Rod \\
\hline & & & & & & Air $/ \mathrm{H}_{2} \mathrm{O}$ & SiC coating & \\
\hline & Cable & & & & & & Alloy $800 \mathrm{H}$ & \\
\hline \multirow{4}{*}{$\begin{array}{l}\text { Inner Control } \\
\text { Rod }\end{array}$} & Canister & $15-60$ & 1100 & & $\mathrm{He}$ & $1600^{\circ} \mathrm{C}^{\mathrm{c}}$ & $3 \mathrm{D} C / \mathrm{C}$ & Tube \\
\hline & Connecter & & & & & & $\mathrm{C} / \mathrm{C}$ & Rod \\
\hline & & & & & & Air $/ \mathrm{H}_{2} \mathrm{O}$ & SiC coating & \\
\hline & Cable & & & & & & Alloy $800 \mathrm{H}$ & \\
\hline \multirow{2}{*}{$\begin{array}{l}\text { Upper Core } \\
\text { Restraint } \\
\text { Blocks }\end{array}$} & \multirow{2}{*}{ Block } & 60 & 500 & $1.5 \times 10^{17}$ & $\mathrm{He}$ & $1200^{\circ} \mathrm{C}^{d}$ & 3D C/C & $\begin{array}{c}\text { Plate }+ \\
\text { Shell } \\
\end{array}$ \\
\hline & & & & & & $\mathrm{Air} / \mathrm{H}_{2} \mathrm{O}$ & SiC coating & \\
\hline \multirow{3}{*}{$\begin{array}{l}\text { Lower Floor } \\
\text { Blocks }\end{array}$} & Upper Layer & 60 & 900 & $1.7 \times 10^{13}$ & $\mathrm{He}$ & $1200^{\circ} \mathrm{C}^{\mathrm{e}}$ & $2 \mathrm{D}, 3 \mathrm{D} \mathrm{C} / \mathrm{C}$ & Plate \\
\hline & Center Layer & & & & & & Alumina & \\
\hline & Lower Layer & & & & & & $2 \mathrm{D} \mathrm{C} / \mathrm{C}$ & Plate \\
\hline \multirow{3}{*}{$\begin{array}{l}\text { Hot Duct } \\
\text { Assembly }\end{array}$} & Support Pipe & 60 & 1000 & $8.7 \times 10^{15}$ & $\mathrm{He}$ & $1150{ }^{\circ} \mathrm{C}$ & Alloy $800 \mathrm{H}$ & \\
\hline & $\begin{array}{l}\text { Ceramic } \\
\text { Liner }\end{array}$ & & & & & & $\begin{array}{c}\mathrm{C} / \mathrm{C}, \\
\text { Alumina }\end{array}$ & $\begin{array}{c}\text { Large } \\
\text { Cylinder }\end{array}$ \\
\hline & Insulation & & & & & & $\begin{array}{l}\text { Alumina, } \\
\text { Zirconia }\end{array}$ & \\
\hline \multirow{2}{*}{$\begin{array}{l}\text { Top Plenum } \\
\text { Shroud }\end{array}$} & Shell & 60 & 500 & $3.4 \times 10^{16}$ & $\mathrm{He}$ & $1050{ }^{\circ} \mathrm{C}$ & Alloy $800 \mathrm{H}$ & \\
\hline & Insulation & & & & & & $\begin{array}{l}\text { Alumina, } \\
\text { Zirconia }\end{array}$ & \\
\hline
\end{tabular}

The Next Generation Nuclear Plant, Materials Selection and Qualification Program Plan [8] includes the $\mathrm{C} / \mathrm{C}$ composite material, but it does not provide an isolated focus on development needs for the material. The intent of the following discussion is to provide such isolation from the dominance of pressure boundary material considerations. Subsequent revisions of the Plan [13,14] and related reports (e.g., [15]) have furnished additional details about planned and ongoing testing of $\mathrm{C} / \mathrm{C}$ and $\mathrm{SiC} / \mathrm{SiC}$ composites for control rod components and guide tubes and for hot duct assembly insulation.

\subsection{NRC Issues}

The Nuclear Regulatory Commission (NRC) review process is embodied in NUREG0800 , which is the standard review guide for light water reactor systems. This guide is not directly applicable to the high-temperature gas-cooled NGNP reactor, but it sets a framework for potential review actions that should be anticipated for preliminary 
planning, design, material development, and testing. In the review process, the NRC expects the licensee to use consensus standards as one of the important sources for documentation. The NGNP Materials Selection and Qualification Program Plan [8] incorporates the use and development of the ASTM consensus process for materials specifications and testing and the use and development of the ASME consensus process for the design and construction codes. The plan recognizes the complexity of introducing composites into the ASME Code and proposes an approach to achieve codification (see Section 3.4.3.3 of [8]).

Precise criteria for NRC acceptance of a new material class are not well defined, especially with respect to the HTGR applications. The potential user or material supplier will need to estimate the qualification criteria and their justification in the initial submittal to the NRC. The result of this acceptance review system historically creates a lengthy approval process in which there are increasingly detailed requests for information from the NRC. There is presently an NRC effort to create a unified design criteria document for NGNP reactor designs [5]. However, it is unclear whether such a document will be available in time to support the NGNP design and acceptance program.

Except for core support structures, the ASME Boiler and Pressure Vessel Code has not included code rules for components internal to the pressure vessel other than in regions of attachment welds. Further, code rules are structural and not intended to provide functional assurance. Reactor designers have often solved the acceptance criteria dilemma by choosing materials and allowable stresses from the vessel code ASME Section III Appendices (subsequently moved to Section II). Internal components are not subject to code stamp certification.

For any new reactor design, the NRC would probably appreciate a consensus structural standard for internal components other than the core supports. The NGNP Materials Selection and Qualification Program Plan [8] did not recognize this aspect of the ASME B\&PV Codes and thus raises another critical issue if a separate code is to be established. The consequences of failure of an internal component are different than the failure of a pressure boundary component because internal component failure influences function more than the structural soundness of the system.

The plan for establishing a consensus code follows the traditional sequence of events. First, material specifications and tests are developed through the ASTM. Next, a request is made to the consensus design and construction standard organization, such as ASME, to create a standard. Then, design and construction rules are developed in committees and voted upon for approval. Public comment is accepted in the process.

Composites are currently identified by manufacturer, composition, and other characteristics. Supporting physical data may include test results using ASTM test specifications. Apparently, ASTM material specifications for $\mathrm{C} / \mathrm{C}$ composites do not 
exist. The American Society for Composites website does not identify any involvement in creating such standards.

The top level consensus document applicable to all material codification activities is the quality assurance program. For specific material selection and qualification testing activities, the requirements of ASME NQA 1997 are imposed by the NGNP program [8, p. 18]. Most commercial testing laboratories can neither support nor want to support the overhead cost and long-term commitment of a nuclear QA program. If a nuclear qualified laboratory is not available for specific tests, the AREVA QA program may provide direct oversight of the test procedures, material procurement, specimen preparation, testing, and witness to obtain qualified test results.

Testing of irradiated specimens presents a different problem. Specifically, laboratories may be NQA qualified but lack experience in composites testing and not have the unique equipment needed for composite testing, particularly for elevated temperatures and irradiated specimens. The needed equipment will have to be purchased for limited use because it will be contaminated in the hot cell and infrequently reused over a period of decades.

The functions of the composite components determine what mechanical properties and other properties are important to the design. NQA qualified labs need to perform the required tests to document the properties and to corroborate data from previous unqualified sources. This testing may represent several product forms and processes because each material can be considered to be unique.

By first selecting the NGNP applications for CMs, the number of product forms, processes, loading conditions, environmental conditions, and test requirements can be identified. Because the qualification of each product form and fabrication process is an extensive effort involving many tests and often many laboratories, the test program needs careful coordination to stay on schedule and within budget. Work on multiple materials require coordination to ensure specimens are available for testing in parallel or in series without disrupting setups or test schedules at the laboratories. Otherwise, additional charges and delays will occur. Also, NQA-1 requalification can cause major delays when schedule slippage prevents a laboratory from exercising the NQA-1 program within required time limits.

\subsection{Status of Codes}

\subsubsection{ASME Section III Carbon-Carbon Composite Code}

No ASME Section III carbon-carbon composite code either exists or has been attempted, as stated in the NGNP Materials Selection and Qualification Program Plan (Reference [8], Section 3.3.5.3). This is a major challenge. 
Establishing a design and construction code for $\mathrm{C} / \mathrm{C}$ composites will be an extensive long-term effort. Instead of starting a new effort, a preferred path might modify current activities to produce a code for graphite core components. An appropriate venue for developing the design and construction code could be the American Society of Mechanical Engineers, Board on Pressure Technology Codes and Standards, The Boiler and Pressure Vessel Standards Committee, Subcommittee on Nuclear Power (SC III), Subgroup on Graphite Core Components (SC III). The initial release may occur within one year of approval.

From the ASME.org web site for the Codes and Standards Committees, the charter approved in May 2005 for the Subgroup on Graphite Core Components is:

"The committee shall establish codes, standards and guides for materials selection and qualification, design, fabrication, testing, installation, examination, inspection, certification, and the preparation of reports for manufacture and installation of nonmetallic internal components for graphite-moderated fission reactors, where nonmetallic internal components are defined as components, including control rods and assemblies, contained within a graphite-moderated fission reactor pressure vessel and manufactured from graphite, carbon, carbon/carbon composites, ceramics, or ceramic matrix composites. The codes, standards and guides shall apply to non-metallic components as defined above. The codes, standards and guides shall not apply to graphite fuel matrix materials, fuel compacts, fuel pebbles, bushings, bearings, seals, blanket materials, instrumentation, or components internal to the reactor other than those defined above."

The ASME staff contact is Christian A. Sanna [17] and the Chair is Timothy D. Burchell, PHD, PE of the U.S. Department of Energy. Committee membership includes representatives from Oak Ridge National Laboratory, PBMR SA, Idaho National Laboratory, AMEC UK regulator, AREVA CEA, and AREVA. The committee has been meeting over much of the last five years and has a draft code about $75 \%$ ready to float for approval. It is anticipated that within 12 months the first code rules for construction will be completed. Another group is involved with in-service inspection requirements.

The initial effort focuses on graphite components. A recent PowerPoint presentation to the committee requested the addition of $\mathrm{C} / \mathrm{C}$ fiber composites. Beyond the stated charter scope there is also consideration of HTR metals currently outside the code rules.

Material properties required by the design code would be subject to the Subcommittee on Materials (SC II), Special Working Group on Non-Metallic Materials (SC II). The group charter includes reviewing all applications of non-metallic materials proposed for use in Boiler \& Pressure Vessel Construction Codes and Code Cases, recommending necessary rules for such use, and developing and applying a process to identify and incorporate acceptable non-metallic materials into Section II. 


\subsubsection{ASTM Material Specifications}

Material specifications for the final product form have not been identified for $\mathrm{C} / \mathrm{C}$ composites. This deficiency needs to be addressed.

For metal alloys, ASME and ASTM material specifications are often equivalent, but the ASME specification can have limitations intended to restrict product grades or forms that can be used in conjunction with the design and construction code. Thus, the material must be specifically included in the Design and Construction Code, in Section II, or in a Code Case to be permitted in construction. For composites, the Design and Construction Code rules will have to be different. Presently, the available ASTM test specifications define standard test methods for product groups. The closest matches to $\mathrm{C} / \mathrm{C}$ and $\mathrm{SiC} / \mathrm{SiC}$ composites appear to be the standards developed by Committee C28 on Advanced Ceramics, Committee C28.07 on Ceramic Matrix Composites. The ASTM staff contact for this committee is Joe Koury (610) 832-9804 and he recommends further contact with Roger Stoller, Committee E10, Nuclear Technology \& Applications, email rku@ornl.gov

According to the NGNP Materials Selection and Qualification Program Plan [8]: "ASTM Committee C28 (Advanced Ceramics), including Subcommittee C28.07 (Ceramic Matrix Composites) already has 13 standard test methods for measuring physical and mechanical properties of Ceramic Matrix Composites. This committee has expressed a willingness to work with the NGNP Materials Program to expand their codes and standards to include the structure and chemistry of ceramic matrix composites (both $\mathrm{SiC} / \mathrm{SiC}$ and $\mathrm{C} / \mathrm{C}$ ) for nuclear applications."

The active standards under the jurisdiction of C28.07 that appear applicable are:

1. C1275-00(2005)e1 Standard Test Method for Monotonic Tensile Behavior of Continuous Fiber-Reinforced Advanced Ceramics with Solid Rectangular Cross-Section Test Specimens at Ambient Temperature

2. C1292-00(2005) Standard Test Method for Shear Strength of Continuous Fiber-Reinforced Advanced Ceramics at Ambient Temperatures

3. C1337-96(2005) Standard Test Method for Creep and Creep Rupture of Continuous Fiber-Reinforced Ceramic Composites under Tensile Loading at Elevated Temperatures

4. C1341-06 Standard Test Method for Flexural Properties of Continuous Fiber-Reinforced Advanced Ceramic Composites

5. C1358-05 Standard Test Method for Monotonic Compressive Strength Testing of Continuous Fiber-Reinforced Advanced Ceramics with Solid Rectangular Cross-Section Test Specimens at Ambient Temperatures 
6. C1359-05 Standard Test Method for Monotonic Tensile Strength Testing of Continuous Fiber-Reinforced Advanced Ceramics With Solid Rectangular Cross-Section Test Specimens at Elevated Temperatures

7. C1360-01(2007) Standard Practice for Constant-Amplitude, Axial, TensionTension Cyclic Fatigue of Continuous Fiber-Reinforced Advanced Ceramics at Ambient Temperatures

8. C1425-05 Standard Test Method for Interlaminar Shear Strength of 1-D and 2-D Continuous Fiber-Reinforced Advanced Ceramics at Elevated Temperatures

9. C1468-06 Standard Test Method for Transthickness Tensile Strength of Continuous Fiber-Reinforced Advanced Ceramics at Ambient Temperature

10. C1469-00(2005) Standard Test Method for Shear Strength of Joints of Advanced Ceramics at Ambient Temperature

11. C1557-03e1 Standard Test Method for Tensile Strength and Young's Modulus of Fibers

In addition, new standards have been proposed, including:

1. WK2303 Standard Practice for Thermomechanical Fatigue of Continuous Fiber-Reinforced Advanced Ceramic Matrix Composites

2. WK10141 Standard Test Method for Acoustic Emission Monitoring during a Room Temperature Tensile Test of a Continuous Fiber-Reinforced Advanced Ceramic Matrix Composite

3. WK10142 Standard Test Method for Monotonic Tensile Behavior of Continuous Fiber-Reinforced Advanced Ceramic Tubular Test Specimens at Ambient Temperature

\subsubsection{Additional Code Work}

\section{ASME}

Much progress has occurred on the graphite component design and construction code to serve as a framework for incorporation of $\mathrm{C} / \mathrm{C}$ composites. The graphite version needs to enter the approval process within the next year to set the pace for incorporating $\mathrm{C} / \mathrm{C}$ composites by about 2011. A code case is probably a shorter and more limited path to interim codification of $\mathrm{C} / \mathrm{C}$ composite design and construction rules that would be acceptable to the NRC. ASME Section III Appendices, Appendix IV, "Approval of New Materials Under The ASME Boiler and Pressure Vessel Code for Section III Application," 1986, provides the procedure and defines the information required to obtain approval of 
new materials. A current edition should be reviewed to update the requirements, but they probably have not changed significantly.

A key complicating factor for a $\mathrm{C} / \mathrm{C}$ composite material is the perception that it is an engineered material system because the composite structure and manufacturing are designed to meet performance requirements for a specific application. Existing ASME design and assessment rationale are guided by homogeneous characteristics for materials typically used in light water reactors. The system for design and assessment of $\mathrm{C} / \mathrm{C}$ composites will have to be revised to properly account for the different behavior. This revision will be especially important when considering specimens for testing to obtain material properties. The specimens will likely need to be cut from prototype components and then be subjected to the appropriate thermal, radiation and environmental conditions [5].

The information needed to develop the code includes:

- Materials specifications (ASTM and other recognized organizations)

- Application

- Temperature Range

- Cyclic Service

- Product Form, Size Ranges, Specifications (fabrication and testing)

Applicable Mechanical Properties considering:

- Stress Rupture \& Creep Data

- Fracture Toughness Data

- Stress Strain Curves

- Fatigue Data

- Ultimate Tensile Strength

- Yield Strength (or equivalent for composites)

- Young's Modulus

- Poisson's ratio

Additional Mechanical Properties to consider:

- Compressive Strength

- Flexural Strength

- Biaxial and Multi-axial Flexural Strength 
- Flexural Modulus

- Strain to failure

- Shear Strength

- Inter-laminar Shear Strength

- Trans-thickness Tensile Strength

- Shear Modulus

Other Physical Properties:

- Coefficient of Thermal Expansion (CTE)

- Thermal Conductivity and Diffusivity

- Emissivity

- Specific Heat

Development of standard fabrication and test methods for $\mathrm{C} / \mathrm{C}$ composites is considered to be an ASME specification issue. For example, different fiber architectures will require new material qualification tests just like a new heat treatment for a steel alloy would require a full run of qualification tests. ASTM standard test specifications are not expected to be a significant problem because many of the ceramic composite test specifications already exist and the ASTM committees are willing to work with the program to develop additional test specifications. The fabrication specifications will be more application dependent and likely cannot be generic standard specifications.

To prove the fabrication specification process works, a demonstration of reproducible test results would be beneficial. Such demonstration will also be necessary if proof tests are used to set design pressures and loads. For a Section III, Division 1, Class 2 Component, proof tests can sometimes be used to establish the design pressure based on NC-6900 (1986). This method possibly could be adapted to define design stresses for $\mathrm{C} / \mathrm{C}$ composite components.

For in-service inspection of $\mathrm{C} / \mathrm{C}$ composite components, examinations are needed to determine what failure mechanisms are to be prevented and to establish characteristics of failure mechanisms relative to in-service inspection intervals (for ISI not construction).

The following long-term testing programs are needed:

- Surveillance Test Specimens

- Accelerated Irradiation Tests

- Elevated-Temperature Exposure to He Environment (including impurities) 


\section{ASTM}

No ASTM material specifications exist for either $\mathrm{C} / \mathrm{C}$ or $\mathrm{SiC} / \mathrm{SiC}$ composites. Any existing fabrication specifications are probably proprietary. For the NGNP program, each ceramic composite application, i.e., product form, needs to have a fabrication process developed and converted to an ASTM style material specification format. About five specifications are needed.

Because of the unique materials, fiber architecture, and design details for each ceramic composite component envisioned within the NGNP reactor, and the non-isotropic, atypical behavior of such materials compared to homogeneous materials, there is a need to determine what specific properties must be measured. Appropriate methods for measuring the properties in a repeatable way must be devised and approved.

While ASTM test methods exist for measuring many of the ceramic composite properties of interest at room temperature, standard test methods to measure such properties at high temperatures are limited and some are still in development. Test methods to evaluate all relevant $\mathrm{C} / \mathrm{C}$ (or $\mathrm{SiC} / \mathrm{SiC}$ ) composite properties at elevated temperatures, including irradiation effects, will need to be developed and formalized through ASTM International. This process can be lengthy, depending on the complexity of the test method proposed and the difficulty with obtaining trial test data. Such trials are usually provided by at least six interested laboratories on a volunteer basis [5].

Finding qualified laboratories for adequate round-robin testing will be a significant challenge. Few labs now testing composites qualify to NQA-1 standards. Also, few labs have facilities for testing irradiated materials. A table of test methods, labs, components, and material properties can be developed as shown in the following partial example:

\begin{tabular}{|c|c|c|c|c|c|c|c|}
\hline \multirow[b]{2}{*}{ Component } & \multirow[b]{2}{*}{ Sub-Unit } & \multirow[b]{2}{*}{ Temperature } & \multicolumn{5}{|c|}{ Material Property Data Test Method } \\
\hline & & & $\begin{array}{c}\text { Tensile } \\
\text { Strength, } \\
\mathrm{MPa}\end{array}$ & $\begin{array}{c}\text { Compressive } \\
\text { Strength, } \\
\mathrm{MPa}\end{array}$ & $\begin{array}{c}\text { Shear } \\
\text { Strength, } \\
\mathrm{MPa}\end{array}$ & $\begin{array}{l}\text { Creep/ } \\
\text { Creep } \\
\text { Rupture }\end{array}$ & $\begin{array}{l}\text { Coef. Of } \\
\text { Thermal } \\
\text { Expansion }\end{array}$ \\
\hline \multirow{2}{*}{$\begin{array}{l}\text { Outer Control } \\
\text { Rod }\end{array}$} & Canister & Ambient & WK10142 & & & & \\
\hline & Connecter & Max. Temp. & & & & & \\
\hline \multirow{2}{*}{$\begin{array}{l}\text { Inner Control } \\
\text { Rod }\end{array}$} & Canister & Ambient & WK10142 & & & & \\
\hline & Connecter & Max. Temp. & & & & & \\
\hline \multirow{2}{*}{\multicolumn{2}{|c|}{ Upper Core Restraint Blocks }} & Ambient & $\mathrm{C} 1275-00$ & C1358-05 & C1292-00 & & \\
\hline & & Max. Temp. & C1359-05 & & & C1337-96 & \\
\hline \multirow{2}{*}{$\begin{array}{l}\text { Lower Floor } \\
\text { Blocks }\end{array}$} & Upper LFB Plate & Ambient & C1275-00 & C1358-05 & C1292-00 & & \\
\hline & Lower LFB Plate & Ambient & C1275-00 & C1358-05 & C1292-00 & & \\
\hline
\end{tabular}


To support the NGNP program, round-robin testing is now being performed to characterize the mechanical properties of tubular and flat plate composite specimens over a range of temperatures [14, 16]. Four laboratories (ORNL, INL, PNNL and University of Bordeaux-France) are supporting these tests, the results of which will be provided to the ASTM subcommittee (or working group) for analysis. Further testing will be performed to complete development of the necessary ASTM standards and to provide data to support component design.

\subsubsection{Additional NRC Licensing Support Work}

Other issues that can affect codification of $\mathrm{C} / \mathrm{C}$ composites include:

- In-service inspection

- Long-term aging phenomena

- Oxidation

- Erosion

Besides ASTM standards and ASME code-related activities already discussed for supporting NRC licensing of $\mathrm{C} / \mathrm{C}$ composites, it is expected testing will be required for insulation materials to be used in the hot duct assembly and in the lower floor blocks in order to ensure their performance for the life of the plant. The required test data will include physical properties, mechanical strength, and long-term thermal and composition stability as a function of temperature. Also, resistance to vibration and acoustic loads, corrosion, and rapid pressure drops, stability to dust release, and other properties will need to be characterized.

\subsection{Timeline and Estimated Cost for Codification of Materials}

The time and cost for codification of $\mathrm{C} / \mathrm{C}$ materials for the NGNP reactor can be estimated based on experience with new material testing [18]. In the case cited, all relevant tests were conducted for a coating material, except for the irradiation tests, within 18 months. Some labs needed assistance in upgrading QA programs to NQA-1 standards. No additional ASTM test specifications had to be either developed or revised. The number of samples tested was small - about 12 for each test set. Fifteen different tests were conducted and most were performed at two labs although seven labs were used in the testing program. The number of labs was determined by the need to cover the scope of all 15 tests and because no lab by itself had the capability to perform every test.

The same situation is expected for the extensive testing needed to obtain the data quality required for developing the code for CCMs. Many labs will likely be needed to perform the tests. Currently, four labs are being used for initial testing of $C / C$ and $\mathrm{SiC} / \mathrm{SiC}$ composite materials $[14,16]$. Moreover, much effort is directed at defining 
component product forms, establishing all of the ASTM test methods for ambient and elevated temperatures, and establishing methods to assess the long-term effects of radiation, elevated temperature, cyclic loads, and the environment.

It is assumed a complete testing program will require 12 short-term tests conducted over a full range of temperatures for a statistically significant quantity. Additionally, at least three sets of long-term tests are needed with one set at a full range of temperatures and the other two sets at elevated temperatures. Irradiation effects will also need to be evaluated, so surveillance specimens should be prepared for comparisons. Testing should be performed at $50{ }^{\circ} \mathrm{C}$ intervals from $50{ }^{\circ} \mathrm{C}$ below ambient to $50{ }^{\circ} \mathrm{C}$ above the maximum temperature.

The following is an initial estimate for the required short-term testing:

\section{Control Rods Other Components}

Product forms:

Number of test procedures:

Statistical sample quantity:

Maximum Temperature +50 :

Temperature Intervals:

Total number of tests:
2

12

20

1650

25

15,840

\section{3}

12

20

1250

25

18,000

It is assumed the use of five product forms will require the full suite of testing be performed for each. For each of the 12 tests, it is assumed 20 specimens will be tested to obtain the necessary sample statistics. Assuming the inner control rods are inserted during a conduction cooldown accident, the maximum temperature for which testing is required will be $1650^{\circ} \mathrm{C}\left(1600^{\circ} \mathrm{C}\right.$ maximum plus $\left.50^{\circ} \mathrm{C}\right)$. Starting at room temperature, the number of temperature intervals is 33 . Thus, the total number of short-term tests is estimated to be on the order of 16,000 for the control rod product forms. Similarly, the number of tests for the other three product forms and a maximum temperature of $1200^{\circ} \mathrm{C}$ will be about 18,000 . Thus, the total number of short-term tests could be on the order of 34,000 . It must be noted that if materials from multiple suppliers are evaluated, then testing for each supplier's material may be required. In other words, if materials from two suppliers are evaluated for all five product forms, the number of short-terms tests could reach 68,000 .

In Reference [5], the cost for performing short-term tests for metals was estimated to be about $\$ 350$ per specimen. Due to the more complex nature of CCMs, the cost for each short-term test might be on the order of $\$ 500$ per specimen. Hence, performing a full range of short-term tests for five product forms could cost on the order of $\$ 17$ million for 
materials obtained from a single supplier and up to $\$ 34$ million for materials obtained from two suppliers.

Cyclical load tests will also be required to assess the fracture resistance properties (i.e., damage tolerance and damage accumulation parameters). Additional long-term tests will be needed for erosion, fatigue, creep rupture and creep fatigue using an appropriate array of exposure conditions (temperature, environment, loads). These tests might require an additional \$5-10 million.

Finally, tests will have to be performed to quantify the effects of irradiation on the physical and mechanical properties. The testing will be expensive, costing several thousand dollars per specimen, and about $\$ 100,000$ for a single test station measuring a single property [5]. Assuming such testing is limited to tube and rod product forms to be used for control rods, the estimated total costs for obtaining the necessary data for irradiated specimens is on the order of $\$ 25$ million.

There will be additional costs to establish the composite component manufacturing base, create the ASTM product and test standards, create the design and performance assessment (e.g., life prediction) methodologies, and complete the related ASME code work. The estimated cost for these efforts is on the order of $\$ 30-50$ million.

In terms of the time requirement, small test programs generally do not get much attention from the large laboratories, but this program should attract interest. Short-term tests may take four labs three years to complete if there is a dedicated commitment. More labs may be needed if the large labs lack capacity.

Long-term tests will be fewer and limited to the normal service temperature conditions. Fatigue tests may be performed in four years, but creep tests will take longer.

In summary, it is estimated testing of the five product forms specified for the five components evaluated in this study might require four to six years, not including the completion of selected long-term tests, at a total cost of about $\$ 80-120$ million. If $\mathrm{SiC} / \mathrm{SiC}$ composites are included for control rod components, then the cost will be closer to $\$ 120$ million.

Also, concurrent testing may have to be performed for selected ceramic insulation materials to ensure long-term performance [16]. While less testing will be required for insulation materials than for structural materials, it is estimated the testing of the former materials may take three to five years at a cost of $\$ 20-30$ million. Furthermore, the completion of long-term aging tests will require more time and funding.

As a final comment regarding schedule and cost for codification, it is recognized that testing of the tubular product form for control rods and guide tubes is already being performed [13-16]. The NGNP testing program for $\mathrm{C} / \mathrm{C}$ and $\mathrm{SiC} / \mathrm{SiC}$ composites has been under way since 2004. The status of the testing effort is unclear and the related expenditures are unknown. Moreover, it appears most testing activities for $\mathrm{C} / \mathrm{C}$ and $\mathrm{SiC} / \mathrm{SiC}$ composite materials was suspended after GFY 2007. 
Substantial planning has been done for testing the candidate insulation materials. However, testing has not started due to a lack of funding [16].

\section{Impact of Lower Temperature Reactor}

This section examines the effect on maximum temperature for each component if the NGNP outlet temperature is reduced from $900{ }^{\circ} \mathrm{C}$ to $750{ }^{\circ} \mathrm{C}$ and the inlet temperature is reduced from $500{ }^{\circ} \mathrm{C}$ to $350^{\circ} \mathrm{C}$.

For the NGNP, changing the outlet temperature primarily affects the normal operating temperature envelop but will have little effect on the peak temperatures resulting from DCC. For DCC, only the timing of the peak temperature may see a significant difference. Therefore, changing the outlet temperature will only affect those components whose peak temperatures occur during normal operations.

As discussed in previous sections, of the four components that would benefit from CMs or CCMs, only the hot duct assembly has a peak temperature dictated by NOC. The other three components, i.e., the control rods, upper core restraint blocks, and lower floor blocks, have peak temperatures determined by conduction cooldown accidents. The materials chosen for these three components would not be affected by a lower temperature.

\section{Recommendations}

The evaluation of the NGNP baseline design indicates the components requiring composites depend upon the selected operating temperatures for the reactor. For a $900{ }^{\circ} \mathrm{C}$ outlet temperature, four of the five evaluated components may benefit from composites.

Designing the initial NGNP reactor for a lower outlet temperature would reduce inherent development risk in the R\&D process.

This study recommends the CM and CCM R\&D program for NGNP focus in the nearterm on:

- $\mathrm{C} / \mathrm{C}$ for Control Rods

- $\mathrm{SiC} / \mathrm{SiC}$ for Control Rods as a potential alternative

- $\mathrm{C} / \mathrm{C}$ for Hot Duct Assembly

- High-purity alumina or zirconia (depending upon the results of a manufacturing capabilities evaluation) for Hot Duct Assembly insulation

- 3-D C/C for the Upper Core Restraint Blocks 
- Alumina or zirconia fiber batt, board, and molded shapes, depending upon the results of a manufacturing capabilities evaluation, for Top Plenum Shroud insulation

- 2-D C/C for the Upper and Lower Layers of the Lower Floor Blocks

- High-purity oxide ceramic fiber insulation for the Intermediate Layer of the Lower Floor Blocks

- CFD thermal-hydraulic model development, verification, and validation to support benchmark cases for NGNP normal and off-normal conditions

Although some thermal and mechanical data exist for most of these materials, there is an appreciable need for high-temperature mechanical and thermal testing and long-term exposure testing of all of these materials. Also, there is a need for irradiation testing of candidate control rod materials.

Section 5.3 outlines the proposed testing program for $\mathrm{C} / \mathrm{C}$ composites. The recommended program requires an estimated four to six years, not including the longterm tests, at an estimated cost of $\$ 80-120$ million. The codification process must take into account the material and the geometry of the CMs and CCMs. The process requires close integration of the design and the R\&D. In addition, testing of ceramic insulation materials will be needed to ensure reliable long-term performance. This testing may take three to five years to complete at a cost of $\$ 20-30$ million. It is recognized that this program is already under way, using preliminary control rod component designs as the basis for establishing specimen geometry and test conditions. The remaining time and budget to complete the R\&D program needs further assessment.

Project risk could be reduced by reducing the outlet temperature. For a $750{ }^{\circ} \mathrm{C}$ outlet temperature, the study recommends composites for three of the five evaluated components: control rods, upper core restraint, and lower floor blocks. Also, the lower outlet temperature may allow a less complex design for the lower floor blocks. 


\section{References}

1. AREVA NP Document 12-9051191-001, "NGNP Preconceptual Design Studies Report," June 2007.

2. Electric Power Research Institute (EPRI), Technical Report 1007505, "Evaluation of Materials Issues in the PBMR and GT-MHR," November 2002.

3. "Thermal Response of a High Temperature Reactor during Passive Cooldown and Pressurized and Depressurized Conditions," Framatome ANP, GmbH paper for the $2^{\text {nd }}$ International Topical Meeting of HIGH TEMPERATURE REACTOR TECHNOLOGY, Beijing, China, September 22-24, 2004.

4. AREVA internal information.

5. INL/EXT-06-11614, Analysis of Potential Materials for the Control Rod Sleeves of the Next Generation Nuclear Plant, October 2006.

6. H. Haque, W. Feltes and G. Brinkmann, "Thermal Response of a High Temperature Reactor during Passive Cooldown under Pressurized and Depressurized Conditions," Proceedings of the Conference on High Temperature Reactors, Beijing, China, September 22-24, 2004, pp. 1-17.

7. AREVA internal information.

8. INEEL/EXT-03-01128, Revision 0, Next Generation Nuclear Plant, Materials Selection and Qualification Program Plan, November 7, 2003.

9. Report 910720, Revision 1, Gas Turbine - Modular Helium Reactor (GT-MHR) Conceptual Design Description Report, July 1996.

10. L. L. Snead, Y. Katoh, W. E. Windes, R. J. Shinavski and T. D. Burchell, "Ceramic Composites for Near Term Reactor Application," Paper HTR200858050, Proceedings of the $4^{\text {th }}$ International Topical Meeting on High Temperature Reactor Technology, HTR-2008, September 28 - October 1, 2008.

11. L. L. Snead, Y. Katoh, and S. Connery, "Swelling of SiC at Intermediate and High Irradiation Temperatures," J. Nuclear Materials, Vol. 367-370, Part 1, 1 August 2007, pp. 677-684.

12. L. L. Snead, T. Hinoke, and Y. Katoh, "Strength of Neutron Irradiated Silicon Carbide and Silicon Carbide Composite," Fusion Materials Semiannual Report DOE/ER-0313/33 (2002), pp. 49-56.

13. INEEL/EXT-05-02581, Next Generation Nuclear Plant Research and Development Program Plan, January 2005. 
14. INL/EXT-05-00758, Revision 2, Next Generation Nuclear Plant Materials Research and Development Program Plan, September 2005.

15. INL/EXT-05-00652, Structural Ceramic Composites for Nuclear Applications, August 2005.

16. INL/EXT-06-11701, Revision 3, Next Generation Nuclear Plant Materials Research and Development Plan, August 2006.

17. Christian A. Sanna, The American Society of Mechanical Engineers, Three Park Avenue, New York, NY 10016. Phone: (212)591-8513, Fax: (212)591-8501, sannac@asme.org

18. M. Snyder, Innovative Technologies International, Personal Communication, August 2008.

19. Y. Katoh, Oak Ridge National Laboratory, Personal Communication, August 2008.

20. ORNL/GEN4/LTR-08-003, Properties of Multilayered SiC/SiC and FMI-222 Graphite Composites after Medium-Dose Irradiation, April 29, 2008.

21. G. Newsome, L. Snead, T. Hinoki, Y. Katoh, and D. Peters, Evaluation of Neutron Irradiated Silicon Carbide and Silicon Carbide Composites, J. Nuclear Materials, Vol. 371, 2007, pp. 76-89 